\title{
Quantitative Fire Risk Analysis Case Study Using CUrisk
}

\author{
By

\section{Xin Mou} \\ A thesis submitted to \\ The Faculty of Graduate Studies and Research \\ in partial fulfilment of \\ the degree requirements of \\ Master of Applied Science \\ Ottawa-Carleton Institute for \\ Engineering \\ Department of Civil and Environmental Engineering \\ Carleton University \\ Ottawa, Ontario, Canada
}

August, 2009

Copyright $\mathbb{C}$

2009, Xin Mou 


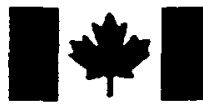

Library and Archives
Canada

Published Heritage Branch

395 Wellington Street Ottawa ON K1A ON4 Canada
Bibliothèque et

Archives Canada

Direction du

Patrimoine de l'édition

395 , rue Wellington

Ottawa ON K1A ON4

Canada
Your file Votre référence
ISBN: 978-0-494-63814-9
Our file Notre référence
ISBN: 978-0-494-63814-9
NOTICE:

The author has granted a nonexclusive license allowing Library and Archives Canada to reproduce, publish, archive, preserve, conserve, communicate to the public by telecommunication or on the Internet, loan, distribute and sell theses worldwide, for commercial or noncommercial purposes, in microform, paper, electronic and/or any other formats.

The author retains copyright ownership and moral rights in this thesis. Neither the thesis nor substantial extracts from it may be printed or otherwise reproduced without the author's permission.
AVIS:

L'auteur a accordé une licence non exclusive permettant à la Bibliothèque et Archives Canada de reproduire, publier, archiver, sauvegarder, conserver, transmettre au public par télécommunication ou par l'Internet, prêter, distribuer et vendre des thèses partout dans le monde, à des fins commerciales ou autres, sur support microforme, papier, électronique et/ou autres formats.

L'auteur conserve la propriété du droit d'auteur et des droits moraux qui protège cette thèse. $\mathrm{Ni}$ la thèse ni des extraits substantiels de celle-ci ne doivent être imprimés ou autrement reproduits sans son autorisation.
In compliance with the Canadian Privacy Act some supporting forms may have been removed from this thesis.

While these forms may be included in the document page count, their removal does not represent any loss of content from the thesis.
Conformément à la loi canadienne sur la protection de la vie privée, quelques formulaires secondaires ont été enlevés de cette thèse.

Bien que ces formulaires aient inclus dans la pagination, il n'y aura aucun contenu manquant.

\section{Canadä}


[ii] 


\section{Abstract}

In this study, the basic concepts of fire risk assessment and types of fire risk assessment methods have been reviewed. A number of up-to-date quantitative fire risk assessment models have been described. These models include CRISP of the U.K., Lund QRA of Sweden, CESARE-RISK of Australia, FiRECAM and FIERAsystem of Canada.

A new fire risk analysis computer model CUrisk developed at Carleton University has been presented. The framework and the theory of CUrisk have been described together with the safety related submodels such as the system submodel, occupant response submodel, and life hazard submodel.

The applicability of CUrisk has been evaluated by conducting a fire risk assessment case study of a multi-occupancy wood-frame building. A relative risk comparison approach was used to identify the cost-effective design option from eight different proposed design alternatives.

The simulation results were examined using past engineering experience and comparisons with statistical data. The results of this study show that risk levels predicted by CURisk are realistic and reasonable. The calculated absolute risk to life safety compares well with statistical data found in the literature.

\section{[iii]}




\section{Acknowledgements}

I take this opportunity to thank the many people who made this thesis possible.

First, I would like to express my gratitude to my supervisor Professor George Hadjisophocleous for the continuous support of my Master study and research, for his patience, suggestions, and insight knowledge. His guidance helped me in all the time of my research and writing of this thesis.

My sincere thanks also go to Professor Jim Mehaffey. He made his precious time from his busy schedule and shared his in-depth knowledge in the field of fire safety engineering and gave his valuable suggestions.

I'm also thankful to my colleague/classmate Mr. Zhengrong Chen for his valuable help in completing this work. I wish to thank Ms Chalotte Mattress for her help in correcting the grammar errors.

I wish to thank my family for providing a loving environment for me. I am gratitude to my wife Xing Qi, who has always been an inspiration and a great help at all time. I'm grateful to my loving sons David and Alex who constantly provided me encouragement and motivation for my work.

Lastly, and most importantly, I wish to thank my parents, Jinhu Liu and Dingfan Mou, who bore me, taught me and loved me. To them I dedicate this thesis. 


\section{Table of Contents}

Abstract $\quad$ iii

Acknowledgements iv

Table of Contents , , v

List of Tables $\quad$ ix

List of Figures $\quad$ xi

Nomenclature $\quad$ xiv

Chapter 1: INTRODUCTION 1

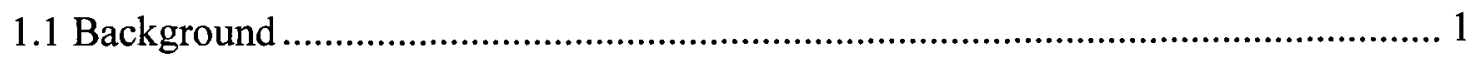

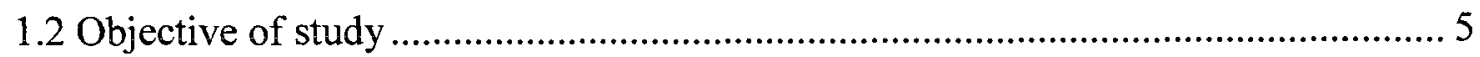

Chapter 2: LITERATURE REVIEW

2.1 Overview of fire risk analysis .................................................................... 7

2.1.1 Fire risk analysis concepts and definitions ............................................... 7

2.1.2 Objective of fire risk analysis .............................................................. 11

2.1.3 Standards and guides for fire risk analysis ............................................ 12

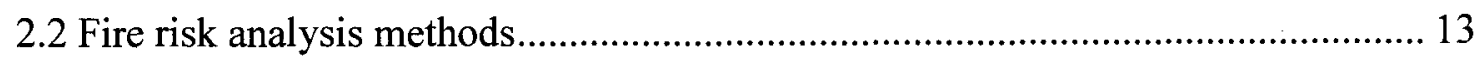

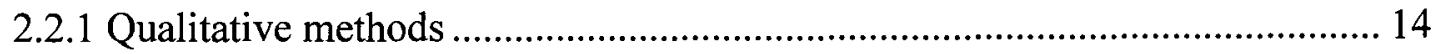

2.2.2 Semi-quantitative methods............................................................... 15

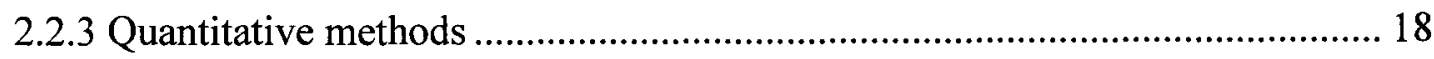

Chapter 3: DESCRIPTION of CUrisk $\quad 42$ 


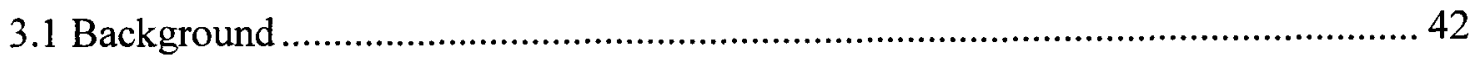

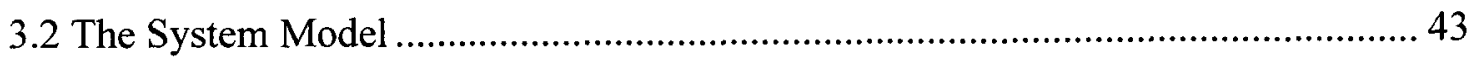

3.3 Fire Scenario submodel................................................................................. 47

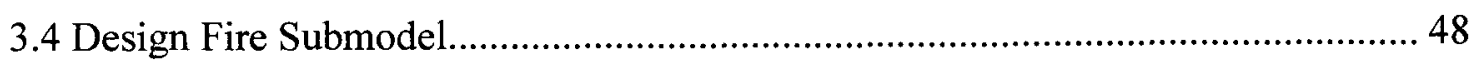

3.5 Fire Growth and Smoke Movement Submodels ...................................................... 48

3.6 Boundary Failure and Fire Spread Submodels ........................................................ 49

3.7 Smoke and Fire Detection Submodel ................................................................ 50

3.8 Fire Department Response and Action Submodel .................................................. 50

3.9 Hazardous Conditions Submodel........................................................................ 51

3.10 Building Cost and Economic Loss Submodel .................................................... 52

3.11 Occupant Response and Occupant Evacuation Submodels .................................. 53

3.12 Life Hazard Submodel ......................................................................................... 56

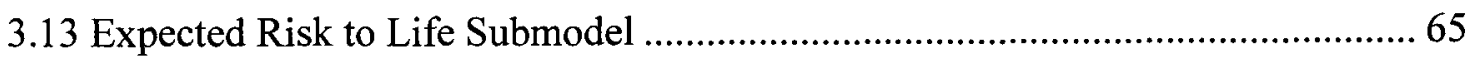

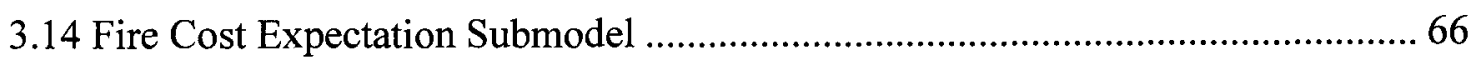

$\begin{array}{lr}\text { Chapter 4: CASE STUDY } & 68\end{array}$

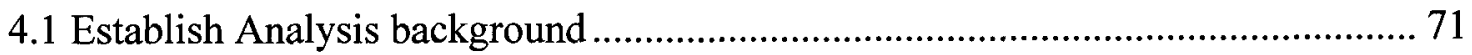

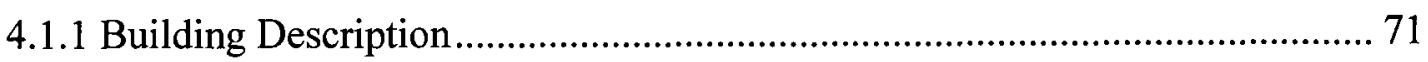

4.1.2 Occupant Characteristics ................................................................................ 76

4.1.3 Fire Protection Measures ................................................................................ 80

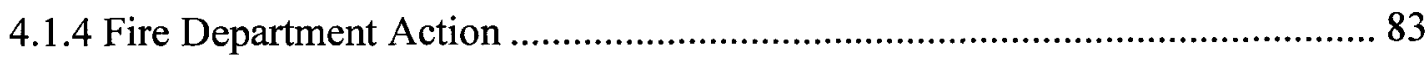

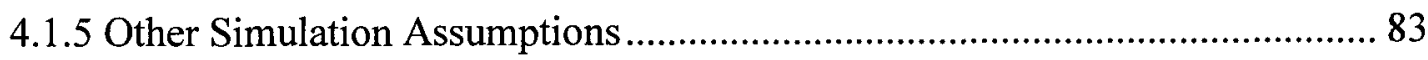

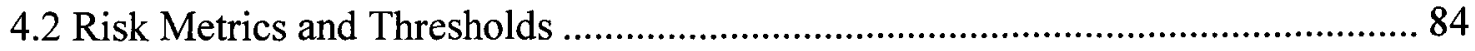

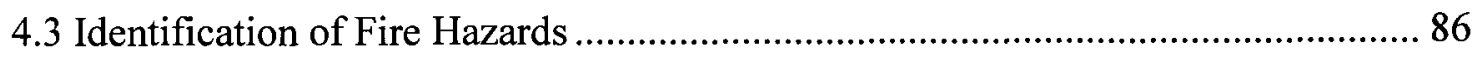

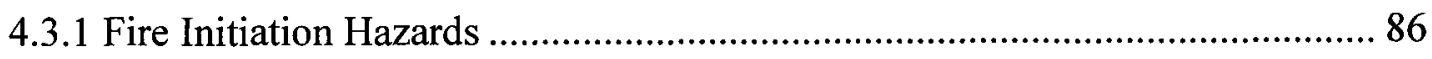

4.3.2 Reliabilities of Fire Protection Systems......................................................... 93

4.3.3 Life Safety Thresholds and Content Sensitivities............................................ 94

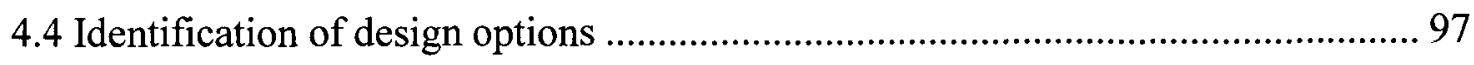

4.4.1 Code-compliant design option ...................................................................... 97

4.4.2 Alternative design options .............................................................................. 97 
4.5 Identification of Scenario Structures ................................................................. 100

4.5.1 Methodology to Create Scenario Structure .................................................. 100

4.5.2 Scenario Structures Identified ................................................................... 101

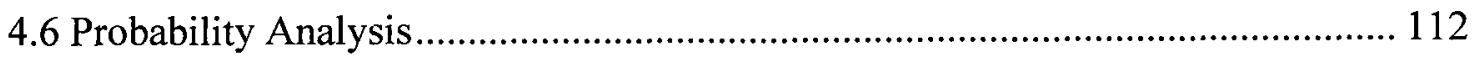

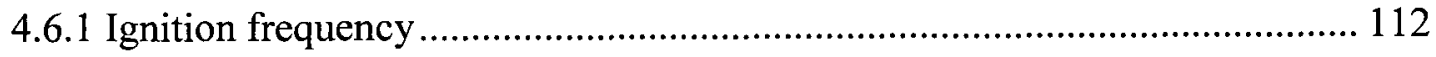

4.6.2 Operational Reliabilities of Fire Protection Systems..................................... 115

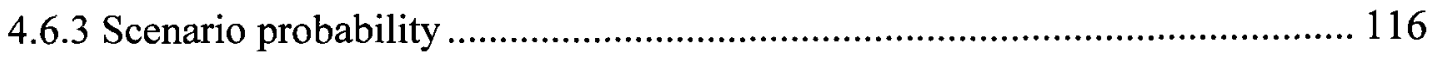

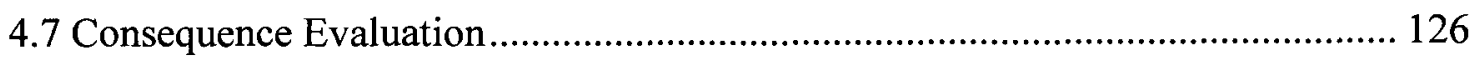

4.7.1 Description of submodel predictions ....................................................... 126

4.7.2 Fire development and smoke spread in the building .................................... 127

4.7.3 Performance of Automatic Sprinkler Systems............................................... 134

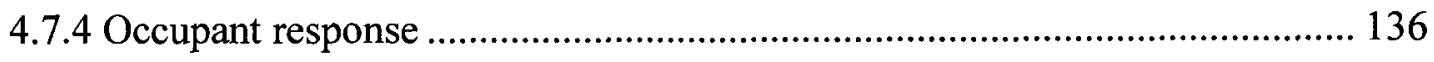

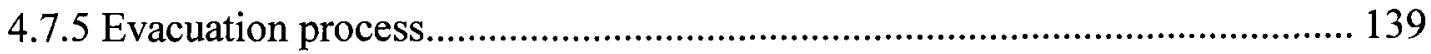

4.7.6 Probability of Death of a Occupant in the Building ...................................... 141

4.7.7 Damage to Building Property ....................................................................... 142

4.7.8 Consequences of the case study ............................................................... 145

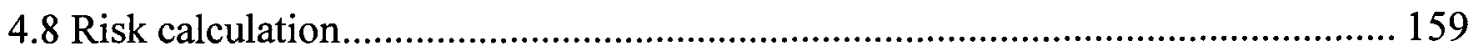

Chapter 5: RESULTS ANALYSIS AND DISCUSSION 165

5.1 Risks Comparison by Occupancy Classification ..................................................... 166

5.1.1 Statistical Data of Risk to Life by Building Occupancies .............................. 166

5.1.2 Calculated Risk to Life of Case Study Building ............................................ 167

5.2 Comparison of Risks of Different Fire Protection Measures................................. 171

5.2.1 Risk data for different Fire Protection Measures......................................... 171

5.2.2 Calculated Risk to Life Safety by Fire Protection Measures ........................... 173

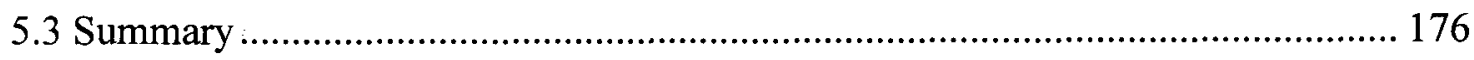

Chapter 6: CONCLUSION AND RECOMMENDATIONS 178

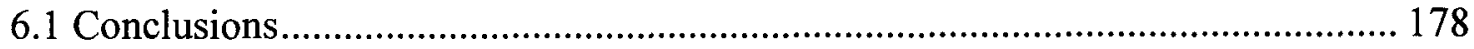

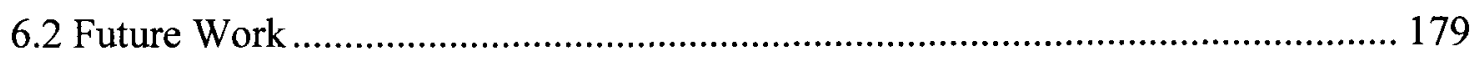


WS4-1.1 Wood Wall Assembly and WIJ-1.1 Ceiling Assembly Structure (Adopted

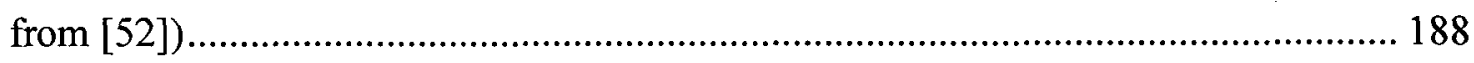




\section{List of Tables}

Table 3.1: Relationship of CUrisk Submodels (Adopted from [3])................................. 46

Table 4.1: Occupancies of Case Study Building ............................................................ 76

Table 4.2: Occupant Load of Case Study Building ........................................................ 78

Table 4.3: Occupant Distribution at the Time of Fire Occurrence .................................... 79

Table 4.4: Occupant Age and Gender in Case Study Building........................................ 80

Table 4.5: Fire Department Response Options ................................................................ 83

Table 4.6: Ranking of Number of Fires, Threat to Life Safety and Property as a Function

of Fire Origin for Occupancies (Adopted from [39]) ........................................................ 88

Table 4.7: Areas of Fire Origin Used for Case Study ………………............................ 89

Table 4.8: Ranking of cause of fire for the Design Fires (Adopted from [39]) ................ 90

Table 4.9: the Design Fire types Used in the Case Study .................................................. 91

Table 4.10: Summary of Design Fires Used for the Case Study ………......................... 92

Table 4.11: Fire Loads and Estimated Fire Duration Used in the Case Study ................. 92

Table 4.12: Summary of Design Fires Used in the Case Study ........................................ 93

Table 4.13: The Operational Reliabilities of Fire Protection Systems for the Case Study94

Table 4.14: The Thresholds of Injury and Death of the Case Study................................. 94

Table 4.15: Damage Sensitivities of Fire Protection Systems for Case Study ................. 95

Table 4.16: Damage Sensitivities Category of Building Contents for Case Study .......... 96

Table 4.17: Fire Safety Design Options Considered for Case Study ................................ 98

Table 4.18: Statistical Fire Ignition Frequencies Pertain to Case Study Occupancies. $\left(10^{-6}\right.$

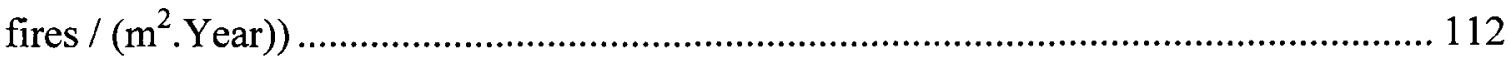

Table 4.19: The Fire Occurrence Rate of Each Occupancy of the Case Study Building 113

Table 4.20: Relative Percentage of Fire Ignition Frequency in Residential Section for

Case Study Building ..................................................................................................... 114 
Table 4.21: Relative Percentage of Fire Ignition Frequency by Fire Origin

Table 4.22: Reliability of Fire Protection System Operability ....................................... 115

Table 4.23: Design Parameters of Scenario No. 77 of Design Option A ........................ 126

Table 4.24: Predicted Time of Occurrence of the Key Events of Scenarios 73 and 77,

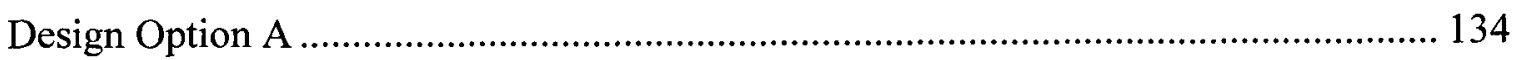

Table 4.25: Fire Consequence of Design option A..................................................... 145

Table 4.26: Fire Consequence of Design option B …………………………….......... 149

Table 4.27: Fire Consequence of Design option C ……………................................. 151

Table 4.28: Fire Consequence of Design option D..................................................... 153

Table 4.29: Fire Consequence of Design option E …………..................................... 154

Table 4.30: Fire Consequence of Design option F ..................................................... 156

Table 4.31: Fire Consequence of Design option G..................................................... 157

Table 4.32: Fire Consequence of Design option H.................................................... 158

Table 4.33: Fire Risks of Eight Design Options ............................................................. 162

Table 5.1: Statistical Data of Death Rate by Building Occupancies ............................... 166

Table 5.2: Calculated risk to life safety of Case Study Building..................................... 167

Table 5.3: Calculated Risk to Life Safety of Case Study Building - Mercantile............. 167

Table 5.4: Calculated Risk to Life Safety of Case Study Building - Office.................... 168

Table 5.5: Calculated Risk to Life Safety of Case Study Building - Residential ........... 168

Table 5.6: Reduction of Death in Relation to Fire Protection Measures in Residential

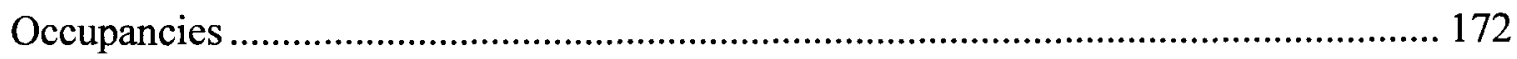

Table 5.7: Normalized Reduction of Fire Death in Relation to Fire Protection Measures in Residential Occupancies ........................................................................................... 172

Table 5.8: Normalized Fire Risk to Life safety of the Design Options ........................... 173 


\section{List of Figures}

Figure 1.1: Civilian Fire Death Rate, US and Canada (Adopted from [1] ) .................... 2

Figure 1.2: Fire Loss Rates Rate of US and Canada (Adopted from [1] )....................... 3

Figure 2.1: Relations of risk analysis, risk assessment and risk management (Adopted

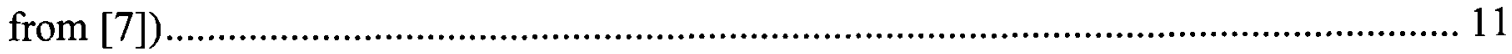

Figure 3.1: Schematic diagram of the CUrisk System Model (Adopted from [3]) ......... 44

Vigure 3.2: The PIA Process (Adopted from [3]) ................................................... 53

Figure 3.3: Probability of flashover after fire spread (Adopted from [31]).................... 61

Figure 4.1: Fire Risk Analysis Work Flow Chart ..................................................... 70

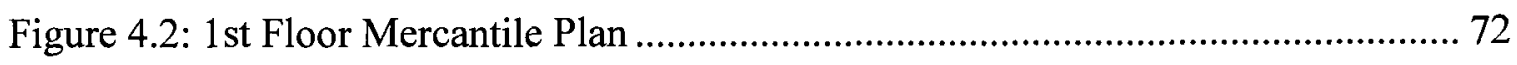

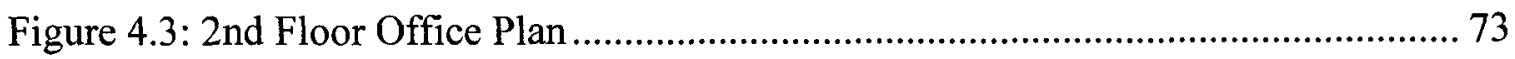

Figure 4.4: 3rd Floor Residential Plan................................................................... 74

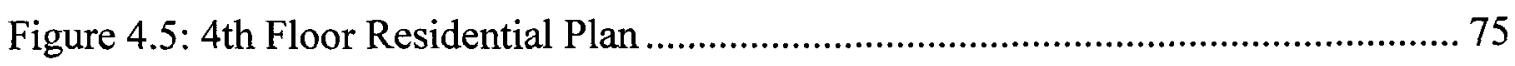

Figure 4.6: Scenario Structure of Design Option A.................................................. 104

Figure 4.7: Scenario Structure of Design Option B.................................................. 105

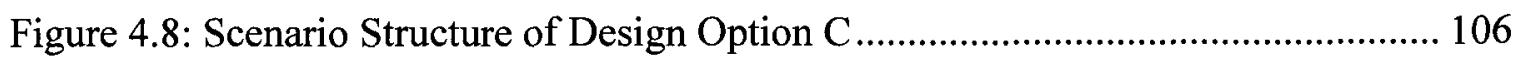

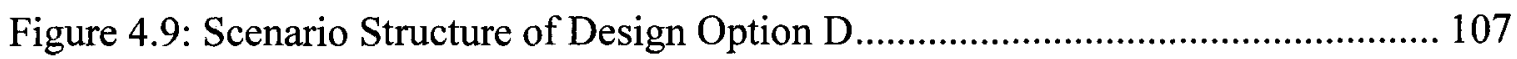

Figure 4.10: Scenario Structure of Design Option E ................................................. 108

Figure 4.11: Scenario Structure of Design Option F ................................................ 109

Figure 4.12: Scenario Structure of Design Option G.............................................. 110

Figure 4.13: Scenario Structure of Design Option H................................................. 111

Figure 4.14: Scenario Probability of Design Option A............................................. 118

Figure 4.15: Scenario Probability of Design Option B............................................. 119

Figure 4.16: Scenario Probability of Design Option C............................................ 120

Figure 4.17: Scenario Probability of Design Option D.......................................... 121 
Figure 4.18: Scenario Probability of Design Option E..................................................... 122

Figure 4.19: Scenario Probability of Design Option F ................................................ 123

Figure 4.20: Scenario Probability of Design Option G.................................................. 124

Figure 4.21: Scenario Probability of Design Option H................................................. 125

Figure 4.22: HRR Curves of Scenario 77 of Design Option A ..................................... 127

Figure 4.23: Upper Layer Temperature Curves of Selected Compartments of Scenario 77,

Design Option A

Figure 4.24: Upper Layer $\mathrm{O}_{2}$ Concentration of Selected Compartments of Scenario 77 of Design Option A

Figure 4.25: Upper Layer $\mathrm{CO}_{2}$ Concentration of Selected Compartments of Scenario 77

of Design Option A.

Figure 4.26: Upper Layer CO Concentration of Selected Compartments of Scenario 77,

Design Option A

Figure 4.27: Soot Concentration Curves of Selected Compartments of Scenario 77,

Design Option A

Figure 4.28: Interface Height of Selected Compartments of Scenario 77 of Design Option A .

Figure 4.29: HRR Curves of Scenario 77 and Scenario 73 of Design Option A............ 135

Figure 4.30: Upper Layer Temperature of the Compartment of Fire Origin of Scenario 77

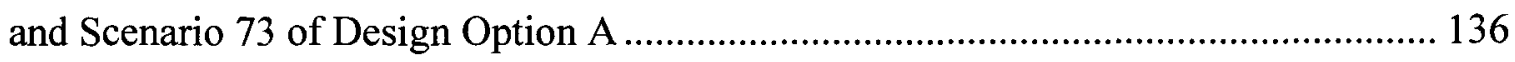

Figure 4.31: Cumulative Probabilities of Occupant Response - To Call Fire Department of Scenario 77, Design Option A.

Figure 4.32: Cumulative Probabilities of Occupant Response - to Evacuate of Scenario

77, Design Option A

Figure 4.33: Evacuation Process - Residual Population in the Building of Scenario 77,

Design Option A

Figure 4.34: Evacuation Process - Individual Occupant.....

Figure 4.35: Probability of Death - Occupant \#19 of Scenario 77, Design Option A ... 141

Figure 4.36: Probability of Death - Occupant \#17 of Scenario 77, Design Option A ... 142 
Figure 4.37: Total Damages to the Building of Scenario 77, Design Option A ............. 143

Figure 4.38: Damages to the Building and Fire Protection Systems of Scenario 77,

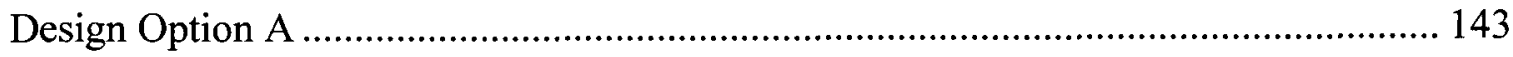

Figure 4.39: Damages to the Building Contents of Scenario 77, Design Option A ....... 144

Figure 4.40: Relative ERL of Design Options............................................................... 163

Figure 4.41: Relative FCE of Design Options ................................................................ 163 


\section{Nomenclature}

A Area, $\mathrm{m}^{2}$

$\mathrm{A}_{\mathrm{T}} \quad$ Total internal surface area, $\mathrm{m}^{2}$

Av $\quad$ Area of the vent, $m^{2}$

$\mathrm{C}_{\mathrm{i}} \quad$ Consequences of the fire scenario $\mathrm{i}$

$\mathrm{CO}(\mathrm{t}) \quad$ Concentration of $\mathrm{CO}(\mathrm{ppm})$, in the compartment at time $\mathrm{t}(\mathrm{min})$

$\mathrm{CO}_{2}(\mathrm{t}) \quad$ Mass percentage of $\mathrm{CO}_{2}$, in the compartment at time $\mathrm{t}$

Fixed capital investment on of the active and passive fire protection

$\operatorname{COST}_{\text {Fixed }}$ systems

Annual maintaining and inspection cost of the active fire protection

$\operatorname{COST}_{\text {Maintain }}$ systems

DL Design life in years of the building

$D_{m}(t) \quad$ Survival status of occupants $m$ at time $t$

$\mathrm{E}_{\mathrm{i}} \quad$ Economic loss of scenario i

ERL The Expected Risk to Life

EROI The Expected Risk of Occupant Injury

F Annual fire frequency of building

FCE The Fire Cost Expectation

$\mathrm{FID}_{\mathrm{co}}(\mathrm{t}) \quad$ Fractional incapacitating dose of $\mathrm{CO}$

$\mathrm{FID}_{\mathrm{HG}}(\mathrm{t}) \quad$ Fractional incapacitating dose due to hot gases

xiv 
FID $_{10}(t) \quad$ Fractional incapacitating dose of low oxygen hypoxia

$\mathrm{FID}_{\mathrm{TG}}(\mathrm{t}) \quad$ Fractional incapacitating dose due to toxic gases.

$\mathrm{F}_{\mathrm{ig}, \mathrm{k}} \quad$ Fire ignition frequency of the occupancy $\mathrm{k}$, fires / year

$\mathrm{F}_{\mathrm{ig}, \mathrm{k}}=\quad$ Fire ignition frequency of unit area of the occupancy $\mathrm{k}$, fires / (year. $\mathrm{m}^{2}$ ).

$f \quad$ Probability density function of the cumulative affecting factor Probability density function of the probability of flashover of the $f_{F O}(\mathrm{t}) \quad$ compartment with time $\mathrm{t}$ Probability density function of the probability of fire spread for the $f_{F O}(\mathrm{x}) \quad$ compartment with time $\mathrm{x}$.

G Margin of evacuation time (State function)

$\mathrm{H} \quad$ Height of vent opening, $\mathrm{m}$

$\mathrm{h}_{\mathrm{k}} \quad$ Effective conductance coefficient, $\left(\mathrm{kW} / \mathrm{m}^{2}\right) / \mathrm{k}$

Hv Height of the vent, $m$

$\mathrm{M}_{\mathrm{i}} \quad$ Number of injuries in scenario $\mathrm{i}$

Ms Model uncertainty factor

$\mathrm{N}_{\mathrm{i}} \quad$ Number of deaths in scenario i

$\mathrm{O}_{2}(\mathrm{t}) \quad$ Mass percentage of $\mathrm{O} 2$ in the compartment at time $\mathrm{t}$

OAC Occupants in Adjacent Compartments

OCF Occupants in the Compartment of Fire Origin

OFM Ontario fire marshal

OOC Occupants in Other Compartments

$\mathrm{P}_{\mathrm{FO}}(\mathrm{t}) \quad$ Probability of inury or death due to fire spread

$\mathrm{P}_{\mathrm{HG}}(\mathrm{t}) \quad$ Probability of death due to exposure to hot gases 


\begin{tabular}{|c|c|}
\hline$P_{i}$ & Probability of scenario $\mathrm{i}$ \\
\hline$P_{i, j}$ & Probability of event $\mathrm{j}$ in scenario $\mathrm{i}$ \\
\hline POP & Number of occupants in the building. \\
\hline $\mathrm{P}_{\mathrm{TG}}(\mathrm{t})$ & Probability of death due to breathing toxic gases at time $t$ \\
\hline$P_{T R}(t)$ & Probability of death due to thermal radiation at time $t$ \\
\hline$P_{T R}(t)$ & Probability of death due to exposure to thermal radiation at time $t$ \\
\hline q"(t) & Incident heat flux $\left(\mathrm{kW} / \mathrm{m}^{2}\right)$ at time $\mathrm{t}$ \\
\hline$Q_{\max }$ & The maximum possible heat release rate of fire, $\mathrm{kW}$ \\
\hline $\mathrm{R}$ & Estimated risk magnitude \\
\hline$s_{i}$ & Events or scenarios \\
\hline $\mathrm{t}$ & Time \\
\hline$T_{D}$ & Calculated time to detection fire \\
\hline $\mathrm{T}_{\mathrm{E}}$ & Calculated movement time for patients \\
\hline $\mathrm{t}_{\mathrm{FO}}$ & Time to reach flashover. \\
\hline $\mathrm{T}_{\mathrm{G}}(\mathrm{t})$ & Temperature of hot gases at time $t(\mathrm{~min})$ in the compartment \\
\hline $\mathrm{TH}_{\mathrm{d}}$ & Threshold of death \\
\hline $\mathrm{T}_{\mathrm{R}}$ & Time for reaction and response for staffs \\
\hline $\mathrm{T}_{\mathrm{S}}$ & Calculated time to untenable conditions \\
\hline$V(t)$ & Thermal dose due to thermal radiant flux at time $t$ \\
\hline $\mathrm{V}_{\mathrm{CO} 2}(\mathrm{t})$ & Multiplication factor for $\mathrm{CO}_{2}$ induced hyperventilation at time $\mathrm{t}$ \\
\hline$\alpha$ & Fire growth rate coefficient \\
\hline
\end{tabular}




\section{Chapter 1: INTRODUCTION}

\subsection{Background}

Fire, man's oldest foe and friend, if used inappropriately can cause huge property damage and human suffering. Fires in buildings cause huge economic loss to property and a large number of fatalities and injuries each year. In Canada, the Council of Canadian Fire Marshals and Fire Commissioners (CCFM/FC) reports an average of 59,936 fire incidents each year, which caused an average of more than 376 fire deaths and 1.2 billion dollars fire losses across Canada each year during the period 1993 to 2002.

To help make our community safer from the devastating consequences of fires, people have taken various strategies to mitigate the negative fire effects on occupant life safety and property. These fire management strategies include: constitute fire safety regulations and ensure code compliance to provide fire protection for the society at the legislation level; install the fire protection features in buildings to prevent fire ignition, control fire and smoke spreading and manage people's exposure to fires; provide fire emergency services for fire responding and rescuing; and facilitate fire insurance to mitigate economic risk incurred from fire incidents.

These efforts have achieved great success in mitigating losses in both occupant life and properties in the past few decades. Figure 1.1 and Figure 1.2 are fire statistics data of 
Canada and the U.S. obtained from NFPA reports [1]. Figure 1.1 shows that in 2001, the Canada civilian death rate was about $1.09 \times 10^{-5}$ (10.9 deaths per million population). The civilian death rate has dropped almost to $1 / 3$ compared with the rate of $3.47 \times 10^{-5}$ of 1977 . During the same period, the direct fire loss in Canada has declined more than half from $0.26 \%$ GDP in 1977 to $0.13 \%$ GDP in 2001 . Both life and economic loss data show the same pattern in the U.S.

Civilian Fine Death Rates, L.S. and Cama

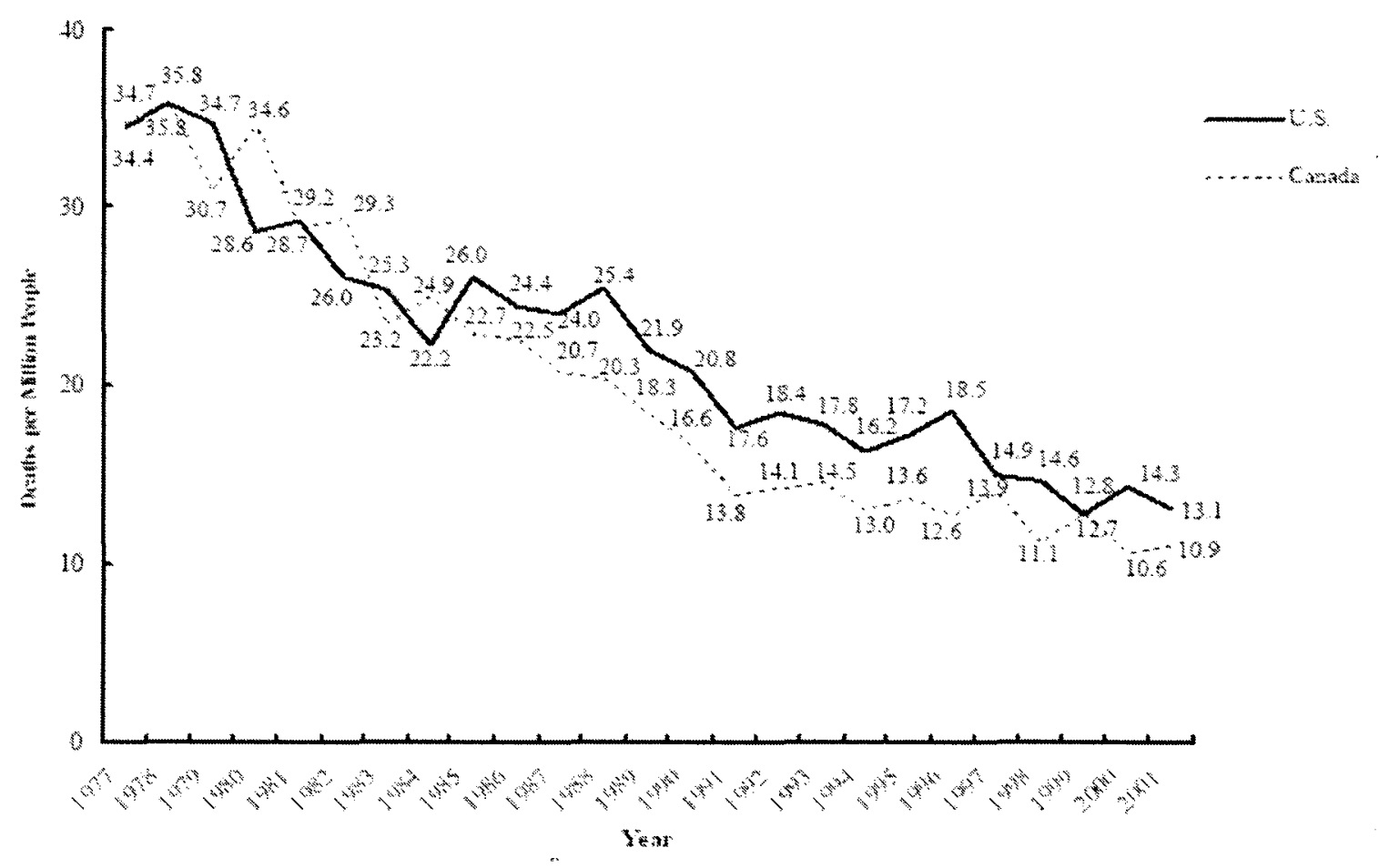

Figure 1.1: Civilian Fire Death Rate, US and Canada (Adopted from [1] ) 


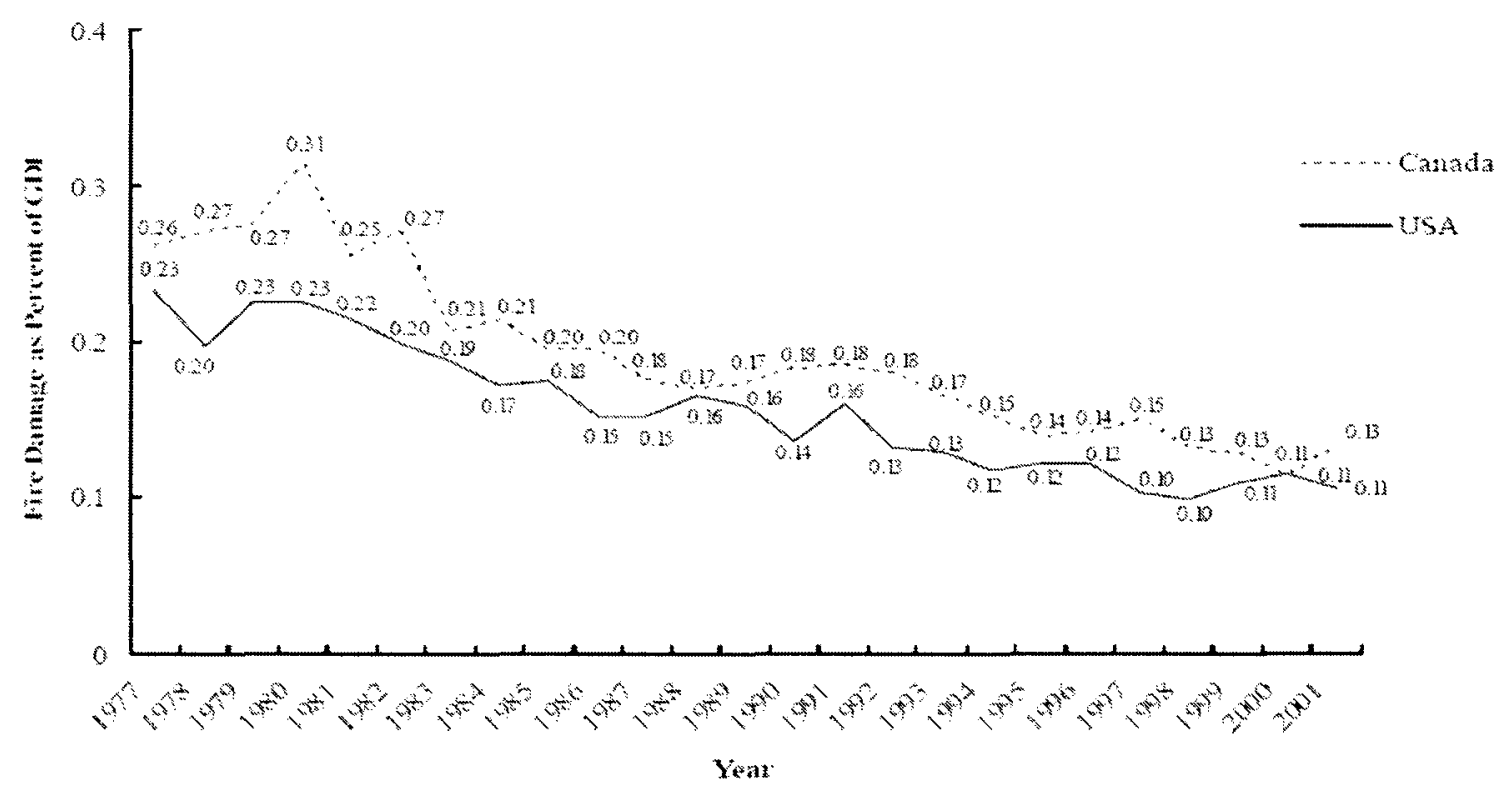

Figure 1.2: Fire Loss Rates Rate of US and Canada (Adopted from [1] )

As the relative direct property loss from fire has declined, the cost to prevent or mitigate the effects of fire has undergone a steady increase through the years and has accounted for a large portion of the total fire cost. In the U.S in 2005 , fires caused $\$ 12.7$ billion property losses in total; on the other hand, the fire protection cost to building construction reached around $\$ 45.9$ billion US dollar, not including the cost of over $\$ 29.4$ billion for fire fighting organizations, and \$13.4 billion for fire insurance [1].

This raises questions to fire protection engineers, building owners, code enforcers and the public: are the current fire protection measures safe enough for occupants and our property values in buildings? How much cost should society invest in fire prevention and fire protection to achieve an acceptable risk level? 
With the support of fire science and technology, developed countries around the world are moving towards performance-based codes and engineering approaches to help address these questions. By using performance-based design approaches, fire protection design engineers can evaluate the cost and compare the risk level of design options. This will assist the design team to achieve goals that may not have been anticipated by the building code, while exceeding or at least maintaining an equivalent level of safety to the one required by prescriptive codes.

Performance-based design approaches have obvious advantages when compared to the traditional prescriptive design approach. Hadjisophocleous and Benichou summarized the main benefits of adopting performance-based design approaches as follows [2]:

- Establishing clear safety goals and leaving the means of achieving those goals to the designer

- Permitting innovative design solutions that meet the established performance requirements

- Permitting the use of new knowledge as it becomes available

- Allowing cost-effectiveness and flexibility in design

- Enabling the prompt introduction of new technologies to the marketplace

- Eliminating the complexity of the existing prescriptive regulations

- Eliminating technical barriers to trade for a smooth flow of industrial products

- Allowing international harmonization of regulation systems 
Despite the numerous advantages performance-based design approaches may bring about into the fire safety engineering practice, the process of performance-based design and approval is more difficult and time consuming than the traditional prescriptive design because of the requirement for greater in-depth understanding of design objectives, fire risk specific to the building and cost-effectiveness of the fire protection features. More engineering calculations and judgement are needed for designers to ensure fulfillment of the fire safety objectives and to demonstrate the economic benefits of their proposed solutions. The interest to implement performance-based codes into fire safety design generates a need for fire risk computer models to help engineers assess quickly the building fire safety and to demonstrate code compliance.

Over the past few years, considerable effort has been put into the development of a new fire risk analysis model called CUrisk at Carleton University [3]. This model is intended to evaluate fire safety designs for timber-framed buildings which account for more than $90 \%$ of homes and a large proportion of commercial buildings built in North America. Currently, the system model of CUrisk and its submodels have been finished except for the boundary failure and fire spread submodel.

\subsection{Objective of study}

The objectives of this study are the following:

1. To develop a user friendly input and output interface for CUrisk .

2. To calibrate model parameters, and to identify and quantify input variables of CUrisk. 
3. To perform a fire risk analysis case study to examine the cost-effectiveness of different fire protection strategies by using the CUrisk model in a real performance-based design environment.

4. To develop a procedure for the documentation and presentation of performancebased design using a quantitative risk assessment approach.

5. To conduct a comparison of case study results with statistical fire data. 


\section{Chapter 2: LITERATURE REVIEW}

This chapter provides a review of the basic concepts and most recent developments in the area of building fire risk analysis and its application in building fire protection design.

\subsection{Overview of fire risk analysis}

\subsubsection{Fire risk analysis concepts and definitions}

\section{Fire Risk}

The term fire risk has been used for years, however the definitions and scope of risk resulting from an unwanted fire are not consistent in the literature. In the SFPE Handbook of Fire Protection Engineering [4], John M.Watts and John R. Hall follow the risk definition of the Society of Risk Analysis that risk is the potential for realization of unwanted, adverse consequences to human life, health, property, or environment.

In the same literature, Brian J. Meacham gives a more specific definition of fire risk as: fire risk can be viewed as the possibility of an unwanted fire hazard in an uncertain situation, which may induce loss or harm to the valued, typically in terms of life, property, business continuity, heritage and environment, etc.

Dobbernack [5] states that in ISO/PDTS 16732 there are two perspectives of fire risk:

1) Risk of a scenario: the risk is the combination of the probability and the unwanted 
consequences of that particular scenario. 2) Risk of a design option: the risk is the combination of the probabilities and consequences of all the scenarios with the design.

Although the scope and definition of risk may vary in the literature, there are many key factors in common to these definitions: unwanted negative consequences and likelihood of occurrence of such events.

\section{Risk triplets}

As John M.Watts and John R. Hall point out [4], whenever we are talking about risk, we are actually asking three questions:

1) What can go wrong?

2) How often can it happen?

3) What are the results if it happens?

The first question "what can go wrong" can refer to a scenario which is the overall sequence of events ending in a fire loss. The second question how often can it happen can refer to the likelihood or probability of that scenario to occur. The third question refers to the consequence, which is the outcome of an event in term of possible loss or damage. It can be the physical effect or impact of the scenario measured qualitatively or quantitatively.

Kaplan and Garrick summarized these fundamental elements of risk into three variables and express the total risk as the set of triplets:

$$
\mathrm{R}=\left\{\mathrm{s}_{\mathrm{i}}, \mathrm{p}_{\mathrm{i}}, \mathrm{c}_{\mathrm{i}}\right\}
$$

Where, 
$\mathrm{R}$ - Estimated risk magnitude

$\mathrm{s}_{\mathrm{i}}$ - Description of events or scenarios

$p_{i}$ - Description of probabilities of scenarios

$c_{i}$ - Description of consequences of scenarios

Most of the modern risk assessment theories or methodologies evaluate risk by addressing qualitatively or quantitatively the risk triplets mentioned above.

\section{Types of Fire risk}

During a fire incident, the products generated by the fuel combustion and sometimes the extinguishing agent used to contain and suppress the fire, present a threat to occupants of the building, property and its neighbours, as well as the environment. The types of risk that result from a building fire may be categorized as:

1) Risk to life safety

Life safety is a major concern in building fire protection engineering. Occupants in the building and fire responders may be threatened by hazardous conditions such as toxic gases, high temperature and heat fluxes in the compartments or egress routes.

2) Risk of financial loss

Financial losses due to fire include damages to the building property and disruption of building operation. The building structure and its contents may be damaged from exposure to heat, corrosive gases in the smoke, and water applied for fire suppression. Business interruption caused by disruption of building operation continuity may result in more financial loss than the direct property damages. 


\section{3) Risk to environment}

Environmental fire risk refers to the potential pollution to the air, water and soil due do the toxic chemical product generated along with combustion and extinguishment agent applied during fire suppression. Risk to environment has gained more and more attention in recent years.

Currently fire risk assessment models address the first two kinds of fire risks. There is very little literature discussing the fire impact on environment and society. In this case study, the risks will be limited to the risk to life and risk of financial loss.

\section{Fire risk analysis, risk assessment and risk management}

Like the terminology fire risk, the definition of fire risk analysis, risk assessment and risk management varies among fire risk professionals. John M.Watts and John R. Hall define [4] risk analysis as the detailed examination performed to understand the nature of undesirable events to human, property and environment and the process of evaluating the likehood and expected negative consequences of such events. In their definition, fire risk analysis includes risk assessment, risk evaluation, and risk management alternatives.

In another well cited literature [6] by the society of the fire protection engineers in the risk analysis field, fire risk analysis and fire risk assessment are not differentiated. They are defined as a process to address appropriate fire scenarios, the likehood of happening of these scenarios, and the consequences if the fire scenarios occur. Fire risk analysis or fire risk assessment is the basis of fire risk management which is the process of deciding what action should be taken to prevent or mitigate fire risks. 
Covello and Frantzich [7] state that fire risk analysis is only one part of the risk management process which is the complete methodology to evaluate and control fire related risks in the building. The hierarchy structure of this relationship is illustrated in Figure 2.1.

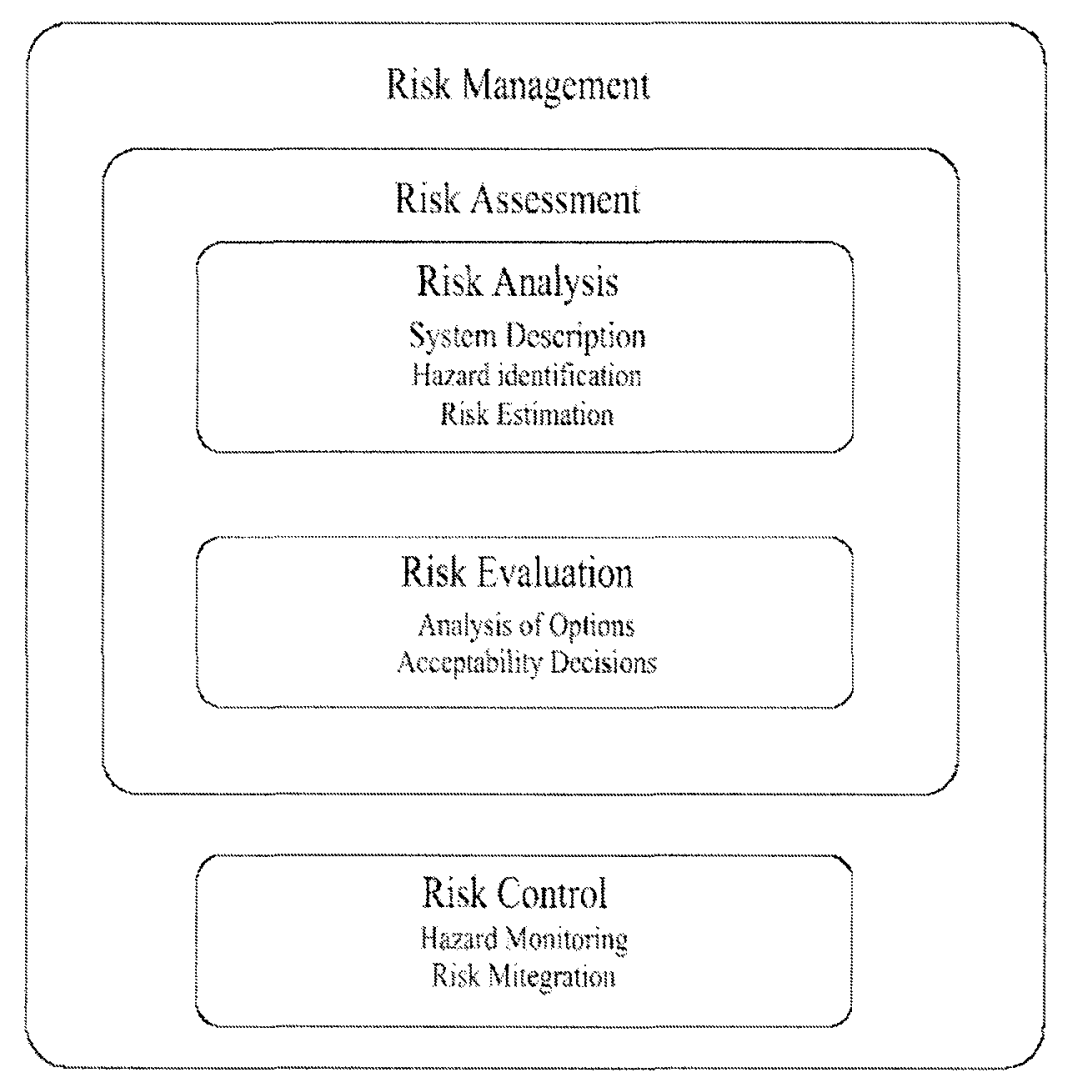

Figure 2.1: Relations of risk analysis, risk assessment and risk management (Adopted from [7])

\subsubsection{Objective of fire risk analysis}

Fire risk analysis is the detailed examination of a fire and its impacts on people and property with consideration to the effects of the fire protection features. This process 
includes risk identification, description and risk estimation of unwanted negative fire impacts on human life, health, property, and environment. The purpose of a fire risk analysis is to provide information about the likehood and magnitude of consequences resulting from a possible fire scenario and help decision-makers to plan to avoid or mitigate these negative impacts.

Risk assessment is commonly used in the fire protection design and construction process as a tool for decision making. Barry outlines the primary functions of fire risk analysis which include the following [8]:

1) To identify and prioritize fire risks so that fire safety investment options can be optimized in the design process.

2) To evaluate code equivalency or compare the relative risk level between fire protection design options.

3) To demonstrate risk level of fire incidents to the community.

4) To provide information to be used in emergency planning and training.

5) To demonstrate to federal or local legislation authority that fire safety objectives are being achieved and maintained

\subsubsection{Standards and guides for fire risk analysis}

In Canada and the U.S. the most often cited standards and guides for risk assessment are:

- NFPA 551- Guide for the Evaluation of Fire Risk Assessments [9]

-ASTM E1776-07 Standard Guide for Development of Fire-Risk-Assessment Standards [10]

- ISO/TS 16732- Fire Safety Engineering - Guidance on fire risk assessment [11] 
- SFPE Engineering guide to application of fire risk assessment in fire protection design [6]

John R. Hall [12] summarized and compared the similarities and differences among these standards in seven elements: purpose of standard; decision maker; measure of consequence; threshold of acceptability; analysis method; treatment of scenarios; and data sources.

NFPA 551 and ASTM E1776-07 are not intended to be used directly to perform a building fire risk assessment. NFPA 551 is designed to help AHJs (authorities having jurisdiction) to review code equivalency of a design proposal. ASTM E1776-07 is not a standard for fire risk assessment but rather a guiding standard to develop a fire risk assessment standard.

The intent of SFPE guide and ISO/TS 16732 is to compare building fire system design alternatives by providing equivalency to a conventional prescriptive code design solution. They are the primary type of fire risk assessment guide used by fire protection engineers and designers in a performance-based design.

\subsection{Fire risk analysis methods}

Fire risk analysis is a systematic approach to help fire professionals better understand and characterize fire related risks. It is a process to estimate the fire losses that combines the potential harm to occupants and damages to property. The risk stakeholders may be better informed when making decisions in the process of building design, construction, and operation and even in a fire incident. 
The approaches used in fire risk analysis can be classified into qualitative, semiquantitative, and quantitative approaches. In the following section, an overall review of these risk analysis methods is provided, with emphasis on quantitative risk analysis methods.

\subsubsection{Qualitative methods}

Narratives, regulations and checklists are primary types of qualitative methods used in fire risk assessment. These methods don not attempt to evaluate quantitatively either the consequence or the probability of fire hazard. However, they are widely used in the fire safety industry to identify fire hazards and hazard control options because of their relative ease of use.

\section{Narratives}

Narratives are probably one of the earliest approaches to fire risk analysis. The narrative approach consists of a series of recommendations related to fire safety. Most current fire safety prescriptive codes and regulations can be viewed as the systematic and more advanced development of narratives over the years. By following narratives and regulations for fire risk management, society acceptable fire safety levels can be achieved. By using this approach, a design alternative is judged to be risk acceptable if it complies with published recommendations [4].

\section{Checklists}


Checklists usually comprise a list of hazards to be avoided and recommended practices. There is no generic fire risk checklist for all types of buildings. Different types of checklists have been developed for certain types of buildings, reflecting the special concerns of building owners. Checklists help the stakeholders of a specific project to focus only on the requirements that are applicable to the project.

\section{Limitation of Qualitative Approaches}

Dobbernack points out that qualitative approaches have little to do with risk assessment methods but give the easiest way of solving fire safety problems [5]. Narratives and checklists are easy to use and they are valuable tools to identify fire risk factors. Frantzich suggests that these qualitative methods may be used as screening methods in preliminary risk analysis [7]. The following are the main limitations of qualitative methods:

1) Do not distinguish the importance of fire risk factors;

2) Do not reflect the interaction of fire risk factors;

3) Can not cover the vast number and variations of human activities.

\subsubsection{Semi-quantitative methods}

Semi-quantitative methods have been used in a wide range of applications to determine hazards and consequences resulting from fires. These methods are developed with the purpose of assessing fire risks for specific types of buildings. 
The primary semi-quantitative methods used in fire risk assessment are commonly referred to as indexing methods which include Rating Schedules, Risk Ranking, Point Scheme Methods, and Numerical Grading [4, 5].

In some more complex methods like state transition models and fire realm models, fire consequences and probabilities values are assigned to events [4]. However, the determination of probabilities is based on subjective judgement. As the correlations of parameters are weak and can not reflect the complex interaction of all components in the fire event, these methods are also categorized as semi-quantitative methods.

\section{Indexing Method}

With indexing methods the hazards are weighted based on a scoring system according to past experience and professional judgement of experts in the industry. The factors that may affect the building risk level are first identified by a group of experienced professionals to reflect the positive and negative impacts of fire to building occupants and property. Then the importance of each factor is assigned a weighting value which is based on the experience and knowledge of professionals in the area. These weighted values and other selected system variables are converted to a parameter representing certain risk level through a predefined mathematical process. Normally the calculated risk value is compared with code requirements or other assessments of similar applications to determine the risk acceptability [4].

Risk indexing methods are considered cost-effective because of their simplicity. These methods provide a structured way to aid people make decisions pertinent to 
potential fire incidents. The use of these methods provides an easy route of understanding the system for persons not familiar with detailed mechanisms or involved in the development process of risk analysis. So despite the development of more and more advanced fire risk models, they are still widely used in the industry to screen fire risks.

Many advancements of fire risk indexing method were brought out by the influence of the insurance industry with the desire to minimize property insurance losses. The severe consequences that fire posed in the chemical process industries, nuclear plants and other industries spawned the invention of various risk assessment index tools dedicated to their specific hazards. Some of the most commonly used rating schedules and indexing tools in the North American and Europe are listed below:

1) ISO (Insurance Service Office) Commercial Fire Rating Schedule [4],

2) Grentener method [14],

3) Dow's Fire and Explosion Index (FEI) [4],

4) FSES, The Fire Safety Evaluation System [15],

5) Mond Fire Explosion and Toxicity Index method [16],

6) Hierarchical approach [5].

\section{Other semi-quantitative method}

In addition to fire indexing methods, some other methods such as fire-induced vulnerability evaluation, and Inspection Testing and Maintenance (ITM) for fire protection systems, are also categorized as semi-quantitative methods [13].

Risk matrices and contours are methods between indexing methods and fully developed probabilistic methods [4]. Hazard and risk matrices evaluate the building fire 
risk by combining the anticipated most severe events and their estimated frequencies. Contours are a related analysis to risk matrices in which the consequence and probability are depicted in two dimensional graphical form. These methods provide valuable information to record judgements on the acceptability of risk and decisions on reducing such risks [6].

\subsubsection{Quantitative methods}

Quantitative analysis methods provide an approach to quantify risk. They offer the capability of being able to identify the relationship between loss prevention and fire protection systems. They also provide the capability of optimizing fire protection investment by allocating resources to the area giving rise to the highest risk. For fire risk analysis to become a useful quantitative approach, engineers and designers need to quantify criteria for acceptable risk and develop methods for calculating fire risk.

Using a quantitative risk analysis method, fire risk acceptability can be determined either by comparing the risk level of the proposed alternative design with that of accepted design solutions or with a tolerable absolute risk level. The first approach is a relative risk assessment strategy, in which the risk of a specific building design option is compared with the risk of a design that satisfies the local prescriptive codes. If the risk of the alternative design option is not higher than that of the code-compliant design option, then the design alternative is considered to be acceptable.

In the second approach a decision is made based on absolute risk. The risks of design alternatives are directly compared with an acceptable level of risk for such type of 
buildings. If the risk of the alternative design option is less than the acceptable risk criterion, then the design alternative is considered to be acceptable.

Due to the complexity of fire phenomena in buildings and the lack of sufficient understanding of human behaviour and its interaction with building and fire protection systems, the relative risk method is considered more reliable and effective than the absolute approach [17].

The "Application of fire safety engineering principles to the design of buildingsCode of practice" from British Standards Institution (BSI) [18] may be the only publication to set acceptable fire risk values. The authors suggest the risk of death for occupants at home is $1.5 \times 10^{-5}$ per individual per year, for occupants elsewhere the risk of death is $1.5 \times 10^{-6}$ per individual per year. They also propose the risk of multiple deaths per building as $5 \times 10^{-7}$ per individual if total deaths are more than 10 individuals and 5 $\times 10^{-8}$ per individual if total deaths are more than 100 individuals. These risk criteria values are based on fire loss statistics in the U.K. [19].

Developing an appropriate method for measuring fire risk is a challenging task. Hadjisophocleous and Benichou grouped fire risk analysis methods into two categories: deterministic methods and probabilistic methods [2]. Deterministic fire methods are based on physical, chemical and thermodynamic relationships and empirical correlations to calculate the impact of fire. Deterministic methods are usually used to analyze the hazards in terms of consequences. Probabilistic methods involve the evaluation of risk based on both frequency and the magnitude of consequence. The application of 
deterministic methods and probabilistic methods are not mutually exclusive, both approaches have been used in many fire risk assessment models.

In this section, five quantitative analysis models are introduced. These models are: CRISP, Lund QRA, CESARE-RISK, FiRECAM, and FIERAsystem.

\subsubsection{CRISP model}

CRISP (Computation of Risk Simulation Indices by Simulation Procedure), is a computer-based fire risk analysis model developed at the Building Research Establishment, Fire Research Station in the U.K [20]. This model assesses fire risk to life safety based on deterministic simulation of fire involving physical objects in the building and probabilistic simulation of random states of building components, occupant activities and fuel characteristics. The typical output of the CRISP model is a distribution of fire loss and the number of casualties.

In the CRISP model, the building-fire-occupant system is treated as a collection of interactive objects. These objects include compartments and vents, detectors and alarms, items of furniture, occupants, hot and cold smoke layers. These objects interchange information with each other through complex interactions happening at the same time.

Fire growth and smoke spread in CRISP are simulated by a two-zone multiple compartment model, coupled with an occupant response and evacuation submodel. The two zone model assumes the formation of two homogeneous layers of uniform temperature, gas concentration and smoke density in the compartments. Each room is clearly defined by an upper hot smoke zone and a lower cool air zone. 
Fire development in the model is divided into three main stages: 1) Thermal decomposition of fuel: the pyrolysis process of fuel into combustible volatiles. 2) Gas phase combustion: the rapid oxidation of pyrolysed fuel into combustion products. 3) Propagation of fire products: the transportation of smoke particles into the upper hot layer in the compartments.

All the fire loads are assumed to be cylindrically-shaped fuel stocks. The empirical equations used to calculate the pyrolysis rate of fuel, HRR and combustion products are presented in reference [21]. The height of the flame is calculated using Heskestad correlation, as a function of the total energy released and area equivalent diameter of the fire source.

The plume model is a two-layer zone model developed by Zukoski and Heskestad [22]. The plume entrains air flow from cold layer and transfers combustion products, like $\mathrm{CO}$ and $\mathrm{CO}_{2}$, fuel gases, heat and smoke into the upper hot layer in the room. The mass flows between hot layers and adjoining layers via doors and windows are calculated by integrating the Bernoulli equation over the vent areas.

The model calculates heat losses from the hot layer to the surrounding enclosure. In the CRISP model, the walls and partitions are assumed to have infinite heat capacity thus the walls remain at constant ambient temperature during the process of heat conduction.

The occupant evacuation model which attempts to describe occupant behavior during fire incidents is the most important submodel of CRISP. A parameter of DOD (degree of difficulty) is used in the model to quantify the tenability level of a room when a fire occurs in the building. The room DOD values also represent the degree of difficulty of a 
door or a window to permit the passage of people, and affects occupants decisions when choosing a route from one room to another during evacuation. The depth of the hot layer, temperature, radiation flux density, smoke obscuration, and the relative respiration rate of occupants in the compartment are factors affecting the tenability level value. The tenability level is calculated separately for the hot and cold layer and the overall tenability in the room is the weighted sum of the two layer tenability values.

This model comprises three components representing physiological response, sensory perception and occupant reaction to the fire. Occupants may perceive fire cues by seeing smoke, feeling the heat from the fire, or hearing of unusual noises during the fire. Most of these perceptions are handled by defining room condition thresholds to alert occupants. Smoke detection has been taken into account by the assumption that if the smoke optical density exceeds the threshold of $0.1 \mathrm{~m}^{-1}$, the smoke detector is activated.

Once alerted by the fire and smoke conditions, the occupants may take various actions. Each action requires a person to move to a new location and continue to do so until they reach the exit. To simplify the evacuation process, the CRISP model allows occupant access to information that they may not have in real life. The occupants are assumed to know the room of fire origin and the rooms the fire has spread to. The occupants also know the DODs of each room and they are able to choose the egress route with the lowest possible degree of difficulty with the minimum evacuation distance.

The life threatening conditions caused by $\mathrm{CO}, \mathrm{CO}_{2}$, oxygen deficiency and convective heat are expressed in terms of respective fractional effective dosages (FED). As the occupants stay in the compartments or move along the egress route, they are 
exposed to smoke, heat and other hazardous conditions and acquire a certain FED. The FED of each toxic compound is integrated over each time step. When one of the predetermined thresholds of FED is exceeded, the occupants in the compartment may be assumed to lose consciousness or die when the FED reaches 100\% [21].

A Monte Carlo method is used to handle random starting conditions and random processes. Random starting conditions include the type and location of the first ignited fuel, the number, location and attributes of occupants, doors and windows open/close status. Random processes include the fuel pyrolysis, fire growth and decay, smoke generation and delay time of evacuation.

CRISP scenarios are defined by randomly selected input condition parameters of season, time of day, room of fire origin and type of the fuel first ignited. The vent open or closed status is further determined by the season and the time of day. Once input conditions have been defined, the model predicts how the scenario develops with time, until the fire is put out or all the occupants are dead or have escaped. As multiple simulations being processed, the histogram distribution of number of occupant deaths or injuries is acquired. The risk to life safety from fire is expressed in terms of the averaged number of deaths over a sufficiently large number of Monte-Carlo simulations [20,21].

Some case studies have been reported in reference [21]. These studies used the CRISP model to investigate the risk level to occupant life safety in the presence of different passive and active the fire protection features. The calculated relative risk values have been compared with reference prescriptive code compliant design options. 


\subsubsection{Lund QRA Method}

At Lund University in Sweden, Frantzich has proposed two fire risk assessment approaches - Lund Standard Quantitative Risk Analysis (QRA) and Extended QRA methods [7]. The main purpose of his work is to develop quantitative methods to determine risk levels to occupants who are exposed to fire in buildings.

Both individual risk and societal risk resulting from a fire can be evaluated using QRA methods. The individual risk is defined as the risk to which any particular occupant is subjected to, while the societal risk is defined as the risk of having multiple fatalities. The typical output for individual risk is described as a probability of death per year of a person being subjected to fire hazards. The societal risk of the QRA method is frequently expressed as a FN curve which describes the probability of an event and the consequence of the event in terms of the number of occupant deaths. The societal risk is also expressed as average societal risk (ASR), which represents the number of fatalities per year for the fire event. ASR condenses the risk profile into one number to make it easy to compare risks of different design options or to determine if a specific design complies with an established tolerable risk level.

To examine the impacts of a fire incident, the concept of Kaplan and Garrick's triplet mentioned in section 2.1.1 above is used. The risk triplet includes accident scenarios, accident frequencies and accident consequences.

On the probabilistic aspect of the Lund QRA method, the description of a scenario structure and quantification of frequency for each scenario are based on event trees. An event tree, also known as probability tree is often constructed by defining an initiating 
event followed by a series of branches each denoting a possible outcome of a chain of events. By using the event tree method, the events that may occur are organized and graphically shown in a scenario structure. Each scenario is assigned a probability by combining all the branch probabilities leading to that scenario.

To quantify the consequence of each scenario resulting from a fire incident, deterministic fire engineering calculations are used in the Lund QRA method. The overall consequence is expressed by a limit state function G. The expression of a limit state function depends on the fire safety objective. In a case study of fire safety risk analysis of a health care facility, Frantzich defined the limit state function as the margin of evacuation time [23].

$$
G=T_{S} * M s-\left(T_{D}+T_{R}+T_{E}\right)
$$

Where,

$\mathrm{G}$ - Margin of evacuation time, which is the time to reach untenable conditions minus the time for evacuation for each scenario in the event tree.

$\mathrm{T}_{\mathrm{S}}$ - Calculated time to untenable conditions

Ms - model uncertainty factor

$T_{D}$ - Calculated time to detection fire

$T_{R}$ - Time for reaction and response for staff

$\mathrm{T}_{\mathrm{E}}$ - Calculated movement time for patients

In the assessment the design fire is assumed to be a $t$-square fire. The time to untenable conditions in the building is determined by simulating the fire scenarios with the computer program CFAST. The detection time is determined by using the program 
Detact-t 2 to calculate the smoke or heat detector activation time. The factor Ms is the uncertainty of the CFAST model. By using a least square fitting method, the expression of $T_{S}$ and $T_{D}$ with respect to fire growth rate and room height and area are obtained. Staff reaction and response time $T_{R}$ is taken as a random variable following a normal distribution in seconds. Movement time $\mathrm{T}_{\mathrm{E}}$ is calculated by a simple equation with respect to the ratio of number of patients and the number of staff during evacuation. The adverse consequence or failure of the evacuation process is defined as $G$ is less than or equal to zero.

As many variables used in the fire protection engineering calculation involve statistical distributions and inevitable uncertainties, the confidence to the risk profile resulting from a standard QRA is unknown. To study the influence of uncertainties in branch probability or variables, the use of an extended QRA is suggested. The Extended QRA takes system uncertainty information into account. The Kaplan and Garrick triplet can then be expressed as $\mathrm{R}=\{\mathrm{si}, \mathrm{pi}(\mathrm{xi})$, ci (yi) $\}$ to reflect the influence of variables subject to uncertainty. However, very few attempts have been made to apply the extended QRA method into fire risk assessment practice [7].

In the standard QRA, the consequences and probabilities of scenarios can be examined individually or together as a system depending on the objectives of the analysis. The advantage of using QRA methods is that a large number of events can be investigated. Furthermore, with the extended QRA method inherent uncertainty in the variable is considered. Frantzich suggests that these two risk analysis methods may be used as decision tools to compare different design options [37]. 


\subsubsection{Risk-Cost Assessment Models}

In Canada and Australia, a risk-cost assessment approach has been developed for evaluating risks in buildings. This method is based on research work conducted by Vaughan Beck [24] aiming to develop a risk assessment tool to assist cost-effective fire protection designs. Beck was the first to develop a methodology that combines all of aspects of fires and outputs the impacts of fires using two performance parameters - ERL (expected risk to life) and FCE (fire cost expectation). These two decision making parameters which represent fire risks to occupants lives and building property losses result from the interactions between fire, building structure, fire protection systems, and occupants during a fire incident. Beck's approach has been further developed collaboratively at the Warren Centre for Advanced Engineering, University of Victoria and National Research Council of Canada (NRCC) and has ultimately resulted in three closely related comprehensive fire risk assessment models CESARE-Risk[24,25] in Australia, FiRECAM[28,29] and FIERAsystem[30, 32] in Canada.

\section{CESARE-Risk model}

The CESARE-Risk model is a fire risk assessment model developed by the Centre for Environmental Safety and Risk Engineering (CESARE) at the Victoria University of Technology in Australia [24]. The applicable building types of this model include apartment buildings, hotel buildings, and aged-care buildings. Along with the launching of the performance-based building code of Australia in 1996, this model was developed 
with the intention to provide fire protection engineers a tool to quantify the performance of fire protection systems and estimate fire risk levels in buildings, thus helping to identify cost-effective design solutions for buildings [24].

CESARE-Risk uses a combination of probabilistic and deterministic approaches to estimate the two decision making parameters ERL and FCE for all fire scenarios that may occur in the building. The ERL is the expected number of fatalities per 1000 fires or expected number of fatalities over the design life of the building. The FCE is the sum of fire protection systems capital investment and all property losses from all fires in the building over the design life of the building.

In the CESARE Risk model, the fire scenarios are described by event trees. The use of the event tree method is to address both successful and unsuccessful operations of fire protection measures in a building. In theory, as a result of event tree analysis there could be an infinite number of scenarios if all the factors that affect the building fire risk level are considered. To limit the complexity of the problem and make computations possible using current computation technology, the CESARE Risk model considers only the most important factors which would present great risk to occupant life safety and property loss. These factors are dimensions and contents of the building, occupant profiles, ignition conditions, fire protection systems, and fire brigade response. A distinct feature of CESARE Risk is that this model uses a dynamic scenario structure to quantify the stochastic process of a fire incident. In the process of a building fire, the barriers and structure components failure is treated as a stochastic process. In smouldering and nonflashover fires, the fire spread to other compartment is not likely to occur. However, for 
post-flashover fires, thus the structure of the event tree may change due to fire spread from the room of fire origin to other rooms. To handle this problem, a dynamic event tree structure is used to represent the fire scenarios in this stochastic process. Zhao and Beck describe a procedure to establish the dynamic scenario structure for residential buildings [27].

CESARE Risk uses the NRCC fire growth model to predict room temperature, smoke concentration and smoke layer height in the room of fire origin. This model is based on a single zone fire growth methodology, and it is modified and validated with the results of experiments conducted at the Victoria University of Technology [25].

With the development of fire, the smoke and product species may transport outside of the room of fire origin. The CESARE centre developed a smoke spread model called CESARE Smoke to predict the propagation of smoke through the building. The CESARE Smoke model couples a one-zone model and a network smoke spread model to predict smoke movement in the floor of fire origin, stairs and floors of non-fire origin [25].

The performance of barriers and structural elements is estimated by the Barrier Failure Model developed by BHP Australia [25]. This model is coupled with the Fire Growth Model to predict the time of failure of barriers and structural elements exposed to a realistic fire and the standard load condition. A Monte Carlo simulation is conducted to simulate multiple fires to determine the probability of failure, standard deviation, and the average time of failure. The criteria used to determine barrier and structural failure are insulation failure, integrity failure and structural failure. 
The human behaviour model addresses the human response during the fire and evaluates the cumulative exposure of occupants to toxic and thermal effects, in conjunction with the fire growth and smoke spread models. The human behaviour model comprises three components:

- Response submodel

- Evacuation submodel

- Fire brigade intervention submodel.

The response submodel addresses the occupant's behaviour prior to the onset of evacuation. This model uses a probabilistic approach to calculate occupant's recognition time and pre-evacuation time based on collected data and a three-point representation distribution.

The evacuation submodel of CESARE Risk is a dynamic network model that handles occupant movement from outside of their room to the outside of the building. Occupants in the building are categorized either as being mobile or non-mobile. The evacuation submodel estimates the occupant spatial distribution at any time during a fire incident and the time occupants stay at each location. Two evacuation models - the standard evacuation and the smoke evacuation have been considered to evaluate the evacuation time with or without the effects of heat and smoke. In the smoke evacuation model, occupants are allowed to change movement direction by looking for alternative egress routes if high smoke obscuration conditions are expected in their route. In CESARE Risk, the life safety risk is assumed to be the result of either temporal accumulation of toxic gases or thermal effects on occupants. The cumulative $\mathrm{COHb}$ (carboxyhaemoglobin) 
dosage in the blood and the temperature are used to determine occupant incapacitation and fatality.

Fire response and the actions of the fire brigade are assessed by a simplified version of the Fire Brigade Intervention Model developed by the Australia Fire Authorities Council (AFAC). The model uses a probabilistic approach to calculate the fire brigade arrival time, preparation time and the time when the fire brigade starts fighting the fire and begins the search and rescue process. The outcomes of this submodel are either the fire is successfully extinguished or not, which is a function of fire severity, the time to start to fight the fire and water availability [26].

The economic submodel is used to calculate the investment cost of the building fire protection systems and property loss as the result of the fire. The calculation of capital cost of fire protection systems includes active and passive fire protection system investment, and the annual inspection and maintenance costs of fire protection systems. The fire losses are estimated by considering fire damages, smoke damages and water damages, and the probabilities of each scenario. The outcome of the model is the Fire Cost Expectation (FCE) which aggregates the monetary cost and loss factors over the design life of the building, and are usually given in dollars at present worth.

\section{FiRECAM model}

The FiRECAM (Fire Risk Evaluation and Cost Assessment Model) model is a fire risk assessment model developed at the National Research Council of Canada (NRCC) in collaboration with Public Works and Government Services Canada (PWGSC) [29]. This 
model is developed with the intention to evaluate the level of fire risk to occupants, as well as the capital and operation costs of fire protection systems and fire losses in an apartment or office building. The model can be used to identify whether a proposed building fire system design option meets the performance requirement specified in a performance-based code, or to demonstrate that the risk level of a proposed design is equivalent to a code-compliant design.

The basic methodology of FiRECAM follows Beck's risk-cost approach [28]. FiRECAM uses both probabilistic and deterministic approaches to calculate the expected risk to life (ERL) and fire cost expectation (FCE) of the building.

FiRECAM uses deterministic approaches to evaluate the consequences of fires in the building by simulating the complete fire process and human behavior during a fire incident. The model considers fires starting in various locations, fire and smoke spread in the building, occupant response and evacuation, and fire brigade reaction. To complete the calculations mentioned above, thirteen submodels have been developed to simulate the dynamic interaction of fire/smoke development, human behaviour, and fire protection system performance in the building. A more detailed description of these submodels is given below.

Building and Risk Evaluation Model is an optional model aiming to correct factors for ignition potential risk and fire characteristics of a building when normal fire statistics can not be applied. The calculations are based on the building layout, types and quantity of combustibles in the building, building management and occupant characteristics and the maintenance of fire suppression systems if installed. The output of this model is used 
later in the Design Fire Model to correct the statistical values of fire occurrence rate, probability of fire types, probability of barrier failure and the reliability of suppression systems [28].

Fire growth and smoke movement in the FiRECAM are simulated using the Design Fire Model and Fire Growth Model. The Design Fire Model predicts the probability of each of the six design fires used in FiRECAM. The Fire Growth Model is a single-zone model which assumes the conditions within the compartment to be uniformly represented by a single temperature and smoke species concentration. The model simulates the development of the design fires in the room of fire origin and calculates the time dependent values of HRR, room temperature, smoke concentration, and the mass flow rate leaving the room of fire origin. The time of occurrence of key events such as development of fire cues, smoke detector activation, heat detector/sprinkler activation, flashover, and fire burnout are determined by this model and used later as inputs to other models.

The structural elements and barriers could fail when subjected to extreme heat or high temperature of a fire. In FiRECAM, the Boundary Failure and Fire Spread Models evaluate the time dependent performance of barriers and calculate the probability of their failure when exposed to fully developed fire conditions. This model uses the normalized heat load concept to determine the failure probability, by comparing the heat received by the boundary elements during the fire in the simulation with the heat received by the same elements in a standard fire resistance test. The calculated failure probability values are then used in the Fire Spread Model to calculate the probability of fire spread in each 
location in the building. Fire fighting effectiveness which affects fire spread in the building is also considered in the calculation. To simplify the fire spread calculation, this model assumes that fire spread to each location in the building occurs at the fire origin burnout time. This assumption simplifies the time dependent calculation into a non-time dependent problem, but this also leads to a conservative fire spread probability estimation.

The Smoke Movement Model calculates the spread of hot gases from the room of fire origin to other parts of the building. The time dependent temperature and the concentration of toxic gases are determined by this model. The time the stairs become untenable, which is the time when the stairs are filled with toxic gases and are no longer available for evacuation is calculated by this model. The Smoke Movement Model also predicts the smoke hazard probability based on occupants exposure to toxic gases and the temperature rise in the building at the time of fire brigade arrival or the time of fire burnout in the room of fire origin.

The fire brigade fire extinguishing activities and rescue efforts are simulated by the Fire Department Response Model. This model calculates the probability of fire department arrival, expected arrival time, fire fighting effectiveness and rescue effectiveness based on the properties of the building, experience and characteristics of fire department, notification and travel conditions. The model assumes that the fire will be controlled and all live occupants are rescued upon the time fire fighters arrive on the scene. 
In a fire incident, occupants may respond to various signals denoting the presence of the fire and take actions to escape the unwanted conditions resulting from the fire. These processes are estimated by the Occupant Response and Evacuation models in FiRECAM. The Occupant Response and Evacuation models calculate the probability of response to fire warnings from fire cues, fire alarm and notification systems, as well as warnings given by other occupants or fire fighters. The probability of response is then used in the Evacuation Model together with the critical time calculated by the Smoke Movement Model to determine whether occupants can evacuate the building or not. The Evacuation Model of FiRECAM uses a deterministic approach to predict the occupant movement in the building. A number of parameters regarding floor layout, exit location and flow of occupants are assumed in order to simplify the calculation.

Life hazard models include the Expected Number of Deaths Model and the Expected Risk to Life Model. Occupants in the building may be threatened by toxic gases, high temperature and heat radiation in the compartments or egress routes. The negative impacts to occupant life safety of each fire scenario are evaluated by the Expected Number of Deaths Model on the basis of smoke hazard values, fire spread probability and the number of occupants in the building obtained from the other models. Other factors like refuge areas which may affect the expected number of deaths are taken into consideration in this model. The expected number of deaths obtained from this model and the probability of occurrence of each scenario obtained from the Design Fire Model are then combined in the Expected Risk to Life Model as the expected risk to life (ERL) to represent the overall fire risk to life in a building [28]. 
FiRECAM's economic and cost models include the Economic Model, the Property Loss Model and the Fire Cost Expectation Model. The Economic Model calculates the cost of fire protection systems, including capital investment and annual inspection and maintenance cost. The Property Loss Model evaluates the cost of fire losses of building contents from smoke, heat and water hazards, and the restoration cost. The overall fire cost expectation (FCE) is calculated in the Fire Cost Expectation Model as the total fire cost as a result of all possible fires in the building, with consideration of each scenario probability obtained from the Design Fire Model.

To evaluate the performance of the FiRECAM model, NRCC and PWGSC have conducted a number of real and fictitious case studies. These studies have concluded that the predictions of the model are generally reasonable and acceptable [29]. FiRECAM is considered to be the first fire risk assessment tool that is able to help fire professionals identify cost-effective design alternatives and evaluate the overall fire safety performance of a building.

\section{FIERAsystem model}

After the successful development of FiRECAM, the National Research Council of Canada (NRCC) decided to extend fire risk assessment concepts developed in FiRECAM to other occupancies. To meet the performance-based fire protection design needs in warehouses, aircraft hangers and other light-industrial building, the FIERAsystem model (Fire Evaluation and Risk Assessment Systems) has been developed [45]. 
FIERAsystem provides fire professionals flexibility in using this model based on individual objectives. It allows the user to use standard engineering correlations to perform simple fire protection engineering calculations for the fire development, smoke/plume movement, fire severity etc. In addition, the user may run individual submodels to evaluate the performance of a particular component of the fire protection systems that they are interested in. Critical parameters like the time of activation of fire detection systems, the time of structural element failure, or the time to flashover can be calculated to evaluate whether a fire protection system will meet the specific fire safety objectives.

On the other hand, FIERAsystem can be used to perform a complete risk analysis to quantify overall fire performance of a building. FIERAsystem evaluates the expected risk to life (ERL) in a building as a result of selected fire scenarios. This model also calculates the fire loss expectation (FCE) of the building in terms of the building fire protection system cost and economic losses due to fire incidents. The two calculated decision making parameters ERL and FCE are used to find optimum fire safety design solutions that comply with the codes.

To calculate the ERL and FCE values, FIERAsystem considers the interactions between fire development, smoke movement, performance of fire protection systems, occupant response and evacuation, and fire department intervention. A number of interacting submodels have been integrated to perform the calculations. These models are described briefly in the following sections. 
FIERAsystem uses design fire models to calculate the time-dependent parameters to characterize fire development. The type of fires being modeled are liquid pool fires, storage rack fires, and $\mathrm{t}^{2}$ fires. The burning rate, room temperature, and the production of smoke gases are calculated by standard engineering correlations [30]. The outputs of the Fire Development Model are provided to the Life Hazard model to predict the probability of death from exposure to high radiant fluxes. The output information is also used by the Building Element Failure model to predict the probability of structural element failure.

FIERASmoke is a two zone model developed for the FIERAsystem to calculate the smoke movement in the building. The two-zone smoke model divides a compartment into two distinct zones: an upper, high temperature zone and a lower, low-temperature zone. Within each of the zones the temperature, gas concentration and smoke density are assumed to be homogeneous. These parameters for each compartment in the building are calculated as a function of time based on mass, energy and species conservation equations. The outputs of the smoke movement model are used to predict the tenability level for the rooms in the building except that of fire origin.

The performance of barriers and structural elements is estimated by the Building Element Failure Model. Standard fire engineering correlations and numerical models have been used in the model to predict the boundary elements performance. Typical outputs of this model include time of failure of structural elements, stress and modulus of elasticity at elevated temperatures. Currently, FIERAsystem building element failure model is able to predict the performance of beams and columns made of steel or wooden materials, wood-frame walls and floors, and concrete slabs. [30]. 
The active fire protection systems which have major influence on the impacts to occupants and property are also evaluated using FIERAsystem submodels. Fire detection and alarm systems provide early warning of fire danger to occupants and activate fire suppression systems thus minimize the impacts of fire to both life and property. The Fire Detection Model has been developed to predict the activation time of heat detectors, sprinkler heads and smoke detectors. The temperature of each heat detection sensor is calculated to determine its activation time. The activation times of smoke detectors are calculated with the information on the smoke layer obtained from the fire development and smoke movement models. The activation time calculated for the fire detection systems are used to determine the response time of the fire department and occupants in the building.

The Suppression Effectiveness Model of FIERAsystem evaluates the effectiveness of automatic sprinkler systems in the building. This model uses a user input suppression effectiveness to modify the HRR curve obtained from the fire development model or from fire tests. In addition, the flame and plume temperatures, as well as the radiant heat fluxes are corrected by the modified HRR values. Equivalent temperatures based on the flame and ceiling impingement temperatures are calculated and used as inputs to other models to determine the time of failure of boundary elements [30].

Occupant response and occupant evacuation are evaluated by the Occupant Response Model and the Occupant Evacuation Model. The Occupant Response Model is used to calculate the probability of occupants starting to evacuate the building in the event of a fire [32]. The calculation of pre-evacuation behavior is based on the concept of PIA 
process which defines pre-evacuation occupant response behaviors in terms of occupant perception, interpretation, and action. The probability of perception of the presence of fire is calculated based on the time dependent state of the fire and the sources of warning at each time step. Once the presence of the fire is perceived, the occupants interpret this information based on the type of perception. The Occupant Response Model uses three interpretation levels to calculate the delay time. The probabilities of the possible actions taken by the occupants are then calculated based on warning sources and occupant classifications. The main outputs of the Occupant Response Model are the cumulative probability of commencing an evacuation for occupants in each compartment as a function of time, as well as the time and probability of calling the fire department.

The Occupant Evacuation Model calculates movement of each occupant from their location at the start of the fire to a safe location. For occupants in each compartment, the model calculates a weighted average speed, the time required for successful evacuation, and the instantaneous and cumulative probability curve of successful evacuation. Together with other submodels, this information is used to determine the number of occupants successfully evacuated or trapped in the building.

FIERAsystem predicts occupant fatalities due to the effects of breathing toxic gases, being exposed to high thermal radiant heat flux, and exposure to high temperatures. The Life Hazard Model calculates the probability of death in each compartment by using the union of the individual probabilities of death from occupant exposure to thermal radiation fluxes, and breathing hot or toxic gases. The time dependent expected number of deaths in the building for a scenario is predicted as the sum of the products of probability of 
deaths times and the residual live occupants in each compartment at any given time [30]. The Expected Risk to Life model then takes into consideration the total expected number of deaths in the building and the probability of occurrence of each scenario to calculate the Expected Risk to Life (ERL).

FIERAsystem considers the economic losses directly or indirectly resulting from fire incidents and the capital investment and maintenance cost of fire protection systems in the building. The Economic Model calculates the capital investment of building construction and contents, the capital investment and annual operation cost of fire protection systems. The direct damages to properties are calculated in The Economic Model for the structure and the contents by considering the impacts of smoke, water, and heat. The Downtime Model calculates the amount of time and respective monetary losses resulting from interruption of business operation after a fire. The fire losses and cost of building fire and the probability of occurrence of each fire scenario are combined to estimate the fire cost expectation (FCE). 


\section{Chapter 3: DESCRIPTION of CUrisk}

\subsection{Background}

As Canada and other developed countries around the world move from traditional prescriptive building codes to performance-based codes, new quantitative risk assessment models are in increasing demand to help fire professionals determine whether building fire safety designs comply with the objectives of these codes, and to identify whether fire safety designs provide the necessary level of fire safety in a cost-effective manner.

Following the approaches developed in FiRECAM and FIERAsystem, a new riskcost model called CUrisk is currently being developed at Carleton University with the aim to extend the risk-cost concept into timber-frame commercial buildings. The development of CUrisk has been supported by the Natural Science and Engineering Research Council of Canada (NSERC) and FPInnovations (formerly Forintek Canada Corporation).

As with other risk models, the CUrisk Model assesses the performance of building fire safety measures using two decision making parameters - the expected risk to life (ERL) and the fire cost expectation (FCE). Although the main objective of CUrisk is to provide a risk assessment tool to evaluate the performance of fire safety measures in timber-frame buildings, the model can be applied to any type of occupancy as long as the 
necessary input data are available to define the design fires and scenario structure needed for risk assessments.

The model consists of a system model and sixteen interacting submodels [3]. The system model deals with the basic methodology and overall framework of risk analysis. The execution sequence and data flow between submodels are controlled by the system model. The submodels simulate individual aspects of building fire performance, including fire growth, smoke movement, fire spread and boundary failure, performance of fire detection and alarm systems, human behaviour, building fire protection cost and economic impact of fires. At present, the system model and most of its submodels have been completed except for the Boundary Failure and Fire Spread Models.

In the following sections, a description of CUrisk will be presented with the focus on the system model, occupant response model, and life hazard model. Only brief consideration will be given to smoke movement model, occupant evacuation model and economic model because the description and preliminary validation of these models can be found in separate publications $[34,36,37]$.

\subsection{The System Model}

The CUrisk System Model performs the risk analysis and determines the execution sequence of the submodels. Figure 3.1 shows a schematic diagram of the fire risk analysis procedure of CUrisk. 


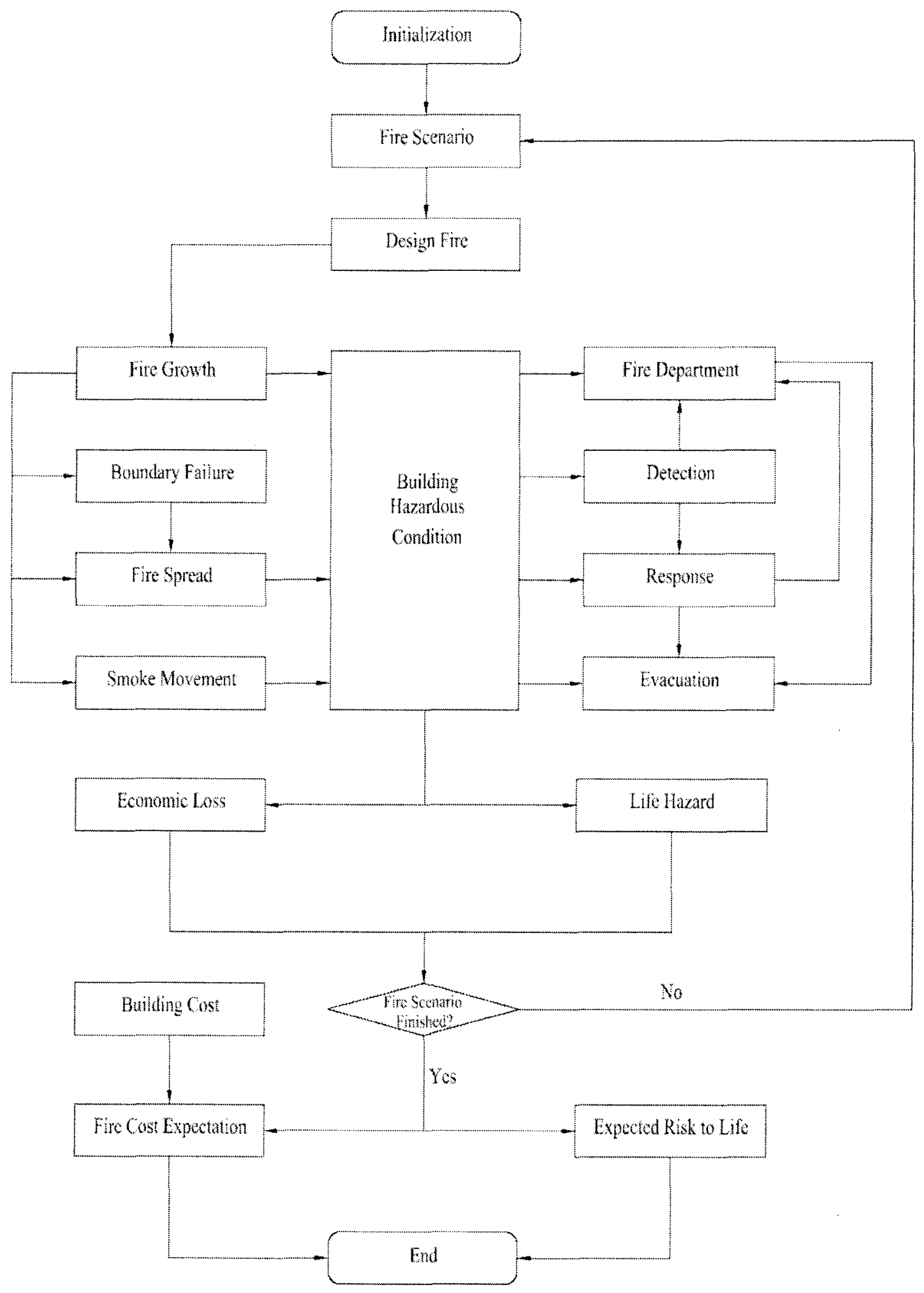

Figure 3.1: Schematic diagram of the CUrisk System Model (Adopted from [3]) 
As illustrated in Figure 3.1, CUrisk begins with the generation of the fire scenarios. A fire scenario in CUrisk is a series of events based on user defined inputs of contents and characteristics of compartments, occupant characteristics, fire brigade response factors, and options of fire safety measures. For each scenario, the risk assessment starts from the selection of the design fire. Then, the hazardous conditions in the compartment of fire origin are predicted by the Fire Growth submodel. The hazardous conditions in compartments away from the fire origin are calculated using the Smoke Movement submodel. The Boundary Failure and Fire Spread submodels provide further hazardous conditions information throughout the building by calculating the probability of fire spread from the compartment of fire origin to other compartments. These models have not been complete yet. The information of the building hazardous conditions is then used in other submodels to calculate life losses and economic losses for each scenario. After looping through all the scenarios, two decision-making parameters - the Expected Risks to Life (ERL) and the Fire Cost Expectation (FCE) are obtained based on the consequence estimation and the probabilities of all the scenarios considered.

A list of the CUrisk submodels and the relationship of these models is given in Table 3.1. A more detailed description of these models will be presented in the following sections. 
Table 3.1: Relationship of CUrisk Submodels (Adopted from [3])

\begin{tabular}{|c|c|c|}
\hline Submodels & Input Submodels & Output Submodels \\
\hline Fire Scenarios & User input & $\begin{array}{l}\text { Expected Risk to Life ; Fire } \\
\text { Cost Expectation }\end{array}$ \\
\hline Design Fire & User input; & Fire Growth \\
\hline Fire Growth & User input; Design Fire & $\begin{array}{l}\text { Smoke Movement; Boundary } \\
\text { Failure; Fire Spread Hazardous } \\
\text { Conditions }\end{array}$ \\
\hline Smoke Movement & User input; Fire Growth & Hazardous Conditions \\
\hline Boundary Failure & Data Input Fire Growth & Fire Spread \\
\hline Fire Spread & $\begin{array}{l}\text { User input; Fire Growth } \\
\text { Boundary Failure }\end{array}$ & Hazardous Conditions \\
\hline $\begin{array}{l}\text { Smoke and Fire } \\
\text { Detection }\end{array}$ & $\begin{array}{l}\text { User input; Hazardous } \\
\text { Conditions }\end{array}$ & $\begin{array}{l}\text { Fire Department Response and } \\
\text { Action Occupant Response }\end{array}$ \\
\hline Occupant Response & $\begin{array}{l}\text { User input; Smoke and Fire } \\
\text { Detection Hazardous } \\
\text { Conditions }\end{array}$ & $\begin{array}{l}\text { Occupant Evacuation; Fire } \\
\text { Department Response and } \\
\text { Action }\end{array}$ \\
\hline $\begin{array}{l}\text { Occupant } \\
\text { Evacuation }\end{array}$ & $\begin{array}{l}\text { User input; Hazardous } \\
\text { Conditions Occupant } \\
\text { Response }\end{array}$ & Life Hazard \\
\hline Life Loss & $\begin{array}{l}\text { Occupant Evacuation Fire } \\
\text { Department Response and } \\
\text { Action Hazardous Conditions }\end{array}$ & Expected Risk to Life \\
\hline $\begin{array}{l}\text { Fire Department } \\
\text { Response and Action }\end{array}$ & $\begin{array}{l}\text { User input; Occupant } \\
\text { Response Smoke and Fire } \\
\text { Detection Hazardous } \\
\text { Conditions }\end{array}$ & Life Hazard \\
\hline $\begin{array}{l}\text { Hazardous } \\
\text { Conditions }\end{array}$ & $\begin{array}{l}\text { Fire Growth Smoke } \\
\text { Movement Fire Spread }\end{array}$ & $\begin{array}{l}\text { Smoke and Fire Detection; } \\
\text { Occupant Response Occupant } \\
\text { Evacuation ; } \\
\text { Fire Department Response and } \\
\text { Action; } \\
\text { Economic Loss ; } \\
\text { Life Hazard }\end{array}$ \\
\hline Building Cost & User input & Fire Cost Expectation \\
\hline Economic Hazard & $\begin{array}{l}\text { User input; Fire Scenarios } \\
\text { Hazardous Conditions }\end{array}$ & Fire Cost Expectation \\
\hline Risk to Life & Fire Scenarios Life Hazard & Final Output \\
\hline $\begin{array}{l}\text { Fire Cost } \\
\text { Expectation }\end{array}$ & $\begin{array}{l}\text { Fire Scenarios Building Cost } \\
\text { Economic Loss }\end{array}$ & Final Output \\
\hline
\end{tabular}




\subsection{Fire Scenario submodel}

Fire risk assessment is scenario based. A scenario is a series of temporal or logical based description of key events in a fire that characterize a fire incident. Fire risk analysis should identify and assess all fire scenarios in a building. However, a comprehensive scenario specification analysis may result in an infinite number of fire scenarios, thus a simplification process is necessary to create a scenario structure with a manageable number of scenarios that can be analyzed by the model.

In CUrisk the event tree method is used to set up the scenario structure. In this model, various factors which may have significant impacts on life or property losses are considered. The event tree consists of a sequence of interrelated events: fire ignition, fire development, smoke movement, performance of automatic suppression systems, fire brigade intervention, and boundary failure. Based on the contents and characteristics of the fire compartment, design fires are selected for each compartment. The fire scenario model considers the door open or closed status of the compartment of fire origin and weather conditions. Then the effects of fire protection system performance and human intervention on fire development and smoke movement are considered. For potential flashover fires, the automatic sprinkler system and fire department response are evaluated to see whether the fire will be suppressed before boundary and structural element failure. The final event in the event tree estimates the probability of fire spread resulting from boundary failure. 
The outputs of the Fire Scenario submodel are the identification of the compartment of fire origin, as well as number of fire scenarios and the probability of occurrence of each scenario, which is used in the Risk to Life and Fire Cost Expectation submodels.

\subsection{Design Fire Submodel}

The Design Fire submodel takes the properties, arrangement, and amount of fuel, as well as the geometry and dimensions of the compartment of fire origin into account to produce growth characteristics of the design fire. This submodel provides the Fire Growth submodel a nominal description of the design fire.

The Design Fire model runs only once for each simulation. Typical output of this submodel include: rate of fire growth in $\mathrm{t}^{2}$ fire, heat of combustion of fuel, composition of the fuel, combustion products to fuel ratios, and the heat release rate.

\subsection{Fire Growth and Smoke Movement Submodels}

In CUrisk, the CUsmoke submodel has been developed to predict both the fire development in the compartment of fire origin and the transport of smoke movement away from the room of fire origin to other rooms in the building. This submodel is a multi-compartment, two-zone fire model based on the research conducted at the National Research Council of Canada. CUsmoke considers the effect of sprinkler suppression and fire department intervention on HRR. Detailed information of this model can be found in the reference [33]. In addition, a number of model validation studies have been made that compare data from full-scale experiments to the predictions of the model [34]. 
The fire conditions in the compartment of fire origin are calculated by the Fire Growth submodel. This model considers the fuel properties, as well as the compartment geometry and ventilation parameters to make adjustments to the fire characteristics obtained from the Design Fire submodel based on the real conditions in the compartment of fire origin.

This model runs only once for each compartment of fire origin. The results of this submodel provide fire and smoke information for the submodels of Smoke and Fire Detection, Boundary Failure, Fire Spread, and Hazardous Conditions. Typical outputs of this submodel include: HRR, temperature of gas layers, and mass flow rates, concentration of $\mathrm{CO}$ and $\mathrm{CO}_{2}$ in the gas layers, smoke optical density, height of smoke interface, radiant heat flux, time of flashover, and time of burnout.

CUsmoke calculates tenability levels in compartments away from the the room of fire origin as a result of the spread of smoke and toxic gases. The smoke hazard in each compartment is predicted as a function of time.

CUsmoke is run once for each scenario. The results of the submodel are used by the Hazardous Conditions submodel and the Life Hazard submodel to calculate the number of deaths.

\subsection{Boundary Failure and Fire Spread Submodels}

The Fire Spread submodel of CUrisk is still under development. Currently a model has been developed to calculate the probability of failure of timber-frame walls when subjected to the standard time-temperature curve [35]. 


\subsection{Smoke and Fire Detection Submodel}

The performance of fire detection and alarm systems is evaluated by the Smoke and Fire Detection submodel. A fire alarm can be initiated by smoke detectors, heat detectors or sprinkler heads installed in the building. The Fire and Smoke Detection submodel takes smoke optical density and upper layer smoke temperature values in each location from the Hazardous Conditions submodel, together with the physical characteristics of each type of detector to calculate smoke detection time, heat detection time, and sprinkler detection time. This model also calculates the overall probability of detection as a function of time. The results are provided as inputs to the Occupant Response and Evacuation submodels, and the Fire Department Response and Action submodel.

\subsection{Fire Department Response and Action Submodel}

The Fire Department Response and Action Submodel is used to estimate the performance of fire department actions in fighting the fires and rescuing occupants in a fire incident. This model assumes the fire will be controlled and the remaining occupants who are alive in the building will be rescued after firefighters enter the building.

The fire department's response efforts depend on the intervention time, which is the period of time from fire start to the first application of fire fighting agent over the fire. The intervention time is calculated as the sum of detection time, notification time, dispatch time, preparation time, travel time and setup time. The calculation of these time 
intervals are based on the detection times, characteristics of the fire department, and the travel distance.

Typical outputs of the Fire Department Response and Action submodel are fire fighter intervention time and their arrival time to each compartment of the building. These data are provided as inputs to the Occupant Response and Evacuation Submodels, and the Economic Loss submodel.

\subsection{Hazardous Conditions Submodel}

In CUrisk hazardous conditions caused by the combustion products in a fire are grouped into two categories: thermal conditions and toxic conditions. Either of them may present potential hazards to occupant life safety and have negative impacts on property.

The Hazardous Conditions submodel collects time-dependent data at each location in the building from other submodels. This submodel collects fire and smoke conditions such as temperature of upper/lower layers, species concentrations, smoke obscuration, and thermal radiant flux in each compartment of the building. Critical parameters of time to detection and time to flashover and burnout time of fire are also obtained from the Fire Growth and Smoke Movement submodels. In addition, the probabilities of fire spread from the fire compartment to any other compartment will be collected from the Fire Spread submodel which is currently under development.

The Hazardous Conditions submodel outputs the collected thermal and toxic information of the fire to the related submodels to predict the fire consequences on both occupant life safety and property. The optical density and temperature values for 
detection are used by the Smoke and Fire Detection submodel to predict the time of fire detection system activation. The submodels of Occupant Response and Occupant Evacuation use these data to judge the fire situation and arrange occupant evacuation routes. The Fire Department Response and Action submodel makes use of the information to judge fire conditions and arrange rescue and fighting operations; and the submodels of Life Hazard and Economic Loss use the information to calculate the number of deaths of occupants and economic losses.

\subsection{Building Cost and Economic Loss Submodel}

CUrisk includes the Building Cost and Economic Loss submodels [36]. The Building Cost submodel is used to calculate the capital cost of the passive and active fire protection systems and the maintenance cost of the active fire protection systems. The calculations are based on user input information of construction components and contents of each compartment in the building, economic values of fire protection systems, and annual costs of each active fire protection system.

The Economic Loss submodel calculates the direct property losses and indirect downtime losses of all fire scenarios. In CUrisk, building contents are categorized into 11 categories based on their sensitivity to be damaged by smoke, high temperature and water. These categories include books, electronic equipment, clothes, food, appliances, upholstered furniture, plastics, machinery, lighting, interior lining and finishing. The model uses fire condition data from the Hazardous Conditions submodel, and fire protection systems and building costs from the Building Cost submodel to estimate the 
economic loss based on the contents damage sensitivities. The output economic loss of each scenario is used by the Fire Cost Expectation submodel to calculate the FCE.

A detailed description of the submodels of Building Cost and Economic Loss submodels can be found in reference [36].

\subsection{Occupant Response and Occupant Evacuation Submodels}

The Occupant response submodel is used to calculate the time dependent probability of occupant response to fire cues and warnings in a fire incident. This submodel addresses the occupant's behaviour from perceived fire cues to the commencement of evacuation. The methodology of this submodel is based on a PIA process, which defines occupant response the in a fire incident into three stages, i.e., perception, interpretation and action. A schematic description of the PIA process is shown in Figure 3.2.

Perception

Direct perception of fire cues

Warning from local alarm

Warning from sprinkler

Warning from central alarm

Warning from voice alarm

Warning from other occupants

Warning from fire department
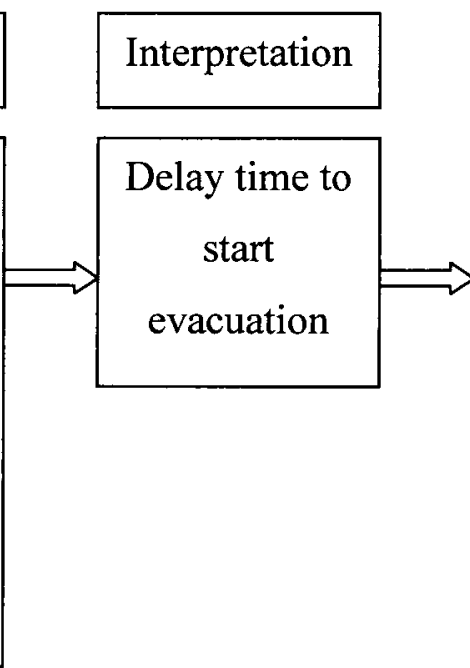

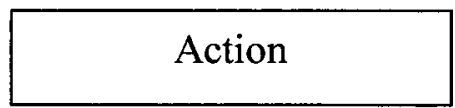

Warn other occupants

Activate pull station

Call fire department

Evacuate

Figure 3.2: The PIA Process (Adopted from [3]) 
The PIA process has been developed during the development of FiRECAM and FIERAsystem. Following this approach, the occupant response to a fire is determined by the complex interaction between fire development, indoor hazardous conditions, and occupant characteristics. Five fire states have been used in the model to characterize the fire development. They are start of fire, fire cues, activation of local smoke detectors, activation of heat detectors and sprinklers, and flashover.

The response of occupants to fire cues and warnings of a fire incident depend on the location of each occupant when the fire starts. In the model, occupants in the building are categorized into three groups according to their ability to perceive fire warnings:

- Occupants in the Compartment of Fire Origin (OCF)

- Occupants in Adjacent Compartments (OAC)

- Occupants in Other Compartments (OOC)

The model assumes that occupants can perceive warnings of the presence of a fire incident from seven different sources: direct perception of fire cues, warning from local smoke detectors, warning from sprinkler activation, warning from central alarm, warning from voice alarm, warning from other occupants, and warning from fire department.

Once the presence of the fire is perceived, occupants start to interpret the fire information and then decide their action to the fire based on the information they obtained and the reliability of the source of the warning. This interpretation process usually causes a delay in evacuation. To predict the interpretation process, CUrisk classifies the seven sources of warning into three categories and assigns corresponding interpretation delay times to each category based on expert judgment. 
After the fire cues and warning signals are interpreted as a real fire incident, occupants may take various actions before they commence evacuation. These actions include warning other occupants in the building, activating the manual pull station, calling the fire department, and commencing evacuation. The probabilities of possible actions taken are based on expert judgment.

The activation probability and activation time of fire detection systems are predicted by a probabilistic method. A triangular activation probability density distribution over the range of detection times is used to calculate the cumulative activation probability of detection.

Occupant movement is predicted by the Occupant Evacuation submodel. This submodel considers the building geometry, occupant characteristics, possible evacuation routes in the building, along with the time-dependent fire conditions from the Hazardous Conditions submodel to track the location of each occupant in the evacuation route as a function of time. This model allows the occupants to select whether or how to evacuate based on building fire conditions. The occupant evacuation process is predicted based on individual occupant decisions made during the fire incident.

Evacuation starts at the time when an occupant decides to evacuate. The model assumes that occupants will try to evacuate the building and will not stay in any room in the egress route. Occupant movement speed is based on gender, age and location of people. This nominal speed is adjusted by smoke obscuration level and population density in the egress route, as well as occupant familiarity with the building. In the development of this model, experiments were conducted by Carleton University to 
quantify the effect of visibility on occupant speed. The Evacuation submodel predicts the location of each occupant during evacuation as a function of time. This information is used later in the Life Hazard submodel to predict the number of casualties based on the hazardous conditions occupants encountered during evacuation.

A detailed discussion of the Occupant Response and Occupant Evacuation submodel can be found in publications $[32,37]$.

\subsection{Life Hazard Submodel}

The Life Hazard submodel is used to calculate the number of occupant injuries and deaths in each fire scenario. This model considers the comprehensive effects of both fire hazard conditions in each location and the occupant evacuation process in the building. The occupant casualties are the consequence of the interaction between hazardous conditions in the building and occupant evacuation. The probability of occupant death or injury is considered as the result of occupants being exposed to hot gases, toxic smoke, high radiant fluxes and fire spread conditions in the building.

$$
\mathrm{P}(\mathrm{t})=\mathrm{P}_{\mathrm{TG}}(\mathrm{t}) \cup \mathrm{P}_{\mathrm{HG}}(\mathrm{t}) \cup \mathrm{P}_{\mathrm{TR}}(\mathrm{t}) \cup \mathrm{P}_{\mathrm{FO}}(\mathrm{t}) \quad \text { Equation } 3.1
$$

Where:

$\mathrm{P}_{\mathrm{TG}}(\mathrm{t})$ - probability of death due to breathing toxic gases

$\mathrm{P}_{\mathrm{HG}}(\mathrm{t})$ - probability of death due to exposure to hot gases

$\mathrm{P}_{\mathrm{TR}}(\mathrm{t})$ - probability of death due to exposure to thermal radiation

$P_{\mathrm{FO}}(\mathrm{t})$ - probability of injury or death due to fire spread 


\section{Breathing toxic gases}

Breathing toxic gases presents lethal threats to occupants in a fire incident. Statistics show more than $70 \%$ of the deaths and injuries are due to inhaling of smoke and other asphyxiant gases. In a fire incident the most common asphyxiant gases include $\mathrm{CO}, \mathrm{HCN}$, and irritant gases like $\mathrm{HBr}, \mathrm{HF}$, and $\mathrm{SO}_{2}$. This model considers only the toxic effects of $\mathrm{CO}$ because it is the primary cause of incapacitation in most fire situations. A hyperventilation multiplication factor due to $\mathrm{CO}_{2}$ and hypoxia effect due to low oxygen concentration is also considered in the calculation. In this model, the total factional incapacitating dosage (FID) for toxic gases is used directly as the probability of death due to asphyxiant gases, thus the equation used to calculate the probability of death due to toxic gases is expressed as the following equation:

$$
\mathrm{P}_{\mathrm{TG}}(\mathrm{t})=\mathrm{FID}_{\mathrm{TG}}(\mathrm{t})=\mathrm{FID}_{\mathrm{co}}(\mathrm{t}) \times \mathrm{V}_{\mathrm{CO} 2}(\mathrm{t})+\mathrm{FID}_{\mathrm{lo}}(\mathrm{t}) \quad \text { Equation } 3.2
$$

Where :

$\mathrm{FID}_{\mathrm{TG}}(\mathrm{t})$ - fractional incapacitating dose due to toxic gases.

$\mathrm{FID}_{\mathrm{co}}(\mathrm{t})$ - fractional incapacitating dose of $\mathrm{CO}$

$\mathrm{V}_{\mathrm{CO} 2}(\mathrm{t})$ - multiplication factor for $\mathrm{CO} 2$ induced hyperventilation

$\mathrm{FID}_{\mathrm{lo}}(\mathrm{t})$ - fractional incapacitating dose of low oxygen hypoxia

The fractional incapacitating dose of $\mathrm{CO}, \mathrm{FIDco}(\mathrm{t})$ is calculated by[38]:

$$
F I D_{C O}(t)=\int_{0}^{t} \frac{8.2925 \times 10^{-4} \times[C O(t)]^{1.036}}{30} d t
$$

Where: 
$\mathrm{CO}(\mathrm{t})$ - the concentration of $\mathrm{CO}(\mathrm{ppm})$, in the compartment at time $\mathrm{t}(\mathrm{min})$

The multiplication factor for $\mathrm{CO}_{2}$ induced hyperventilation $\mathrm{VCO}_{2}(\mathrm{t})$ is calculated by[38]:

$$
\mathrm{V}_{\mathrm{CO} 2}(\mathrm{t})=\frac{\exp \left[\% \mathrm{CO}_{2}(t) \times 0.2490+1.9086[\right.}{6.8} \quad \text { Equation } 3.4
$$

Where:

$\mathrm{CO}_{2}(\mathrm{t})$ - the mass percentage of $\mathrm{CO}_{2}$, in the compartment at time $\mathrm{t}$

The fractional incapacitating dose of low oxygen hypoxia $\operatorname{FID}_{\mathrm{lo}}(\mathrm{t})$ is calculated by[38]:

$$
\mathrm{FID}_{10}(\mathrm{t})=\frac{t}{\exp \left\{8.13-0.54\left[20.9-\% O_{2}(t)\right]\right\}} \quad \text { Equation } 3.5
$$

Where:

$\mathrm{O}_{2}(\mathrm{t})$ - the mass percentage of $\mathrm{O}_{2}$ in the compartment at time $\mathrm{t}$

In Equations 3.3 3.5, the value of the time dependent parameters $\mathrm{CO}_{2}(\mathrm{t}), \mathrm{CO}(\mathrm{t}), \mathrm{O}_{2}(\mathrm{t})$ are obtained form the Hazardous Conditions submodel which collects fire hazardous information from fire growth submodel, smoke movement submodel, and fire spread submodel.

\section{Breathing or Exposure to Hot Gases}


Breathing or exposure to hot gases may present considerable risk to occupant life safety. Hot gases may cause burns, heat shocks and dehydration to occupants who are exposed to excessive heat, and result in occupant injury and death.

Similar to the calculation of the probability of death due to toxic gases, a probability of death is also computed to account for exposure to hot gases. This probability is directly determined by the respective FID value [38].

$$
\mathrm{P}_{\mathrm{HG}}(\mathrm{t})=\mathrm{FID}_{\mathrm{HG}}(\mathrm{t})=\int_{0}^{t} \frac{1}{\exp \left[5.1849-0.0273 T_{G}(t)\right]} d t \quad \text { Equation } 3.6
$$

Where:

$$
\begin{aligned}
& \operatorname{FID}_{\mathrm{HG}}(\mathrm{t}) \text { - the fractional incapacitating dose due to hot gases } \\
& \mathrm{T}_{\mathrm{G}}(\mathrm{t}) \text { - the temperature of hot gases at } 2 \mathrm{~m} \text { height at time } \mathrm{t}(\mathrm{min}) \text { in the } \\
& \text { compartment }
\end{aligned}
$$

\section{Thermal Radiation}

The radiant heat flux from the fire plume and the upper hot gas layer in the compartment is another major life safety hazard to the occupants in a building. In CUrisk, the Life Hazard submodel uses Tsao and Perry's revised vulnerability model [4] to calculate the probability of death due to thermal radiation.

$$
\mathrm{P}_{\mathrm{TR}}(\mathrm{t})=\int_{-\infty}^{(\ln V(t)-17.8)}\left(e^{-\eta^{2} / 2}\right) d \eta
$$

Where:

$$
P_{T R}(t) \text { - the probability of death due to thermal radiation }
$$


$V(t)$ - the thermal dose due to thermal radiant flux

The thermal dose $V(t)$ is calculated by the following equation:

$$
\mathrm{V}(\mathrm{t})=\int_{0}^{t}\left[q^{\prime \prime}(t)\right]^{4 / 3} d t \quad \text { Equation } 3.8
$$

Where:

$q$ " $(\mathrm{t})$ - the incident heat flux $\left(\mathrm{kW} / \mathrm{m}^{2}\right)$ at time $\mathrm{t}$, obtained from the fire growth and smoke movement submodels.

\section{Fire Spread}

The Life Hazard submodel also considers occupants injuries and casualties caused by direct exposure to flame due to fire spread conditions. It is assumed that whenever flashover occurs in a compartment the occupants in that compartment will be killed. That is, the occupant death probability due to fire spread equals to the probability of flashover in the compartment after fire spread. In mathematics, the cumulative probability of flashover after fire spread can be expressed in a form of the integral of its own probability density function:

$$
\mathrm{P}_{\mathrm{FO}}(\mathrm{t})=\int f_{F O}(t) d t
$$

Where,

$f_{F O}(\mathrm{t})$ - the probability density function (PDF function) of the probability of flashover in a compartment after fire spread to that compartment. 
Hadjisophocleous and $\mathrm{Fu}[31]$ proposed an approach to predict the flashover time of a compartment after fire spread. This approach first calculates the normal flashover time $\left(t_{\mathrm{FO}}\right)$ after a fire ignition in a compartment. Then it is assumed that the flashover time of a compartment due to fire spread is the time of fire spread plus the calculated normal flashover time. In a time-cumulative probability diagram this is expressed as a horizontal shift of the probability curve of fire spread by a distance equal to the flashover time.

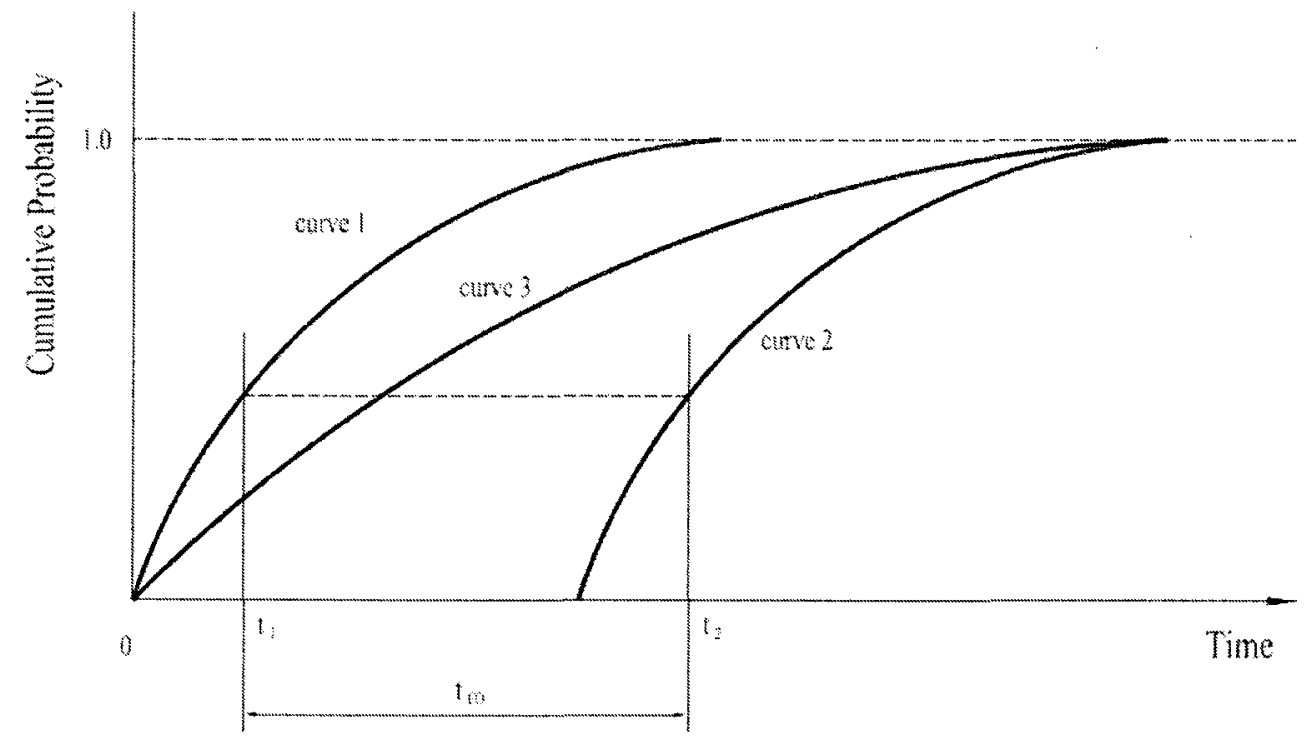

Figure 3.3: Probability of flashover after fire spread (Adopted from [31])

In Figure 3.1 above, the probability of flashover at time $t_{2}$ is uniquely determined by the probability of fire spread at time $t_{1}$, and the flashover time $t_{\mathrm{FO}}$.

Curve 1 - is the probability of fire spread;

Curve 2 - is the ideal probability of flashover by shifting curve 1. 
Hadjisophocleous and Fu further suggested that in reality flashover is likely to occur between the ends of the fire spread curve and the ideal probability of flashover curve, which is shown as curve 3 in Figure 3.1. Figure 3.1 also indicates that the probability of flashover will be affected by the probability of fire spread and the fire development conditions in the compartment after fire spread. This relationship is mathematically expressed as the following correlation:

$$
\begin{array}{ll}
\mathrm{P}_{\mathrm{FO}}(\mathrm{t})=F a \cdot \mathrm{P}_{\mathrm{FS}}\left(\mathrm{t}-\mathrm{t}_{\mathrm{FO}}\right) & \text { Equation } 3.10
\end{array}
$$

In Equation 3.10, a factor $F a$ is introduced to represent the various factors affecting probability of flashover due to fire spread.

In derivative form, the PDF function of flashover as a result of fire spread to a compartment can be calculated as

$$
f_{F O}(t)=\int_{t-t_{\mathrm{FO}}}^{t} f \cdot f_{F S}(x) d(x)
$$

Where, $f_{F O}(\mathrm{t})$ - is the probability density function (PDF function) of the probability of flashover of the compartment with time $t$. $f_{F S}(\mathrm{x})$ - is the probability density function (PDF function) of the probability of fire spread for the compartment with time $\mathrm{x}$.

$f$ - is the probability density function (PDF function) of the factor $F a$.

For a $\mathrm{t}^{2}$ fire, the model calculates the factor $F a$ by the following equation:

$$
F a=\left(\frac{t-t_{0}}{t_{F O}}\right)^{2}
$$


Thus the probability density function factor $f$ is:

$$
f=\left(\frac{2\left(t-t_{0}\right)}{t_{F O}{ }^{2}}\right)
$$

Where,

$\mathrm{t}$ - is the time variable,

$t_{0}-$ is the reference time point.

$t_{\mathrm{FO}}$ - is the time to reach flashover.

Replacing $t_{0}$ with $\mathrm{x}$ of $\mathrm{f}$ in Equation 3.13 and substituting it into Equation 3.11, the model calculates the PDF function of flashover of the compartment for a $t^{2}$ fire using the following correlation:

$$
f_{F O}(t)=\int_{t-t_{F O}}^{t}\left(\frac{2(t-x)}{t_{F O}{ }^{2}}\right) \cdot f_{F S}(x) d(x)
$$

In Equation $3.14, f_{F S}(x)$ is the time dependent distribution of the probability of fire spread which is obtained from fire spread model. In addition the time to reach flashover ( $\left.t_{\mathrm{FO}}\right)$ of a $\mathrm{t}^{2}$ fire can be approximated by the following correlation [4]:

$$
t_{F O}=\left[\frac{610\left(h_{\mathrm{k}} A_{T} A_{w} H^{1 / 2}\right)^{1 / 2}}{\alpha}\right]^{1 / 2}
$$

Where,

$\alpha$ - fire growth rate coefficient of a t-square fire, $\left(\mathrm{kW} / \mathrm{s}^{2}\right)$

$h_{k}$ - effective conductance coefficient, $\left(\mathrm{kW} / \mathrm{m}^{2}\right) / \mathrm{K}$

$A_{T}$ - total internal surface area, $\mathrm{m}^{2}$

$A_{w}$ - area of vent opening, $\mathrm{m}^{2}$ 


$$
\mathrm{H} \text { - height of vent opening , } \mathrm{m}
$$

\section{Expected Number of Occupant Fatalities for a Fire Scenario}

In this model, the number of deaths is calculated by computing the probability of death of each occupant in the building. The total probability of death, $\mathrm{P}_{\mathrm{m}}(\mathrm{t})$, for any occupant $\mathrm{m}$ at a time $\mathrm{t}$, is considered as the union of the individual probabilities of death due to exposure to hot gases, toxic smoke, high radiant fluxes and fire spread conditions in the building.

$$
\mathrm{P}(\mathrm{t})=\mathrm{P}_{\mathrm{m} \cdot \mathrm{TG}}(\mathrm{t}) \cup \mathrm{Pm}_{\mathrm{m} \cdot \mathrm{HG}}(\mathrm{t}) \cup \mathrm{P}_{\mathrm{m} \cdot \mathrm{TR}}(\mathrm{t}) \cup \mathrm{P}_{\mathrm{m} \cdot \mathrm{FO}}(\mathrm{t}) \quad \text { Equation } 3.16
$$

By tracking the occupant's movement in the building and comparing with the fire and smoke conditions at each location at each time step, the total probability of death and injury of occupant $m$ can be determined by two user defined thresholds. If the $P_{m}(t)$ is greater than the injury threshold, the occupant is considered injured, If the $P_{m}(t)$ is greater than the death threshold $\left(\mathrm{TH}_{\mathrm{d}}\right)$, the occupant is considered dead.

A survival status of occupant $D_{m}(t)$ is defined by the threshold $T H_{d}$. If $P m(t) \geq T H_{d}$, $\operatorname{Dm}(t)=1$ meaning the occupant is dead; if $P m(t)<T_{d}, D m(t)=0$ the occupant is alive.

For any given fire scenario $i$, the total number of deaths at time $t$ is calculated as the sum of all dead occupants.

$$
N_{i}(t)=\sum_{m=1}^{P O P} D_{m}(t)
$$

Where,

POP - number of occupants in the building

$N_{i}(t)$ - number of deaths for scenario i at time $t$ 


$$
D_{m}(t) \text {-survival status of occupant } m
$$

The calculated number of deaths for a specific fire scenario is used as an input to the Expected Risk to Life submodel.

\subsection{Expected Risk to Life Submodel}

In CUrisk, the overall fire risk to occupant life safety is measured by a performance parameter - Expected Risk to Life (ERL), which is defined as the expected death frequency per year per occupant in the building.

$$
E R L=\frac{F \sum_{i=1}^{n}\left(P_{i} \times N_{i}\right)}{P O P}
$$

Where:

$$
\begin{aligned}
& \text { F - annual fire frequency of building, } \\
& n \text { - total number of scenarios, } \\
& \mathrm{P}_{\mathrm{i}} \text { - the probability of scenario } \mathrm{i}, \\
& \mathrm{N}_{\mathrm{i}} \text { - the number of deaths for scenario } \mathrm{i} \\
& \text { POP - number of occupants in the building, }
\end{aligned}
$$

In Equation 3.18, the annual fire frequency of the building is a user input. It is based on historical statistical data. The number and probabilities of scenarios are obtained from the Fire Scenario Submodel. The number of deaths for each fire scenario is obtained from the Life Hazard submodel. The number of occupants in the building is a direct user input. 
The ERL can be directly used as a decision-making parameter to determine whether a proposed fire safety design complies with the requirements of building codes or regulations in terms of risk to occupant.

\subsection{Fire Cost Expectation Submodel}

As a risk-cost model, CUrisk not only evaluates the effectiveness of fire safety design in terms of occupant life safety, but also evaluates the economic effectiveness of the fire safety measures used to achieve the desired life safety level. The Fire Cost Expectation Submodel is developed to estimate the economic cost and losses associated with fire protection provisions and the impact of fire events in the building.

CUrisk considers the fire costs of a building design of three components including capital investment of active and passive fire protection systems, annual maintenance and inspection costs of the active fire protection system, and the expected losses due to fires in the building. Other costs such as the fire losses related to the impact on the environment, cost of fire department services and the cost of fire insurances are not considered in the current version of CUrisk. In addition, the calculation of the expected fire cost over the span of building design life is based on current data because of the difficulty to predict both accurate market interest rates and future annuity fire cost over the span of the building design life.

In the model, the economic components are aggregated into a performance parameterFCE which is defined as the ratio of total fire costs of the building over the design life divided by the total building investment. 


$$
F C E=\frac{C O S T_{\text {Fixed }}+D L\left[C O S T_{\text {Maintain }}+F \sum_{i=1}^{n}\left(P_{i} \times E_{i}\right)\right]}{C O S T_{\text {Total }}}
$$

Where:

$\operatorname{COST}_{\text {Fixed }}$ - fixed capital investment of the active and passive fire protection systems, obtained from the Building Cost submodel.

DL - Design life in years of the building, user input.

$\operatorname{COST}_{\text {Maintain }}-$ the annual maintaining and inspection cost of the active fire protection systems, obtained from the Building Cost submodel.

$P_{i}-$ the probability of scenario i, obtained from the Fire Scenario Submodel

$E_{i}-$ the economic loss of scenario i, obtained from the Economic Loss Submodel

F - annual fire frequency of building, user input based on historical statistical data

$$
F \sum_{i=1}^{n}\left(P_{i} \times E_{i}\right)^{- \text {represents the expected annual fire losses as a result of all }}
$$

possible fire scenarios in the building, that is,

$$
\left.\operatorname{Cost}_{\text {Loss }}=F \sum_{i=1}^{n}\left(P_{i} \times E_{i}\right)\right]
$$

The FCE is used in conjunction with the ERL as decision-making parameters to determine whether a proposed fire safety design is economically effective while satisfying the requirements of building codes or regulations on occupant life safety, i.e., how much is the monetary cost the owner pays for achieving the proposed safety level. 


\section{Chapter 4: CASE STUDY}

This section provides a quantitative assessment of the fire related risks to life safety and economic losses in a 4 storey residential-commercial building.

In the process of this study, three computer programs are developed to help set up the risk evaluation model, calculate the probabilities for scenario structure, quickly retrieve and analyze the resultant data. These programs are:

1) CUriskIPT, a windows-based pre-processing tool providing a user friendly interface for compiling input files for simulation.

2) Event Tree Creator, a program creating the scenario structure for a design option and calculate the probabilities of scenarios in the event tree.

3) CUriskOPT, a post-processing tool for quickly retrieving simulation result data and creating graphs for data comparison.

These programs are developed using Visual Basic and Excel spreadsheet. A detailed description of these programs is given in a separate report.

The fire risk analysis investigates the life safety and cost-effectiveness of different fire protection options in a wood-frame building. The fire protection features of interest 
are active fire protection systems including sprinklers, smoke alarms and central alarm systems. The risk level of eight design options with combinations of these the fire protection features are examined and compared.

Specifically, the objectives of this case study are to:

(1) Investigate fire risks to occupant life safety and the economic losses of residentialcommercial mixed-use building with a range of active fire protection options.

(2) Develop a systematic approach that allows fire protection design options to be compared in terms of decision making parameters.

(3) Examine the capabilities, limitations and identify future work required to adopt CUrisk for use in a performance-base design environment.

The approach taken to complete this assessment involves the identification of building construction, occupant and fire protection characteristics, identification of fire hazards, identification of design strategies, identification of representative scenarios and scenario clusters. After this information is addressed, the fire scenario probability analysis and the consequence analysis are conducted using CUrisk to determine the two decision making parameters ERL and FCE for each of the eight design strategies. Finally, a determination of cost-effective design strategies is made by comparing ERL and FCE for each of the design options with those of the code-compliant reference design strategy.

The flow chart of fire risk analysis procedure used in the case study is shown in Figure 4.1 below: 


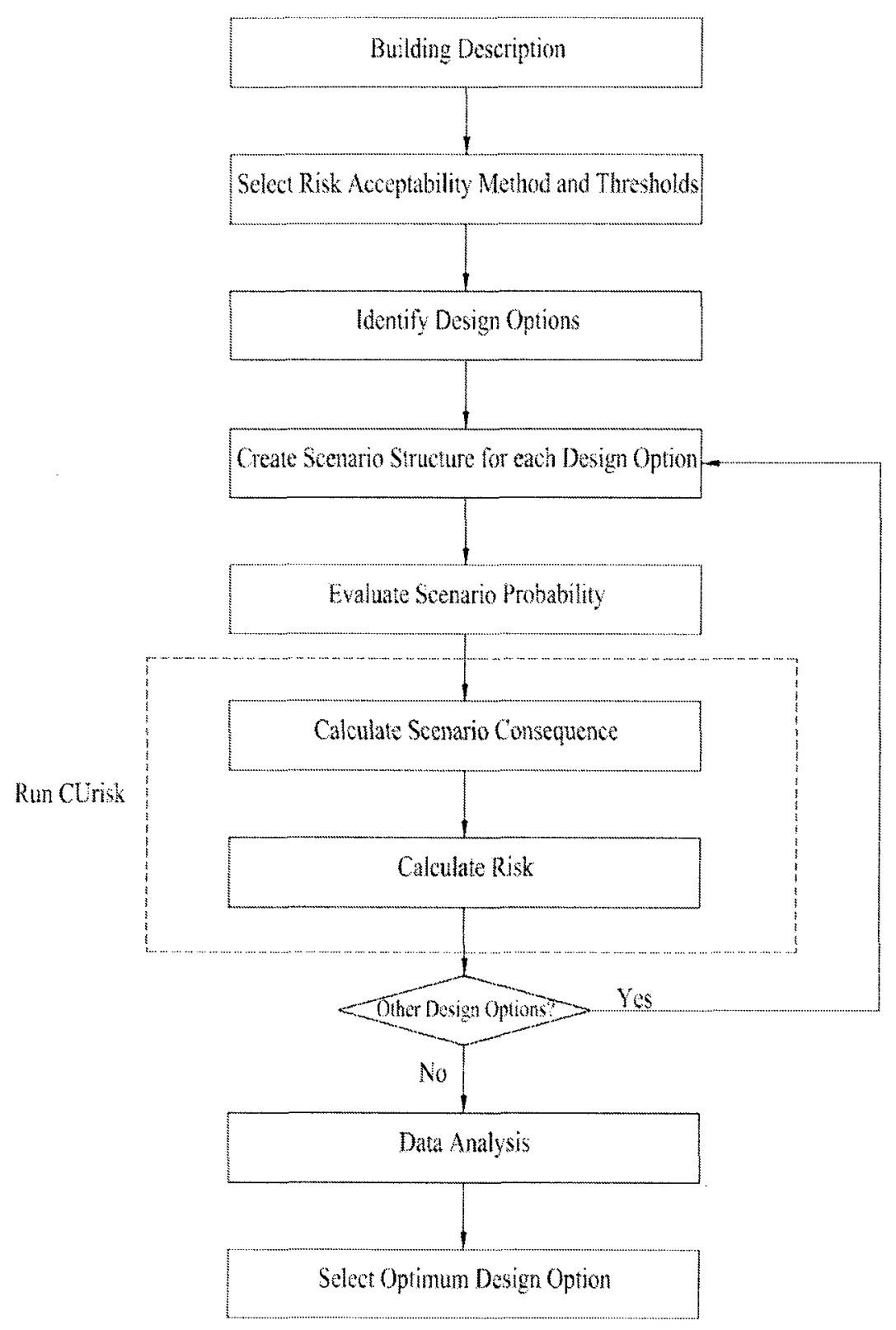

Figure 4.1: Fire Risk Analysis Work Flow Chart

Each of the steps shown in Figure 4.1 is discussed in the following section. 


\subsection{Establish Analysis background}

\subsubsection{Building Description}

The building to be studied is a four-storey, residential-commercial mixed-use building being constructed in the south of Ottawa. This building is designed to provide opportunities of living, services, and business in close proximity. The total building area is $3288 \mathrm{~m}^{2}$, with a building height of $12 \mathrm{~m}$. The functions of the building include an open concept two-storey commercial space on the $1^{\text {st }}$ and $2^{\text {nd }}$ floors, and twelve units of two-

level residential townhouses on the $3^{\text {rd }}$ and $4^{\text {th }}$ floors. The floor area for each floor is 822 $\mathrm{m}^{2}$. This building is a wood-framed building with a flat roof. The typical floor plans are given in Figures 4.2 to 4.5 below: 
85

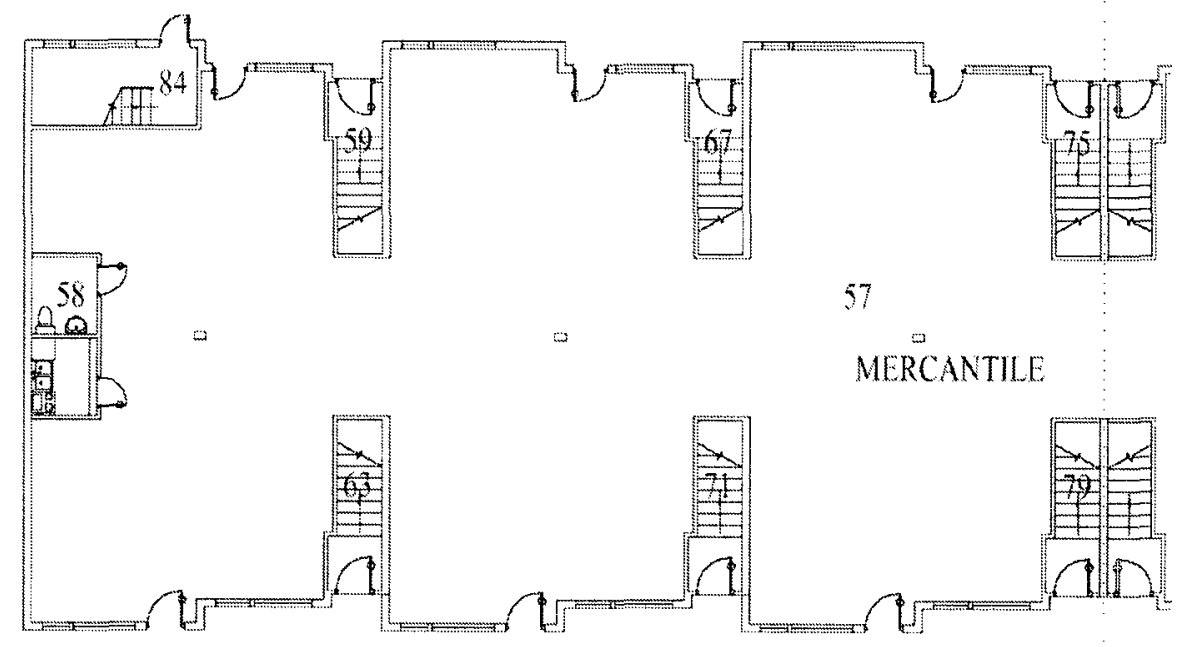

$x$

Figure 4.2: 1st Floor Mercantile Plan 


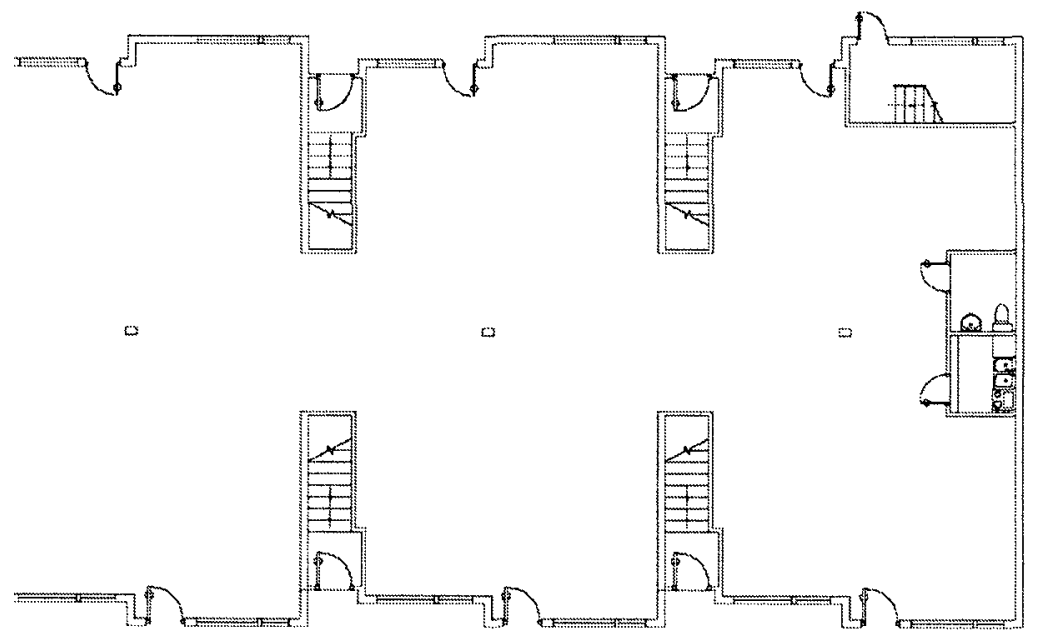




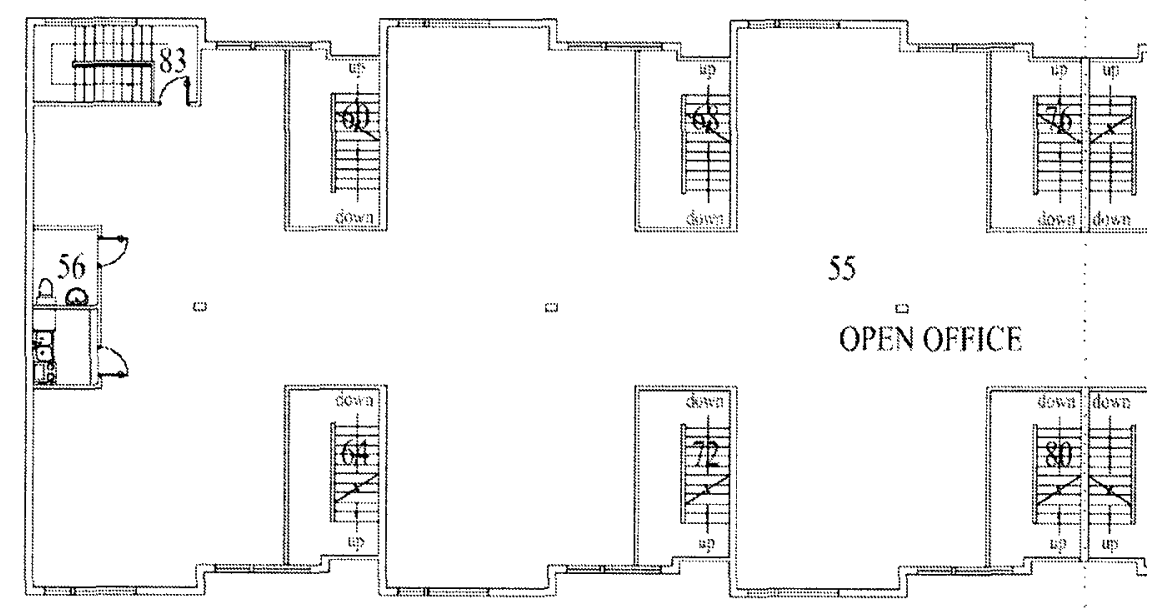

Figure 4.3: 2nd Floor Office Plan 


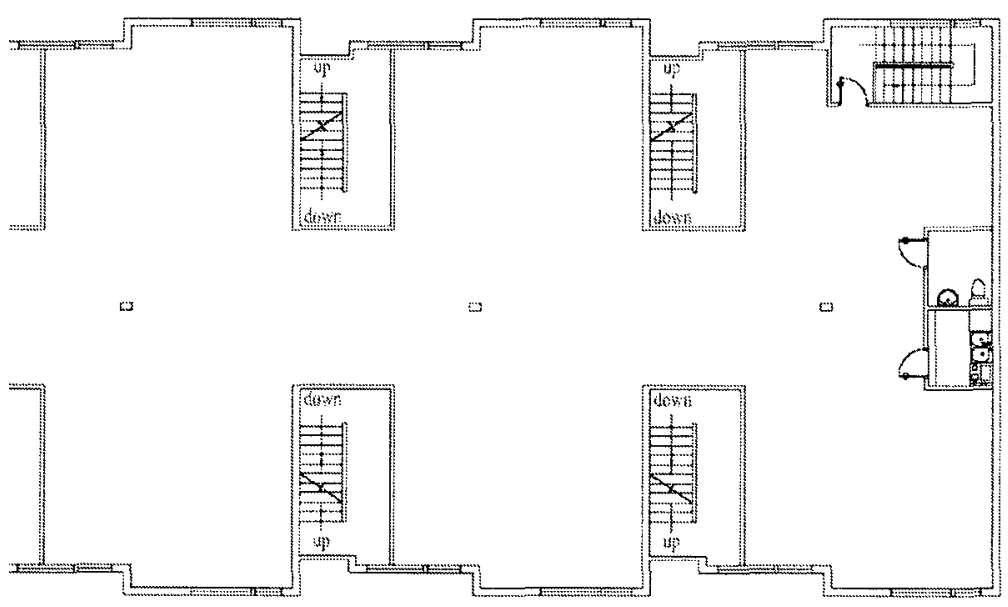




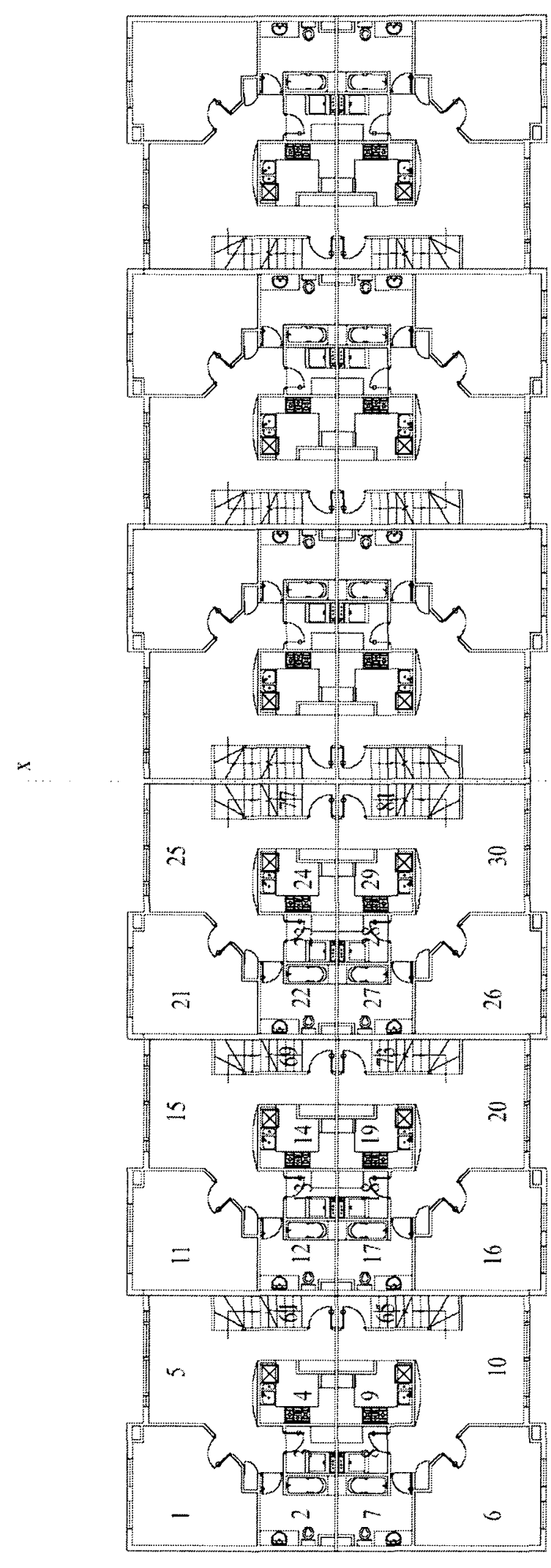

i 


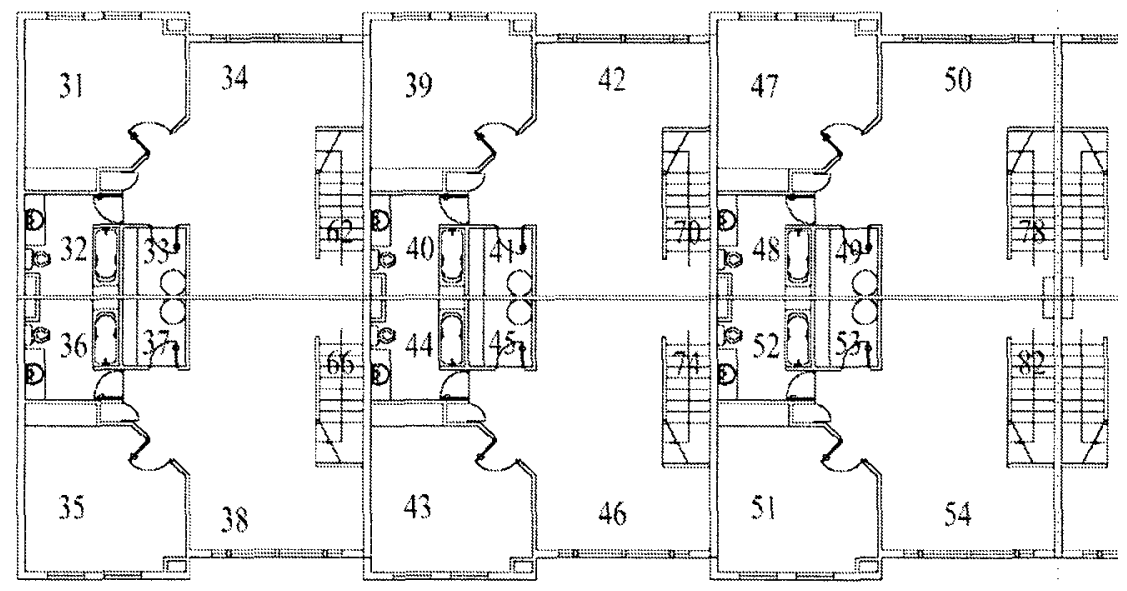

Figure 4.5: 4th Floor Residential Plan 


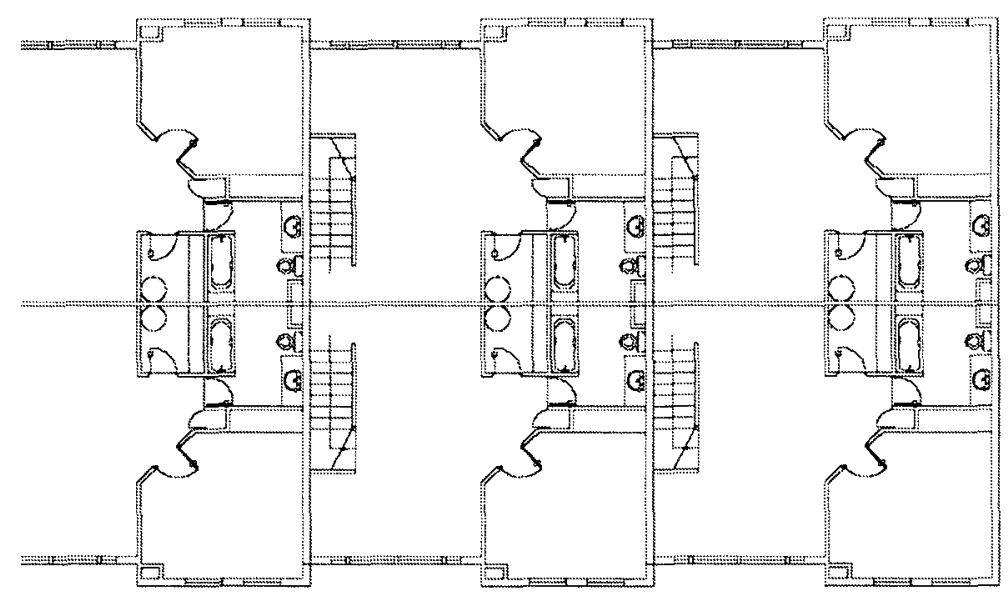




\section{Building Occupancy Classification}

Due to the complex arrangement of the building use, a single occupancy classification cannot be assigned for this building, so section by section multiple occupancy classification is used. The classification is based on the Ontario Building Code (OBC) 2006.

The first floor store section is considered a Mercantile occupancy (Group E); The second floor office section is considered a Business and personal services occupancy (Group D); the third and fourth floor dwelling unit section is considered a Residential occupancy (Group C).

A summary of occupancies of the building is shown in Table 4.1.

Table 4.1: Occupancies of Case Study Building

\begin{tabular}{|c|c|c|c|c|}
\hline Floor & Use & $\begin{array}{c}\text { Occupancy } \\
\text { group }\end{array}$ & Area (m²) & Notes \\
\hline 1st & Mercantile & Group E & 822 & \\
\hline 2nd & Office & Group D & 822 & \\
\hline 3rd and 4th & Residential & Group C & 1644 & \\
\hline Total & & & 3288 & \\
\hline
\end{tabular}

\subsubsection{Occupant Characteristics}

Occupant characteristics affect the ability of the occupants to perceive, and interpret the fire cues and warning signals, and their ability to evacuate the building and avoid untenable conditions that may develop in a fire incident. In order to evaluate 
appropriately fire risk to life safety in a building, it is important to have a detailed knowledge of the occupant characteristics including the capacity and behaviour of the occupants in a fire occurrence.

Many parameters affect occupant ability to perceive and avoid fire risks during a fire incident. These parameters include the number and distribution of occupants, their ages and gender, physical abilities, familiarity with building egress route, condition of the occupants at the time of fire event, the presence of groups, and occupant knowledge and experience.

In CUrisk, a number of key parameters are considered and addressed quantitatively. These factors include:

- Occupant load of the building

- Initial occupant location and distribution

- Age and gender of occupants

\section{Occupant load}

The occupant load depends on the type of occupancy, and is determined on the basis of $\mathrm{OBC} 2006$, Subsection 3.1.16. For the case study building, the number of occupants in the first floor mercantile section and second floor office section is based on floor area and the recommended occupant density per unit floor area. The occupant number calculation of dwelling units is two persons per sleeping room or sleeping area in a residential suite. To make this simulation conservative, two people are also included in each living room.

The summary of occupant load is shown in Table 4.2. 
Table 4.2: Occupant Load of Case Study Building

\begin{tabular}{|c|c|c|c|c|}
\hline Floor & Use & $\begin{array}{c}\text { Occupant } \\
\text { Density }\end{array}$ & $\begin{array}{c}\text { Number of } \\
\text { Occupants }\end{array}$ & Notes \\
\hline 1st & Mercantile & $3.7 \mathrm{~m}^{2 /}$ people & 222 & \\
\hline 2nd & Office & $9.3 \mathrm{~m}^{2 /}$ people & 88 & \\
\hline 3rd and 4th & Residence & 8 people /Unit & 48 & \\
\hline Total & & & 358 & \\
\hline
\end{tabular}

\section{Occupant distribution}

The initial occupant location influences the exposure level of people to the hazardous conditions in the building, as well as the way people respond to the fire event and their expected evacuation speed. The occupant number and initial occupant distribution at the time of fire events used in this case study is shown in Table 4.3. The compartment numbers in Table 4.3 are depicted in the floor plan of Figures 4.2 to 4.5 . 
Table 4.3: Occupant Distribution at the Time of Fire Occurrence

\begin{tabular}{|c|c|c|c|c|}
\hline Compartment \# & Room Use & Floor & Occupants & Occupant \# \\
\hline 1 & Bedroom & 3 & 2 & $\# 01 \sim \# 02$ \\
\hline 5 & Living room & 3 & 2 & $\# 03 \sim \# 04$ \\
\hline 6 & Bedroom & 3 & 2 & $\# 05 \sim \# 06$ \\
\hline 10 & Living room & 3 & 2 & $\# 07 \sim \# 08$ \\
\hline 11 & Bedroom & 3 & 2 & $\# 09 \sim \# 10$ \\
\hline 15 & Living room & 3 & 2 & $\# 11 \sim \# 12$ \\
\hline 16 & Bedroom & 3 & 2 & $\# 13 \sim \# 14$ \\
\hline 20 & Living room & 3 & 2 & $\# 15 \sim 16$ \\
\hline 21 & Bedroom & 3 & 2 & $\# 17 \sim \# 18$ \\
\hline 25 & Living room & 3 & 2 & $\# 19 \sim \# 20$ \\
\hline 26 & Bedroom & 3 & 2 & $\# 21 \sim \# 22$ \\
\hline 30 & Living room & 3 & 2 & $\# 23 \sim \# 24$ \\
\hline 31 & Bedroom & 4 & 2 & $\# 25 \sim \# 26$ \\
\hline 34 & Living room & 4 & 2 & $\# 27 \sim \# 28$ \\
\hline 35 & Bedroom & 4 & 2 & \#29 \#30 \\
\hline 38 & Living room & 4 & 2 & $\# 31 \sim \# 32$ \\
\hline 39 & Bedroom & 4 & 2 & $\# 33 \sim \# 34$ \\
\hline 42 & Living room & 4 & 2 & $\# 35 \sim \# 36$ \\
\hline 43 & Bedroom & 4 & 2 & $\# 37 \sim \# 38$ \\
\hline 46 & Living room & 4 & 2 & \#39 \#40 \\
\hline 47 & Bedroom & 4 & 2 & $\# 41 \sim \# 42$ \\
\hline 50 & Living room & 4 & 2 & $\# 43 \sim \# 44$ \\
\hline 51 & Bedroom & 4 & 2 & $\# 45 \sim \# 46$ \\
\hline 54 & Living room & 4 & 2 & $\# 47 \sim \# 48$ \\
\hline 55 & Office & 2 & 88 & \#49 \#136 \\
\hline 57 & Store & 1 & 222 & $\# 137 \sim \# 358$ \\
\hline
\end{tabular}




\section{Occupant Age and Gender}

Occupant age and gender have important influences on the occupants behaviour and evacuation speed in the fire building. Table 4.4 shows the ratio of males to the total population and percentage of younger occupants. The younger occupants are the occupants who need assistance in responding and evacuating the building.

Table 4.4: Occupant Age and Gender in Case Study Building

\begin{tabular}{|l|c|}
\hline Male \% of Population Ratio & $50 \%$ \\
\hline Younger \% of Population Ratio & $33 \%$ \\
\hline
\end{tabular}

\subsubsection{Fire Protection Measures}

Fire protection systems play a key role in overall building fire performance. CUrisk categorizes fire protection systems into three groups: active fire protection systems, passive fire protection systems, and emergency fire protection systems [11]. As the objective of this case study is to analyze the performance and cost of design options of various combinations of active fire protection system, the passive fire protection and emergency fire protection systems used in the case study follow the prescriptive requirements described in OBC 2006 and they are discussed in the following sections. The options for active the fire protection features are discussed in Section 4.4. 


\subsubsection{Passive fire protection systems}

Passive fire protection systems in the building include: compartment fire boundaries and protection of openings to prevent structural element failure and fire/smoke propagation, and egress routes.

\section{Fire Boundary Separations}

The case study building is a wood-framed building. Walls and floors are light frame assemblies. According to $\mathrm{OBC} 2006$, fire separations are required between building storeys and compartment separation walls. A one hour fire-resistance rating separation is required between mercantile occupancy (Group C) and the Business and Personal Services occupancy (Group D). One-hr fire-resistance rating separations are required for other walls and floors in the dwellings.

As the Fire Spread submodel is still under development, the fire analysis for this case study will not consider the impact of fire spread. Based on this assumption, the wall and floor assemblies used in this case study are all selected with 1-hr fire-resistance rating from both sides. To simplify the simulation input, the fire rated walls are all selected as one-hour fire rated load bearing wood frame wall assembly WS4-1.1, and the floors are all selected as one-hour fire-resistive floor/ceiling assembly WIJ-1.1. Detailed description of structure and thermal properties of these separation assemblies can be found in Appendix A. 


\section{Egress routes}

Separated egress and fire attack routes are provided for each of the occupancies of this building. In the first floor mercantile section, 12 exit doors are located on the north and south side of the building. The office section is served by two enclosed stairway enclosures located on the northwest and northeast side of the building. The stairway doors are self-closing and fire rated. There are 12 dwelling units in the third and fourth floor residential section. Each dwelling unit is served by a separate egress stairway. The exit door of each unit is on the first floor on the north side of the building.

Detailed information of the egress routes can be found in the floor layout shown in Figures 4.2- 4.5.

\subsubsection{Emergency Fire Protection Systems}

The emergency fire protection systems considered in CUrisk include emergency lighting, exit signs, and posted emergency floor plans. CUrisk does not quantify the impact on occupant life safety from emergency fire protection systems. However, the property losses of these components in the fire are addressed by the Economic Submodel.

In this case study, twenty battery pack emergency lighting units are used in the building for the illumination of the primary exit paths and twenty additional illuminated exit signs are installed above the exit door and in the stairwell.

In the building design, there is no emergency power generator. However, four passive graphic annuciators are installed at the exit doors in the first and second floors to provide help for occupant evacuation and fire department operations. 


\subsubsection{Fire Department Action}

CUrisk allows users to analyze the performance of fire department actions in fighting fire and rescuing occupants in a fire incident. Two fire department response options used in the model are shown in Table 4.5. Option 1 represents the case when fire fighters arrive at the building in 510 s, and Option 2 represents the case when no fire fighters arrive at the scene.

Table 4.5: Fire Department Response Options

\begin{tabular}{|c|c|c|c|}
\hline $\begin{array}{c}\text { Option } \\
\text { No }\end{array}$ & $\begin{array}{c}\text { Notification } \\
\text { Time (s) }\end{array}$ & $\begin{array}{c}\text { Response } \\
\text { Time (s) }\end{array}$ & $\begin{array}{c}\text { Setup } \\
\text { Time(s) }\end{array}$ \\
\hline 1 & 30 & 360 & 120 \\
\hline 2 & 600 & 600 & 600 \\
\hline
\end{tabular}

\subsubsection{Other Simulation Assumptions}

Other simulation assumptions used in this case study are:

1). Weather: The season of fire occurrence is assumed to be in the spring of the year. The outside pressure is $1.0 \mathrm{~atm}$, and the outside temperature is $15^{\circ} \mathrm{C}$.

2). Time of fire occurrence: day time

3). Windows and doors status: windows are all open; doors are open within the units, and are closed between units.

4). Occupants Status: awake

5). Simulation time: $1800 \mathrm{~s}$ 


\subsection{Risk Metrics and Thresholds}

The metrics to measure fire risk and their acceptability thresholds are determined by the fire safety objectives and the approaches used to quantify the fire related risks. The objectives of a typical quantitative fire risk analysis are organized around three strategic goals:

- Minimize the risk to life

- Minimize the economic losses

- Protect the environment

In this study, fire safety design objective is to identify cost-effective design options for the active fire protection systems to satisfy the life safety requirements of the building code. The risk to environment due to the contamination of air, water, land, animal, and other factors is not included in the scope of this risk analysis.

Before determing how these decision-making parameters can be used as the risk acceptability thresholds, proper approaches to risk tolerability need to also be identified. SFPE has recommended three approaches to define risk acceptability criteria [6]:

- De minimis risk

- As Low As Reasonably Achievable or Practicable (ALARA/ ALARP)

- Risk comparison

Both De minimis risk and ALARA/ ALARP approaches are based on absolute risk calculations. Due to the conservative assumptions made in the current risk analysis models and the difficulties of reaching an agreement on an acceptable level for all 
stakeholders, these absolute risk approaches are so far not appropriate for design purposes.

The approach of risk comparison has gained more wide use in fire risk area. In the risk comparison approach, the calculated risk is compared with the risk of a reference strategy which is already considered acceptable.

As discussed in Chapter 3, CUrisk evaluates the risks to occupant life safety and economic losses in terms of ERL and FCE. A fire safety alternative is thought to be acceptable if the assessment shows that the calculated risk to life is lower or similar to that for an acceptable code-compliant design, while the cost to achieve such risk level is less than that of the code-compliant design. 


\subsection{Identification of Fire Hazards}

The purpose of fire hazard identification in the process of risk assessment is to support the development of the scenarios, and the selection of representative scenarios for use in the assessment.

A systematic review of fire hazards in the building requires a detailed investigation of the building physical characteristics, the intended function and usage of the building, occupant characteristics, the fire protection features, and historical fire data for similar buildings. Methods involved in the process of hazard identification for building fire risk analysis normally include [5]:

- Review of fire events in similar occupancies

- Walk-through of building site or spaces of concern, or similar occupancies

- Fire protection engineering judgment

In this study the process of hazard identification in this building includes a review of past fire events in similar occupancies, and engineering judgment.

\subsubsection{Fire Initiation Hazards}

The purpose of identification of the initiation hazards is to determine the compartment of fire origin, fire load, and fire incident frequencies which can be used to create scenario structure and to evaluate fire consequences. Initiation hazards include [6]:

(1) Heat sources - any object that emits sufficient heat to ignite nearby combustibles and initiate a fire incident is deemed as an initiating hazard.

(2) Fuel source - combustible material that can be ignited by the heat source 
(3) Hazardous practices - any practice or behavior that may cause an ignition event.

(4) Hazardous environment- conditions or environment that invites or encourages hazardous practice or that causes a degradation of heat source conditions and fuel source conditions.

Due to the multiple occupancy of the case study building, an occupancy by occupancy fire statistical data review was used to identify the initiation hazards in this building. Relevant statistical data can be found in Juneja's thesis [39]. The results of the study are used to determine fire origin and fire size for this study. Fire data used in [39] are based on 1995-2002 Ontario Fire Marshal (OFM) database.

\section{Area of Fire Origin}

A fire could start any place inside a building. This may lead to an identification of an unmanageable number of fire origins. To effectively complete a fire risk analysis, a limited number of fire origins need to be identified to represent all probable fires in the building. In this study, the selection of areas of fire origin is based on a review of the statistical data and engineering judgment. The fire origins are determined based on the number of fire incidents that caused the most casualties and the most property losses.

An occupancy by occupancy review of fire historical data was conducted using Ontario Fire Marshal (OFM) data during 1995 to 2002 [39]. The top three fire origin areas based on the number of fires, threat to life safety and property for the occupancies used in case study are summarized in Table 4.6 below: 
Table 4.6: Ranking of Number of Fires, Threat to Life Safety and Property as a Function of Fire Origin for Occupancies (Adopted from [39])

\begin{tabular}{|c|c|c|c|}
\hline & $\begin{array}{l}\text { Mercantile } \\
\text { Occupancy }\end{array}$ & $\begin{array}{c}\text { Office } \\
\text { Occupancy }\end{array}$ & $\begin{array}{l}\text { Residence } \\
\text { Occupancy }\end{array}$ \\
\hline $\begin{array}{l}\text { Number of } \\
\text { fires }\end{array}$ & $\begin{array}{l}\text { 1. Cooking area or } \\
\text { kitchen }(16.1 \%) \\
\text { 2. Sales, show room } \\
(7.2 \%) \\
\text { 3. Exterior Wall }(6.8 \%)\end{array}$ & $\begin{array}{l}\text { 1. Office }(9.2 \%) \\
\text { 2. Mech. } / \text { Elec. } \\
\text { Room }(8.1 \%) \\
\text { 3. Lobby, Entrance } \\
(6.8 \%)\end{array}$ & $\begin{array}{l}\text { 1. Cooking area or } \\
\text { kitchen }(26.6 \%) \\
\text { 2. Living area } \\
\text { (11.6\%) } \\
\text { 3. Sleeping area or } \\
\text { bedroom }(10.3 \%)\end{array}$ \\
\hline Total deaths & $\begin{array}{l}\text { 1. Storage }(19.8 \%)^{*} \\
\text { 2. Cooking area or } \\
\text { kitchen }(12.2 \%) \\
\text { 3. Sales, show room } \\
(12.2 \%)\end{array}$ & $\begin{array}{l}\text { 1. Lobby, Entrance } \\
(100 \%)\end{array}$ & $\begin{array}{l}\text { 1. Living area } \\
(40.3 \%) \\
\text { 2. Sleeping area or } \\
\text { bedroom }(17.0 \%) \\
\text { 3. Cooking area or } \\
\text { kitchen }(15.9 \%)\end{array}$ \\
\hline Total injuries & $\begin{array}{l}\text { 1. Sales, show room } \\
(33.3 \%) \\
\text { 2. Cooking area or } \\
\text { kitchen }(16.7 \%) \\
\text { 3. shipping/receiving } \\
\text { loading platform } \\
(16.7 \%)^{*}\end{array}$ & $\begin{array}{l}\text { 1. Office }(21.1 \%) \\
\text { 2. Storage }(9.1 \%)^{*} \\
\text { 3. Mech. /Elec. } \\
\text { Room }(7.9 \%)\end{array}$ & $\begin{array}{l}\text { 1. Cooking area or } \\
\text { kitchen }(31.3 \%) \\
\text { 2. Sleeping area or } \\
\text { bedroom }(18.5 \%) \\
\text { 3. Living area } \\
(18.1 \%)\end{array}$ \\
\hline $\begin{array}{l}\text { Damage to } \\
\text { property }\end{array}$ & $\begin{array}{l}\text { 1. Storage }(20.3 \%)^{*} \\
\text { 2. Undetermined area } \\
(10.9 \%) \\
\text { 3. Sales, show room } \\
(10.8 \%)\end{array}$ & $\begin{array}{l}\text { 1. Undetermined } \\
\text { area }(14.5 \%) \\
\text { 2. Office }(11.8 \%) \\
\text { 3. Storage }(8.9 \%)^{*}\end{array}$ & $\begin{array}{l}\text { 1. Attic area }(21.3 \%) \\
\text { 2. Living area } \\
(14.4 \%) \\
\text { 3. Cooking area or } \\
\text { kitchen }(11.7 \%)\end{array}$ \\
\hline
\end{tabular}

\section{Design Fire Origins Identified for Case Study}

Based on the data shown in Table 4.6, areas of fire origin identified for this case study are: 
Table 4.7: Areas of Fire Origin Used for Case Study

\begin{tabular}{|c|c|}
\hline Occupancy & Area of Fire Origin \\
\hline Mercantile & Store (open space) \\
\hline Office & Office (open space) \\
\hline \multirow{3}{*}{ Residence } & Living room \\
\cline { 2 - 2 } & Bedroom \\
\cline { 2 - 2 } & Kitchen \\
\hline
\end{tabular}

\section{Design Fire}

In CUrisk, fire in the fire compartment is evaluated on the basis of a t-square design fire. The parameters used to characterize a t-square design fire include design fire type, level of HRR, duration of fire.

\section{Design Fire Type}

In this study, a review of fire statistical data of the cause of fires has been conducted to identify the type of design fire in the compartment of fire origin. Details of this information can be found in Juneja's thesis [39]. The top three causes of fires for all the occupancies used in the case study are outlined in Table 4.8 [39]: 
Table 4.8: Ranking of cause of fire for the Design Fires (Adopted from [39])

\begin{tabular}{|c|c|c|c|}
\hline & $\begin{array}{l}\text { Mercantile } \\
\text { Occupancy }\end{array}$ & $\begin{array}{c}\text { Office } \\
\text { Occupancy }\end{array}$ & $\begin{array}{l}\text { Residence } \\
\text { Occupancy }\end{array}$ \\
\hline$\underset{\text { fires }}{\text { Number of }}$ & $\begin{array}{l}\text { 1. Electrical failure } \\
(18.4 \%) \\
\text { 2. Arson }(10.6 \%) \\
\text { 3. Vandalism }(7.9 \%)\end{array}$ & $\begin{array}{l}\text { 1. Electrical failure } \\
(22.1 \%) \\
\text { 2. Arson }(12.2 \%) \\
\text { 3. Equipment } \\
\text { improperly discarded } \\
(7.8 \%)\end{array}$ & $\begin{array}{l}\text { 1. Equipment } \\
\text { unattended }(16.6 \%) \\
2 . \text { Electrical failure } \\
(11.5 \%) \\
\text { 3. Maintenance } \\
\text { deficiency }(7.4 \%)\end{array}$ \\
\hline $\begin{array}{l}\text { Total } \\
\text { deaths }\end{array}$ & $\begin{array}{l}\text { 1. Arson }(33.3 \%) \\
\text { 2. Vandalism }(16.7 \%) \\
\text { 3. Improper storage } \\
(16.7 \%)\end{array}$ & 1. Arson $(100 \%)$ & $\begin{array}{l}\text { 1. Arson }(11.3 \%) \\
\text { 2. Equipment: Other } \\
(11.2 \%) \\
\text { 3. Equipment } \\
\text { unattended }(6.0 \%)\end{array}$ \\
\hline $\begin{array}{c}\text { Total } \\
\text { injuries }\end{array}$ & $\begin{array}{l}\text { 1. Arson (23.7\%) } \\
\text { 2. Electrical failure } \\
(8.3 \%) \\
\text { 3. Equipment } \\
\text { improperly discarded } \\
(7.7 \%)\end{array}$ & $\begin{array}{l}\text { 1. Arson }(10.5 \%) \\
\text { 2. Electrical failure } \\
(9.2 \%) \\
\text { 3. Equipment too } \\
\text { closed to combustibles } \\
(5.3 \%)\end{array}$ & $\begin{array}{l}\text { 1. Equipment } \\
\text { unattended }(23.5 \%) \\
\text { 2. Equipment } \\
\text { improperly discarded } \\
(7.7 \%) \\
\text { 3. Equipment too } \\
\text { closed to combustibles } \\
(7.3 \%)\end{array}$ \\
\hline $\begin{array}{c}\text { Damage to } \\
\text { property }\end{array}$ & $\begin{array}{l}\text { 1. Arson }(17.7 \%) \\
\text { 2. Electrical failure } \\
(13.1 \%) \\
\text { 3. Equipment too } \\
\text { closed to combustibles } \\
(3.1 \%)\end{array}$ & $\begin{array}{l}\text { 1. Arson }(20.5 \%) \\
\text { 2. Electrical failure } \\
(14.3 \%) \\
\text { 3. Vandalism }(4.4 \%)\end{array}$ & $\begin{array}{l}\text { 1. Electrical failure } \\
(11.5 \%) \\
\text { 2. Equipment } \\
\text { unattended }(9.6 \%) \\
\text { 3. Arson }(7.8 \%)\end{array}$ \\
\hline
\end{tabular}

Note: undetermined causes excluded in Figure 4.8. 
The design fire types for the areas of fire origin used in this study are shown in Table 4.9:

Table 4.9: the Design Fire types Used in the Case Study

\begin{tabular}{|c|c|}
\hline Area of Fire Origin & Fire Growth Type \\
\hline Store (open space) & Medium \\
\hline Office (open space) & Medium \\
\hline Living room & Medium \\
\hline Bed room & Slow \\
\hline Kitchen & Fast \\
\hline
\end{tabular}

\section{Peak HRR}

Following flashover, fire can quickly develop into post-flashover stage. At this stage the potential maximum HRR needs to be predicted based on the ventilation and fuel conditions in the fire compartment. With the window and door open status taken into account, the maximum possible heat release rate can be approximated by the correlation [4]:

$$
\dot{Q}_{\max }=1518 A v \sqrt{H v}
$$

Equation 4.1

Where:

$\dot{Q}_{\max }$ - The maximum possible heat release rate of fire (MaxHRR), $\mathrm{kW}$

$\mathrm{Av}-$ Area of the vent, $\mathrm{m}^{2}$

Hv - Height of the vent, $\mathrm{m}$

Based on the case study building characteristics and the assumption that ventilation openings are opened during the entire simulation time, the peak HRR of design fires for each identified area of fire origin are shown in Table 4.10. 
Table 4.10: Summary of Design Fires Used for the Case Study

\begin{tabular}{|c|c|}
\hline Area of Fire Origin & Max HRR(MW) \\
\hline Store (open space) & 8 \\
\hline Office (open space) & 8 \\
\hline Living room & 6 \\
\hline Bed room & 5 \\
\hline Kitchen & 3.5 \\
\hline
\end{tabular}

\section{Duration of Fire}

The duration of a fire is mainly determined by the fire load, and the HRR of the fire in the compartment. It is used to estimate the length of the level off period of the design fire curve and the time to decay. Table 4.11 shows the fire loads and the estimated fire duration used in this study.

Table 4.11: Fire Loads and Estimated Fire Duration Used in the Case Study

\begin{tabular}{|c|c|c|c|}
\hline Area of Fire Origin & $\begin{array}{c}\text { Estimated } \\
\text { Duration (Hr) }\end{array}$ & $\begin{array}{c}\text { Fire load } \\
\left(\mathbf{M J} / \mathbf{m}^{2}\right)\end{array}$ & $\begin{array}{c}\text { Data } \\
\text { Source }\end{array}$ \\
\hline Store (open space) & 21.4 & 1300 & {$[41]$} \\
\hline Office (open space) & 17.2 & 760 & {$[40]$} \\
\hline Living room & 0.7 & 450 & {$[40]$} \\
\hline Bed room & 1.0 & 846 & {$[40]$} \\
\hline Kitchen & $0.7^{*}$ & 940 & {$[40]$} \\
\hline
\end{tabular}

* Based on actual peak HRR in simulation. 


\section{Summary}

A summary of the design fires used in the case study is shown in the Table 4.12 below:

Table 4.12: Summary of Design Fires Used in the Case Study

\begin{tabular}{|c|c|c|c|c|}
\hline $\begin{array}{c}\text { Area of Fire } \\
\text { Origin }\end{array}$ & $\begin{array}{c}\text { First Ignited } \\
\text { item }\end{array}$ & $\begin{array}{c}\text { Fire Growth } \\
\text { Rate }\end{array}$ & $\begin{array}{c}\boldsymbol{\alpha} \\
\left(\mathbf{k W} / \mathbf{s}^{2}\right)\end{array}$ & $\begin{array}{c}\text { Max HRR } \\
(\mathbf{M W})\end{array}$ \\
\hline Store (open space) & Shop counters & Medium & 0.012 & 8 \\
\hline Office (open space) & $\begin{array}{c}\text { Office } \\
\text { furniture }\end{array}$ & Medium & 0.012 & 8 \\
\hline Living room & Wood Table & Medium & 0.012 & 6 \\
\hline Bed room & Wood furniture & Slow & 0.003 & 5 \\
\hline Kitchen & Cooking oil & Fast & 0.047 & 3.5 \\
\hline
\end{tabular}

\subsubsection{Reliabilities of Fire Protection Systems}

Reliabilities of fire protection systems are essential inputs used to evaluate the performance of fire safety measures installed in the building. In CUrisk, the reliability is expressed as operational reliability which indicates the probability of a fire protection system will operate or not when needed.

A review of operational reliabilities of the active fire protection systems has been conducted to quantify the enabling conditions in the case study building. Based on the building condition and the statistical data, the operational reliabilities of fire protection systems used in the case study are listed in the Table 4.13. 
Table 4.13: The Operational Reliabilities of Fire Protection Systems for the Case Study

\begin{tabular}{|c|c|c|}
\hline System & Reliability & Reference \\
\hline Local Alarm & 0.60 & {$[39]$} \\
\hline Sprinkler & 0.95 & {$[42]$} \\
\hline Heat Detector & 0.90 & {$[42]$} \\
\hline Smoke Detector & 0.90 & {$[42]$} \\
\hline Central Alarm & 0.90 & {$[42]$} \\
\hline Voice Alarm & 0.90 & N/A \\
\hline
\end{tabular}

\subsubsection{Life Safety Thresholds and Content Sensitivities}

In CUrisk, the vulnerabilities of the occupants exposed to a fire are evaluated based on the probability of injury and the probability of death due to fire hazardous conditions in the building. The user defined thresholds of injury and death used in this study are shown in the Table 4.14 .

Table 4.14: The Thresholds of Injury and Death of the Case Study

\begin{tabular}{|c|c|}
\hline Threshold of injury & 0.1 \\
\hline Threshold of death & 0.8 \\
\hline
\end{tabular}

The damages to the property due to a fire are evaluated based on the fire damage sensitivities due to high temperature, smoke and water. The damage sensitivities of building contents and fire protection systems used in the case study are outlined in the Tables 4.15 and 4.16 below [36]. 
Table 4.15: Damage Sensitivities of Fire Protection Systems for Case Study

\begin{tabular}{|c|c|c|c|}
\hline Fire protection system Category & Temperature & Smoke & Water \\
\hline Active FP- Alarm systems - Dual stage & LO & LO & LO \\
\hline $\begin{array}{c}\text { Active FP- Alarm systems - Other } \\
\text { components- Manual pull bar station }\end{array}$ & LO & LO & LO \\
\hline $\begin{array}{c}\text { Active FP- Detection - Smoke detectors - } \\
\text { Photoelectric - Location - Compartment }\end{array}$ & LO & LO \\
\hline $\begin{array}{c}\text { Active FP- Suppression systems - Manual } \\
\text { extinguishers - Type ABC }\end{array}$ & NS & NS & NS \\
\hline $\begin{array}{c}\text { Active FP- Suppression systems - Fire hose } \\
\text { /standpipe }\end{array}$ & LO & NS \\
\hline $\begin{array}{c}\text { Active FP- Suppression systems - } \\
\text { Sprinklers - Wet pipe }\end{array}$ & NS & NS & NS \\
\hline $\begin{array}{c}\text { Active FP- Suppression systems - } \\
\text { Passinklers - Other costs - Supply }\end{array}$ & NS & NS \\
\hline $\begin{array}{c}\text { Passive ES - Emergency lighting } \\
\text { Passive ES - Posted emergency floor plans }\end{array}$ & NS & NS \\
\hline
\end{tabular}


Table 4.16: Damage Sensitivities Category of Building Contents for Case Study

\begin{tabular}{|c|c|c|c|}
\hline Title of contents & Temperature & Smoke & Water \\
\hline Books & HS & HS & HS \\
\hline Electronic & HS & MO & HS \\
\hline Furniture(upholstered) & HS & HS & LO \\
\hline Furniture(wood) & LO & LO & LO \\
\hline Linings/finishes & LO & LO & LO \\
\hline Lighting & LO & VS & LO \\
\hline Partitions & LO & LO & LO \\
\hline
\end{tabular}

Notes:

NS: Non sensitivity

LO: Low sensitivity

MO: Moderate sensitivity

HS: High sensitivity

VS: Very High sensitivity 


\subsection{Identification of design options}

\subsubsection{Code-compliant design option}

For the four-storey case study building, active fire protection systems required by the prescriptive requirements of $\mathrm{OBC} 2006$ include:

-Automatic Suppression Systems: the building is to be protected by a full sprinkler system. The Automatic Sprinkler system is assume to be a wet-pipe system and is designed with an intention to control fire size, extinguish fire, as well as to minimize fire risk to occupants and to limit fire losses.

-Fire Alarm and Detection Systems: As the building has more than three floors, and a total occupant load more than 300 people, as well as a sleeping accommodation of more than 10 persons in the residential section, $\mathrm{OBC} 2006$ requires a fire alarm and detection system to be installed in this building. The fire alarm system is assumed to be a single stage fire alarm system, which contains local smoke detector and a central alarm system. The function of the fire alarm system is to provide early warning of fire so that occupant evacuation and fire suppression can quickly begin.

\subsubsection{Alternative design options}

The current Ontario Building Code 2006 is objective-based. The latest objectivebased National Building Code of Canada (2005) also allows designers to submit alternative design options as long as the code intended life safety objectives are achieved. This change may promote the introduction of new technologies and allow costeffectiveness and flexibility into building fire safety designs. 
In this study, the performance of various active protection systems in a mix-use wood- frame building will be examined. To accomplish this objective, seven alternative design options are identified. These alternative design options will be compared with the prescriptive code-compliant design option in terms of decision making parameters of ERL and FCE to find a cost-effective fire safety design option for this building.

Alternative design options and the code-compliant design options considered for this study are shown in Table 4.17.

Table 4.17: Fire Safety Design Options Considered for Case Study

\begin{tabular}{|c|c|c|c|c|}
\hline $\begin{array}{c}\text { Design } \\
\text { Option \# }\end{array}$ & $\begin{array}{c}\text { Auto } \\
\text { Sprinkler? }\end{array}$ & $\begin{array}{c}\text { Smoke } \\
\text { Detector? }\end{array}$ & $\begin{array}{c}\text { Central } \\
\text { Alarm? }\end{array}$ & Note \\
\hline A & Y & Y & Y & \\
\hline B & Y & Y & - & \\
\hline C & Y & - & Y & Code-compliant design option \\
\hline D & Y & - & - & \\
\hline E & - & Y & Y & \\
\hline F & - & Y & - & \\
\hline G & - & - & Y & \\
\hline H & - & - & - & \\
\hline
\end{tabular}

Option $\mathrm{C}$ is the code-compliant design alternative which is used as the reference option with active the fire protection features of: an automatic sprinkler system and central fire detection and alarm system. 
Option A is a hypothetical design option with active the fire protection features of: an automatic sprinkler system, central fire detection and alarm system and additional local smoke detector. This option is chosen to examine the performance of the building with presence of both local smoke detectors and a central fire detection and alarm system.

Option B is a possible performance-based design alternative which has active the fire protection features of: an automatic sprinkler system and local smoke detector. This option is chosen to compare the performance of local smoke detectors and central fire detection and alarm system.

Option $\mathrm{D}$ is a proposed design alternative which has active the fire protection features of an automatic sprinkler system, and no smoke detection and alarm system is installed.

Option $\mathrm{E}$ is a hypothetical design option with active the fire protection features of: central fire detection and alarm system and additional local smoke detectors. This option is similar to option A, except that the building is not sprinkler protected.

Option $\mathrm{F}$ is a possible design alternative which has active the fire protection features of local smoke detector only. This option is similar to option B, except that the building is not sprinkler protected.

Option $\mathrm{G}$ is a proposed design alternative which has active the fire protection features of central smoke detection and alarm only. This option is similar to option C, except that the building is not sprinkler protected.

Option $\mathrm{H}$ is a proposed design alternative which does not include any active fire protection systems. 


\subsection{Identification of Scenario Structures}

The quantitative fire risk assessment is scenario based. A fire scenario is the description of a fire incident from fire ignition to decay, including key events to characterize a fire occurrence, and differentiate it from other possible fires. The effort of fire scenario identification for risk analysis usually has two aspects:

(1) Qualitative characterization of fire scenarios, which aims to create fire scenario structures for each design strategy;

(2) Quantification of fire scenarios, which includes quantification of fire scenarios probability and evaluation of consequences.

In this section, the creation of fire scenario structures for the design options will be discussed. Quantification of fire scenarios will be discussed in the probability and consequence evaluation sections.

\subsubsection{Methodology to Create Scenario Structure}

The fire scenario identification is developed based on the fire hazard identification discussed in Section 4.3. In most cases, a thorough investigation of fire hazards in the building may lead to an identification of infinite number of fire scenarios which makes a complete consequence calculation impossible.

To solve this problem, a representative scenario set with a manageable number of scenarios must be developed, so that the probability and consequence of each scenario can be evaluated. This representative scenario set is also called the design fire scenarios. These scenarios are developed with the intention of representing all possible scenarios 
which can result from an accidental fire incident. To achieve this, two techniques are used:

(1) Combine scenarios into scenario clusters;

(2) Exclude scenarios with negligible risk.

The Event Tree Method (ETM) is used to construct scenario structures. The main steps of creating scenario structures using the Event Tree Method include:

(1) Define a relevant fire initial event that may present risk to occupant life safety and property loss.

(2) Identify the the fire protection features used to mitigate the accidental fire event for each the design strategy.

(3) Connect the nodes that represent success or failure of the the fire protection features to create a tree structure for each design strategy.

A computer program called Event Tree Creator has been developed to identify paths for each scenario and construct the scenario structure. The Event Tree Creator enables users to easily design event trees and allows then to enter the reliability of each component in the event tree, and calculate the probabilities of all possible scenarios in the event tree.

\subsubsection{Scenario Structures Identified}

By studying relevant hazard factors that have been identified in the previous Section 4.3, eight individual scenario structures have been created representing each of the eight design options. Each design option scenario structure is comprised of some or all of the following events depending on the settings of each design strategy: 
(1) selection of room of fire origin and design fire

(2) fire department arrival or non-arrival

(3) sprinkler activation and suppression

(4) smoke detector activation

(5) central alarm activation

The result of scenario structure for each design option created by Event Tree Creator is illustrated below in Figures 4.7- 4.14. These figures graphically illustrate the dependence of events and are used to calculate scenario probabilities. 


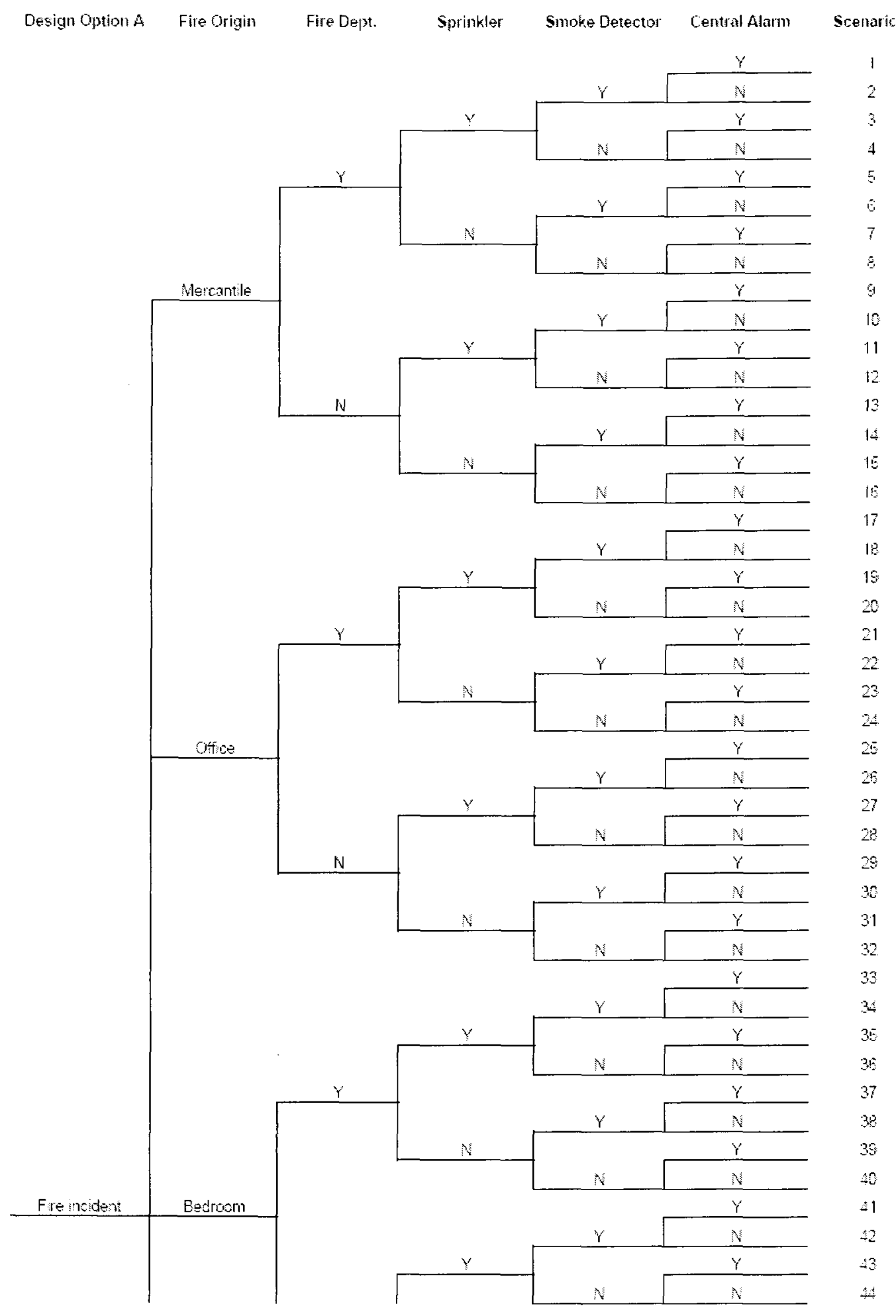




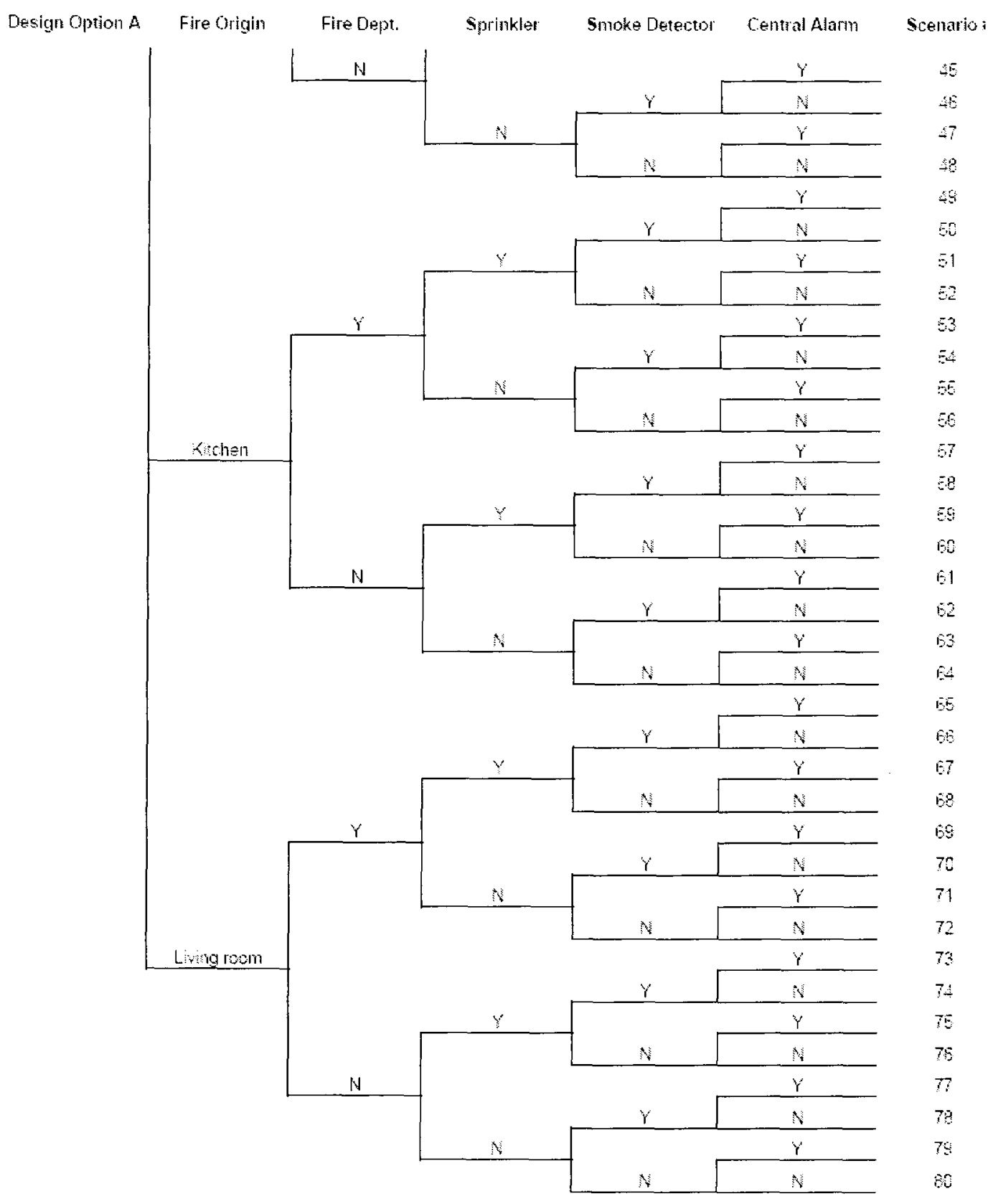

Figure 4.6: Scenario Structure of Design Option A 


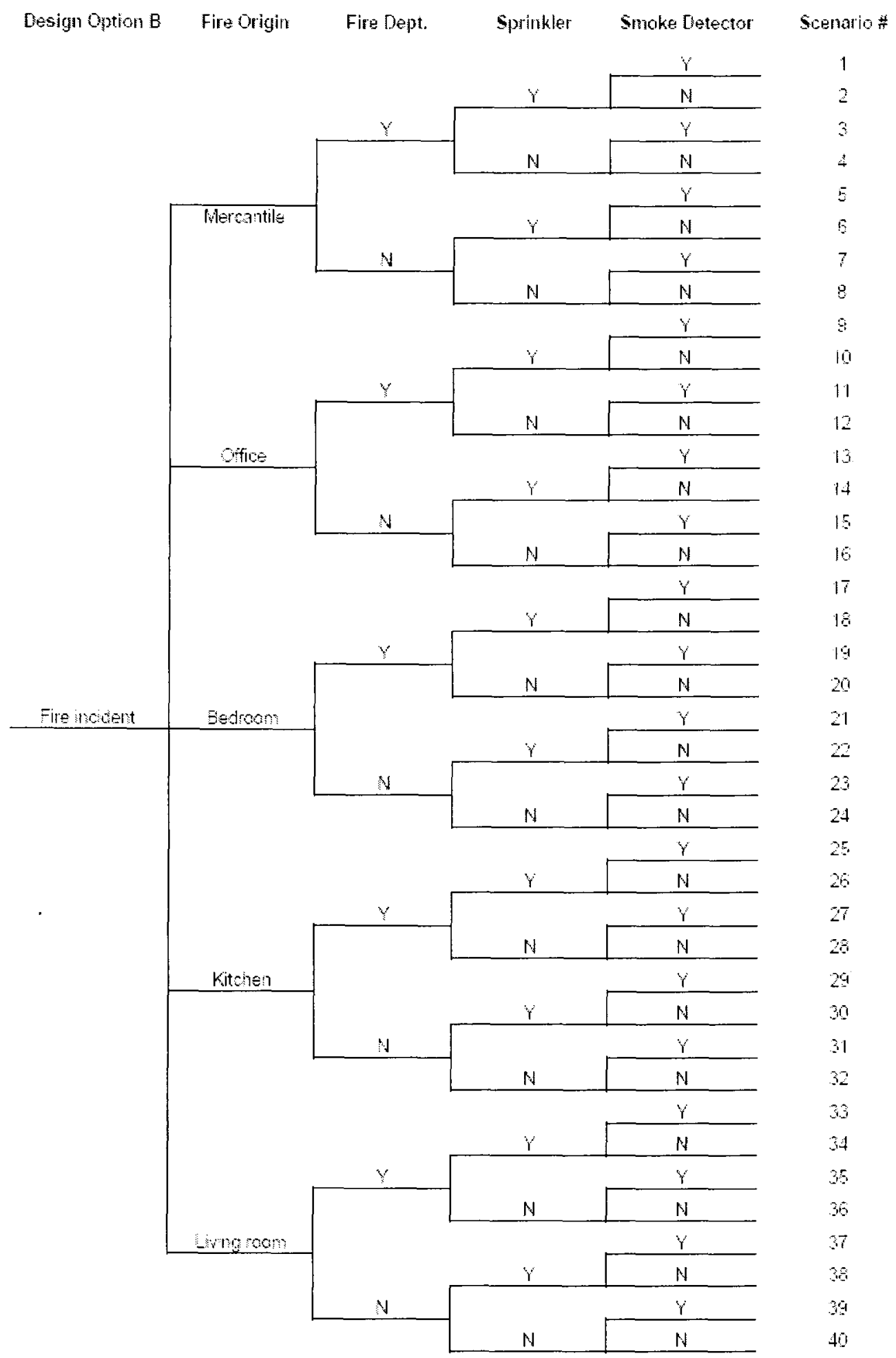

Figure 4.7: Scenario Structure of Design Option B 


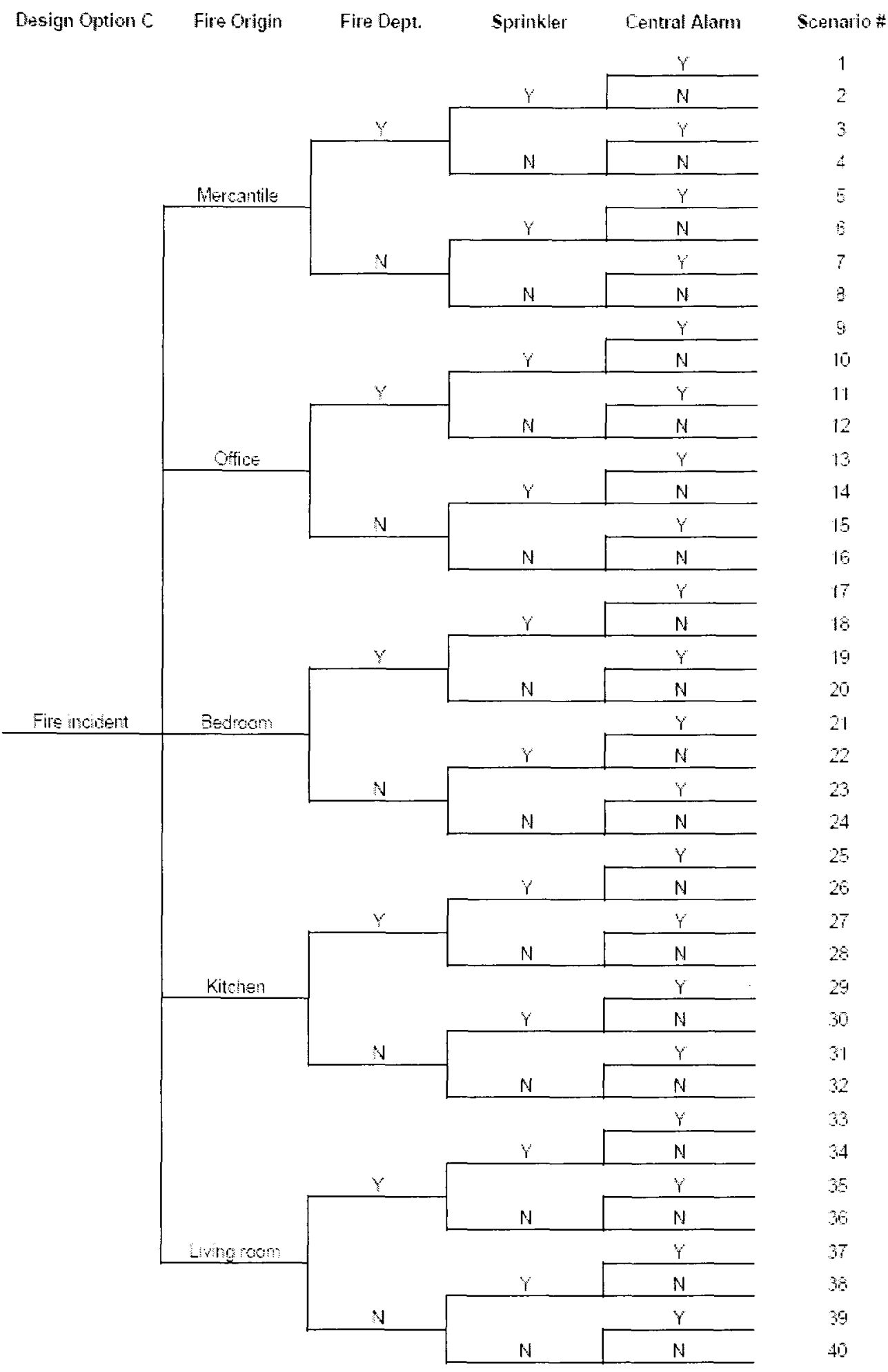

Figure 4.8: Scenario Structure of Design Option C 


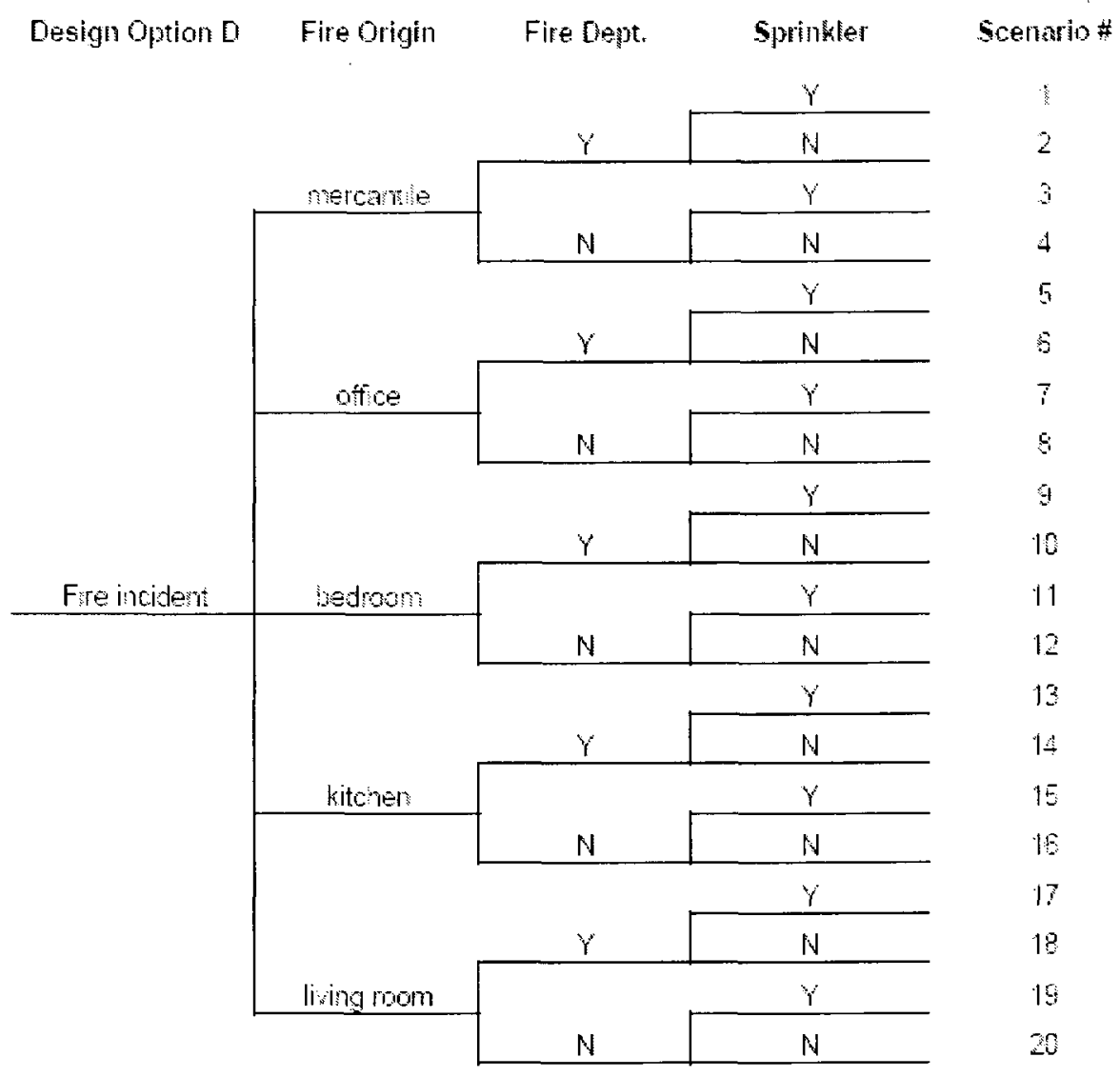

Figure 4.9: Scenario Structure of Design Option D 


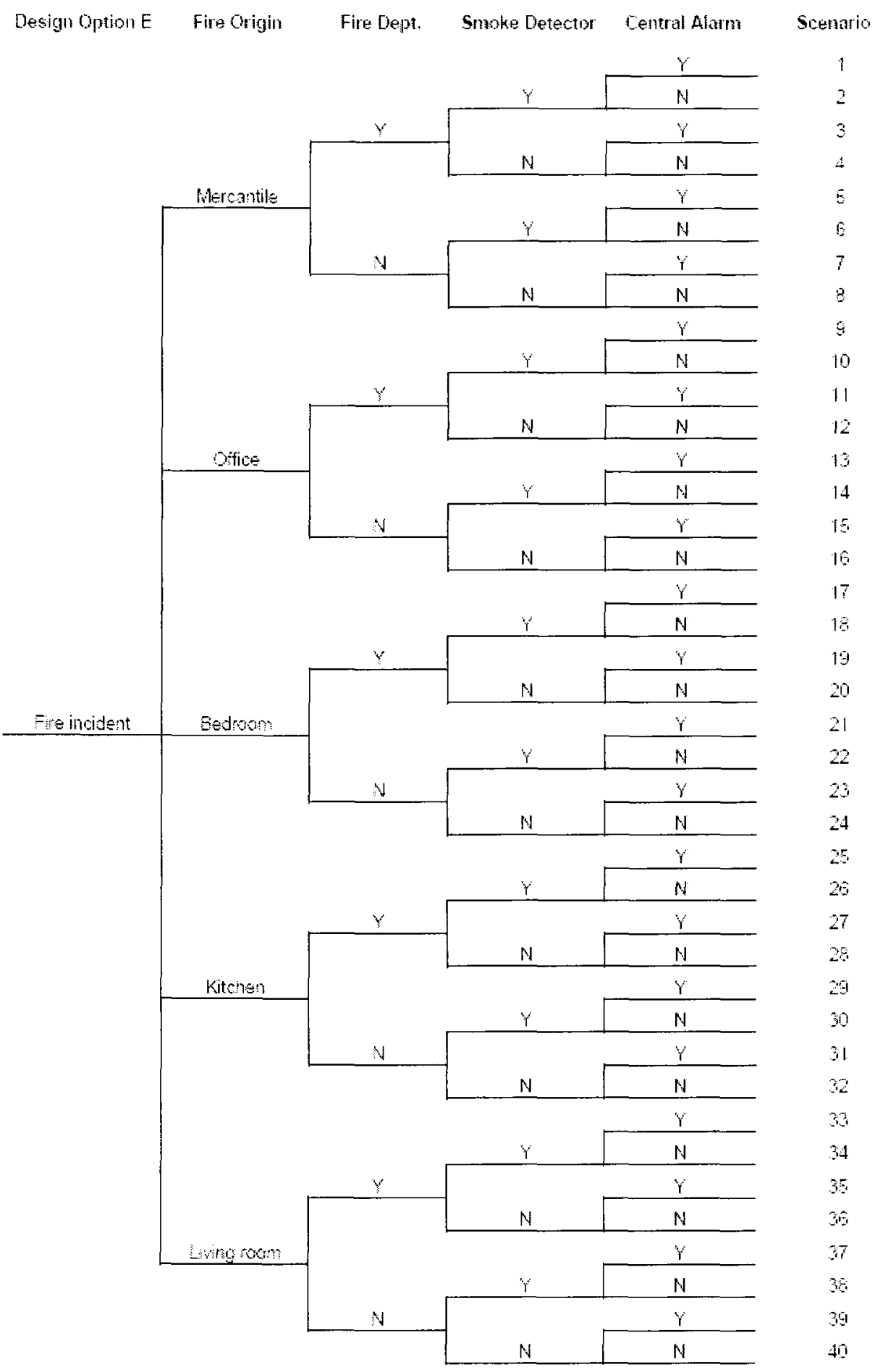

Figure 4.10: Scenario Structure of Design Option E 


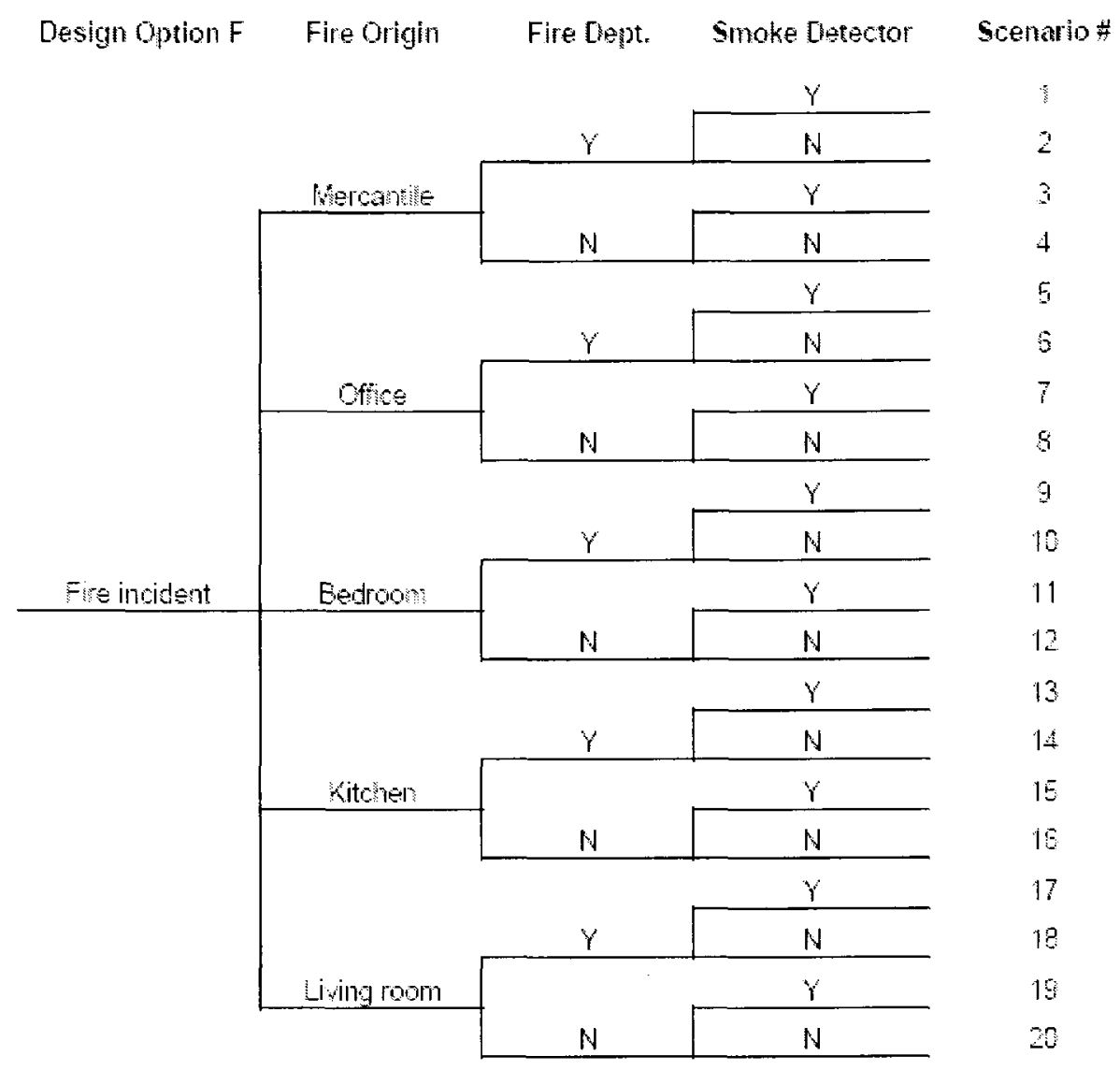

Figure 4.11: Scenario Structure of Design Option F 


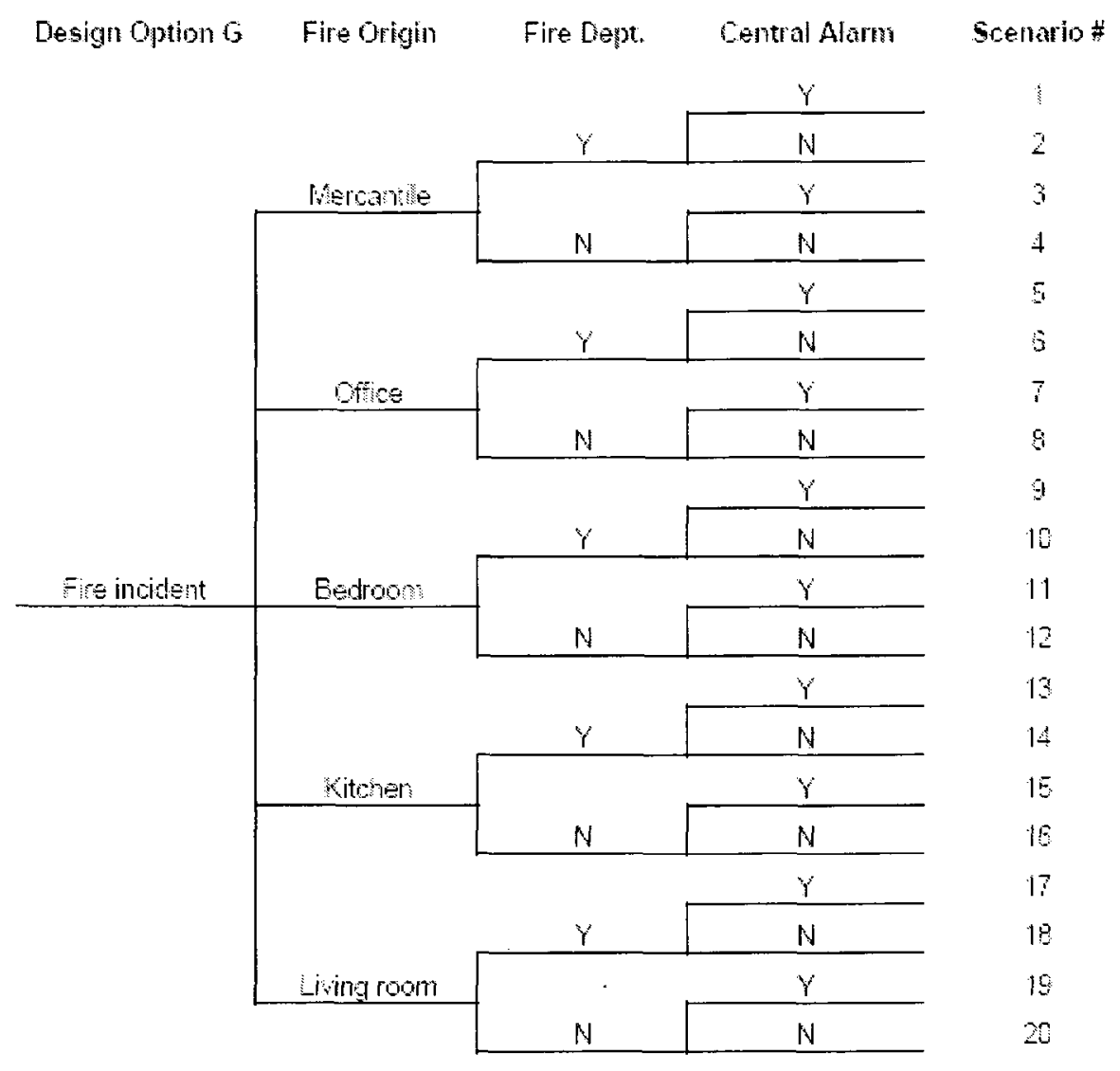

Figure 4.12: Scenario Structure of Design Option G 


\begin{tabular}{|c|c|c|c|}
\hline \multirow[t]{3}{*}{ Design Option $\mathrm{H}$} & Fire origin & Fire Dept. & Scenario \\
\hline & & $Y$ & 1 \\
\hline & Mercantile & $N$ & 2 \\
\hline \multirow[b]{4}{*}{ Fine incident } & & $Y$ & 3 \\
\hline & onice & N & 4 \\
\hline & \multirow[b]{2}{*}{ Bedroom } & $Y$ & 5 \\
\hline & & $\mathrm{N}$ & 8 \\
\hline & \multirow[b]{2}{*}{ Kitchen } & $Y$ & 7 \\
\hline & & N & 8 \\
\hline & \multirow[b]{2}{*}{ Livign: } & $y$ & 9 \\
\hline & & $N$ & 10 \\
\hline
\end{tabular}

Figure 4.13: Scenario Structure of Design Option H 


\subsection{Probability Analysis}

After identifying the scenario structure of each of the design options, a probability analysis is conducted. To quantify the probabilities of each scenario used in the risk calculations. It is first necessary to determine the probability of each event in the event tree. This can be done by statistical data review and engineering judgment. In the following discussion three types of probability will be evaluated, which include:

- Ignition frequency and ignition probability

- Reliability of fire protection systems

- Scenario probability

\subsubsection{Ignition frequency}

\section{Ignition Probability for Occupancies}

The statistical data of fire ignition frequencies pertain to occupancies of this case study building found in the literature $[45,47]$ are summarized in Table 4.18:

Table 4.18: Statistical Fire Ignition Frequencies Pertain to Case Study Occupancies. $\left(10^{-6}\right.$ fires / $\left(m^{2}\right.$. Year $\left.)\right)$

\begin{tabular}{|c|c|c|c|}
\hline Building type & Ontario & U.K & Finland \\
\hline Mercantile & - & 22.0 & 6.6 \\
\hline Office & 7.68 & 5.3 & 2.5 \\
\hline Residential & $2.61 \times 10^{-3} /$ unit & - & 6.3 \\
\hline All & - & - & 9.0 \\
\hline
\end{tabular}

From Table 4.18, it can be seen that the ignition frequencies found in the literature vary significantly. This is due to the different approaches used in the data collection, 
different definition of occupancy types, and different regions the fire data have been collected from, as fire ignition frequencies data varies significantly with the region.

In this study the Ontario data will be used. The data are converted so that fire ignition frequencies of different occupancies from different sources are based on the same unit. A typical area of $150 \mathrm{~m}^{2} /$ unit is assumed for an average Canadian town house and this value is used to convert residential fire ignition frequencies into number of fires per year. Furthermore, since the North American mercantile and office fire ignition frequency data are missing, the U.K (London) data are used to approximate the fire incident rate of mercantile and office spaces of the case study building. The fire occurrence rates of the three occupancies are estimated using the following equation:

$$
F_{i g, k}=F^{\prime \prime}{ }_{i g, k} * A
$$

Equation 4.2

Where:

$\mathrm{F}_{\mathrm{ig}, \mathrm{k}}$ - Fire ignition frequency for the occupancy $\mathrm{k}$, fires / (year).

$F_{i g, k} "$ - Fire ignition frequency of unit area of the occupancy $k$, fires / (year. $\left.\mathrm{m}^{2}\right)$.

A - Total area of the occupancy, $\mathrm{m}^{2}$

Table 4.19: The Fire Occurrence Rate of Each Occupancy of the Case Study Building

\begin{tabular}{|c|c|c|c|}
\hline Building type & $\begin{array}{c}\text { F ig,k" } \\
\left.\text { fires / (year. } \mathbf{~ m}^{\mathbf{2}}\right)\end{array}$ & $\begin{array}{c}\text { Area } \\
\left(\mathbf{m}^{2}\right)\end{array}$ & $\begin{array}{c}\mathbf{F} \text { ig,k } \\
\text { (fires } / \text { year) }\end{array}$ \\
\hline Mercantile & $22 \mathrm{E}-06$ & 822 & $1.81 \times 10^{-2}$ \\
\hline Office & $7.68 \mathrm{E}-06$ & 822 & $0.63 \times 10^{-2}$ \\
\hline Residential & $17.4 \mathrm{E}-06$ & 1644 & $2.86 \times 10^{-2}$ \\
\hline All & & & $5.30 \times 10^{-2}$ \\
\hline
\end{tabular}




\section{Ignition probability of the area of fire origin}

As described in the hazard identification and scenario creation section earlier, the following five spaces have been identified as representative fire origins in the case study: store space on the first floor; open office on the second floor; bedroom; kitchen, and living room of typical dwelling units on the third and fourth floor. In order to quantify the probability of each scenario in the event tree and assess the risk of fire in the building, the relative ignition probability of each area of fire origin needs be identified.

The relative percentage of fire ignition frequency in residential occupancies is computed using the Ontario fire statistical dada from 1995 to 2002 collected by the Ontario Fire Marshal (OFM) [39]. Table 4.20 shows data of number of fires in the bedrooms, kitchens, and living rooms. From these values the relative frequency of the fire in these areas is computed.

Table 4.20: Relative Percentage of Fire Ignition Frequency in Residential Section for Case Study Building

\begin{tabular}{|c|c|c|c|}
\hline Fire origin & No of fires & $\begin{array}{c}\text { \% of total } \\
\text { residential fires* }\end{array}$ & $\begin{array}{c}\text { Relative } \\
\text { percentages }\end{array}$ \\
\hline Bed room & 6124 & $10.30 \%$ & $21.24 \%$ \\
\hline Kitchen & 15722 & $26.60 \%$ & $54.85 \%$ \\
\hline Living room & 6865 & $11.60 \%$ & $23.92 \%$ \\
\hline All Residential pertain to case & 28761 & $48.50 \%$ & $100 \%$ \\
\hline
\end{tabular}

* The total number of residential fires is 59,217 in Ontario from 1995 to 2002 [39].

The relative fire ignition frequencies by area of fire origin used in this case study are further calculated and shown in Table 4.21. 
Table 4.21: Relative Percentage of Fire Ignition Frequency by Fire Origin

\begin{tabular}{|c|c|c|}
\hline Fire origin & $\mathbf{P}_{\text {ig }}$ (fires / year) & Ignition probability of fire origin \\
\hline Mercantile & $1.81 \times 10^{-2}$ & $32.19 \%$ \\
\hline Office & $0.63 \times 10^{-2}$ & $11.24 \%$ \\
\hline Bed room & $0.61 \times 10^{-2}$ & $12.01 \%$ \\
\hline Kitchen & $1.57 \times 10^{-2}$ & $31.03 \%$ \\
\hline Living room & $0.68 \times 10^{-2}$ & $13.53 \%$ \\
\hline
\end{tabular}

\subsubsection{Operational Reliabilities of Fire Protection Systems}

The reliability of fire protection system is the possibility that the fire protection system will operate as intended in a fire incident. As discussed in Section 4.5.2, the active fire protection systems considered in this study are fire department response, automatic sprinkler system, smoke detection system and central alarm system. The respective operational reliabilities used in this study are determined based on statistical data in the literature [42] and engineering judgment. The result is outlined in the Table 4.23:

Table 4.22: Reliability of Fire Protection System Operability

\begin{tabular}{|c|c|c|}
\hline Fire Protection System Operability & Probability & Notes \\
\hline Fire department & 0.6 & N/A \\
\hline Automatic Sprinkler & 0.95 & {$[42]$} \\
\hline Local smoke detector & 0.90 & {$[42]$} \\
\hline Central alarm system & 0.90 & {$[42]$} \\
\hline
\end{tabular}




\subsubsection{Scenario probability}

In the previous sections, the probabilities relating to the fire protection systems used in the event tree are discussed. The scenario probability is derived by multiplying the probabilities of the events in each scenario path.

$$
\begin{array}{ll}
P_{i}=\prod_{i=1}^{n} P_{i, j} \cdot \quad \text { Equation } 4.3
\end{array}
$$

Where:

$\mathrm{n}$ - Total number of events considered in the scenario structure.

$\mathrm{i}$ - Scenario number in the event tree, from 1 to $\mathrm{m}$

$\mathrm{j}$ - Event number in the event tree, from 1 to $\mathrm{n}$

$P_{i}$ - probability of scenario $i$

$P_{i, j}$ - probability of event $j$ in scenario $i$

For example, in the scenario structure of design option A (refer to Figure 4.14), the probability of scenario 1 can be calculated as:

$$
\begin{aligned}
& \mathrm{P}_{1}=\mathrm{P}_{1, \mathrm{ig}} \times \mathrm{P}_{1, \mathrm{FO}} \times \mathrm{P}_{1, \mathrm{FD}} \times \mathrm{P}_{1, \mathrm{SD}} \times \mathrm{P}_{1, \mathrm{CA}} \\
& =1 \times 0.3219 \times 0.6 \times 0.95 \times 0.9 \times 0.9 \\
& =0.14862
\end{aligned}
$$

In this study, the scenario probability calculations are performed based on the event tree scenario structures identified for each design option discussed in Section 4.5.2 . The scenario probabilities are shown in Figures 4.14-4.21. 


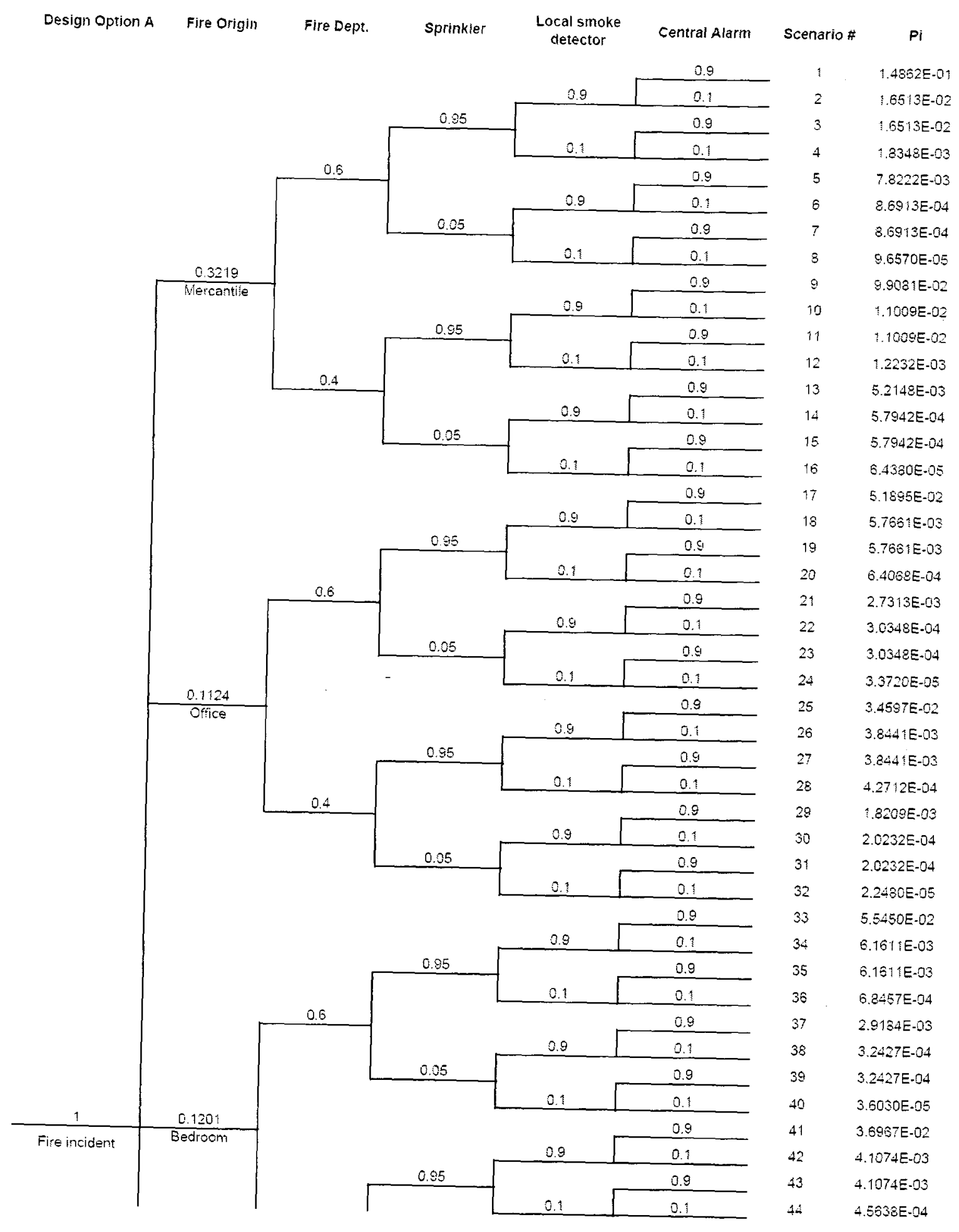




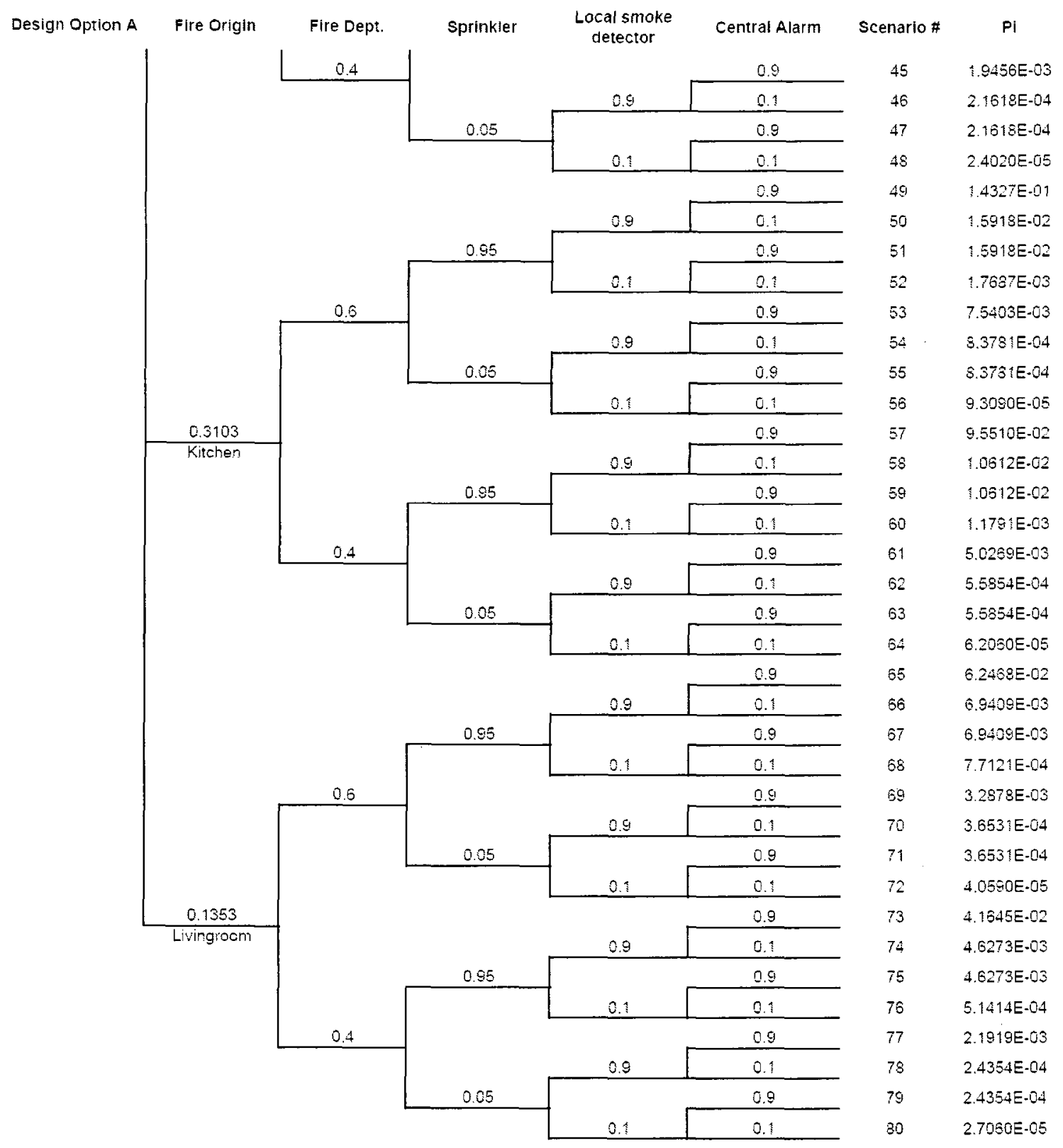

Figure 4.14: Scenario Probability of Design Option A 


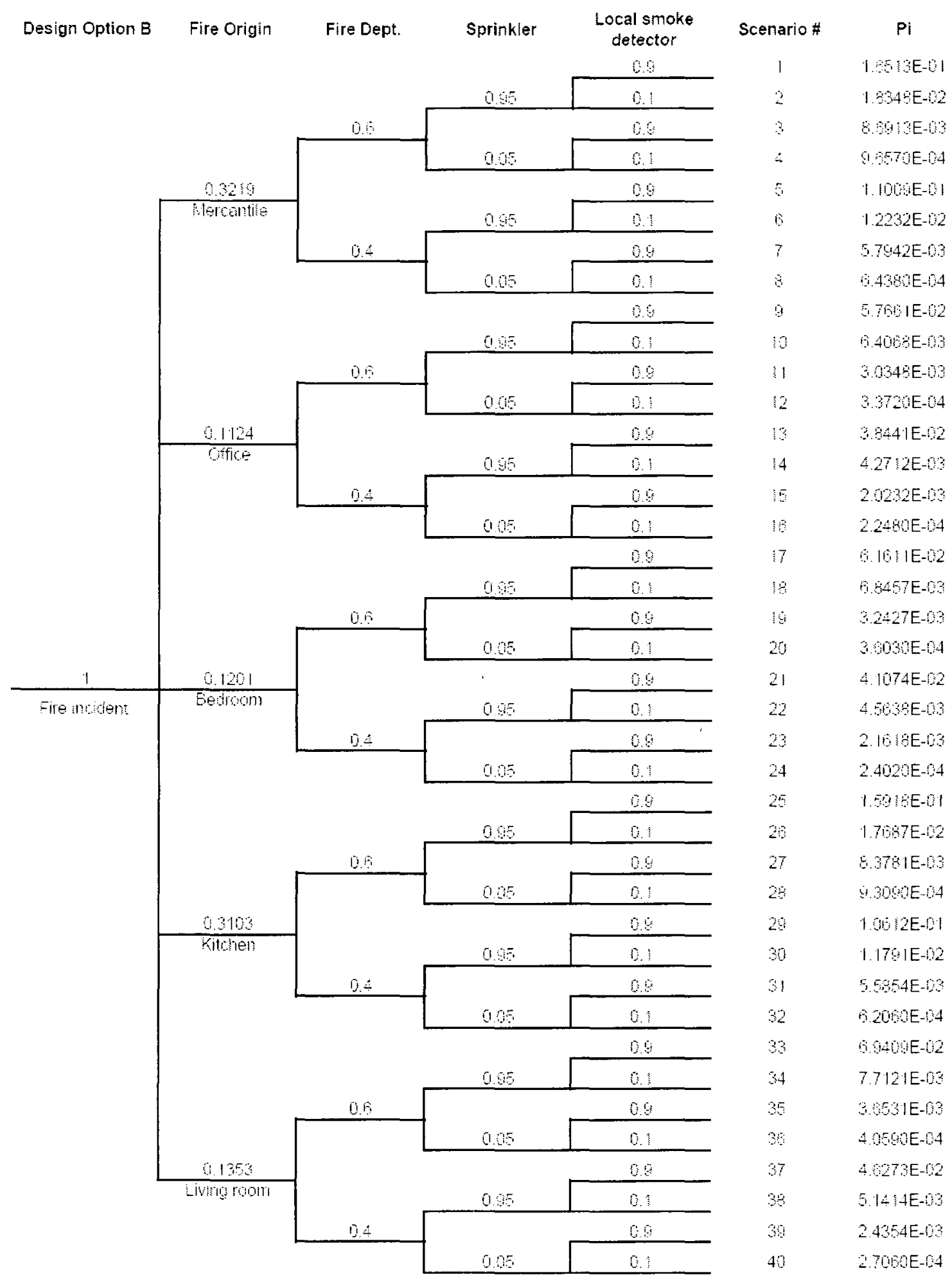

Figure 4.15: Scenario Probability of Design Option B 


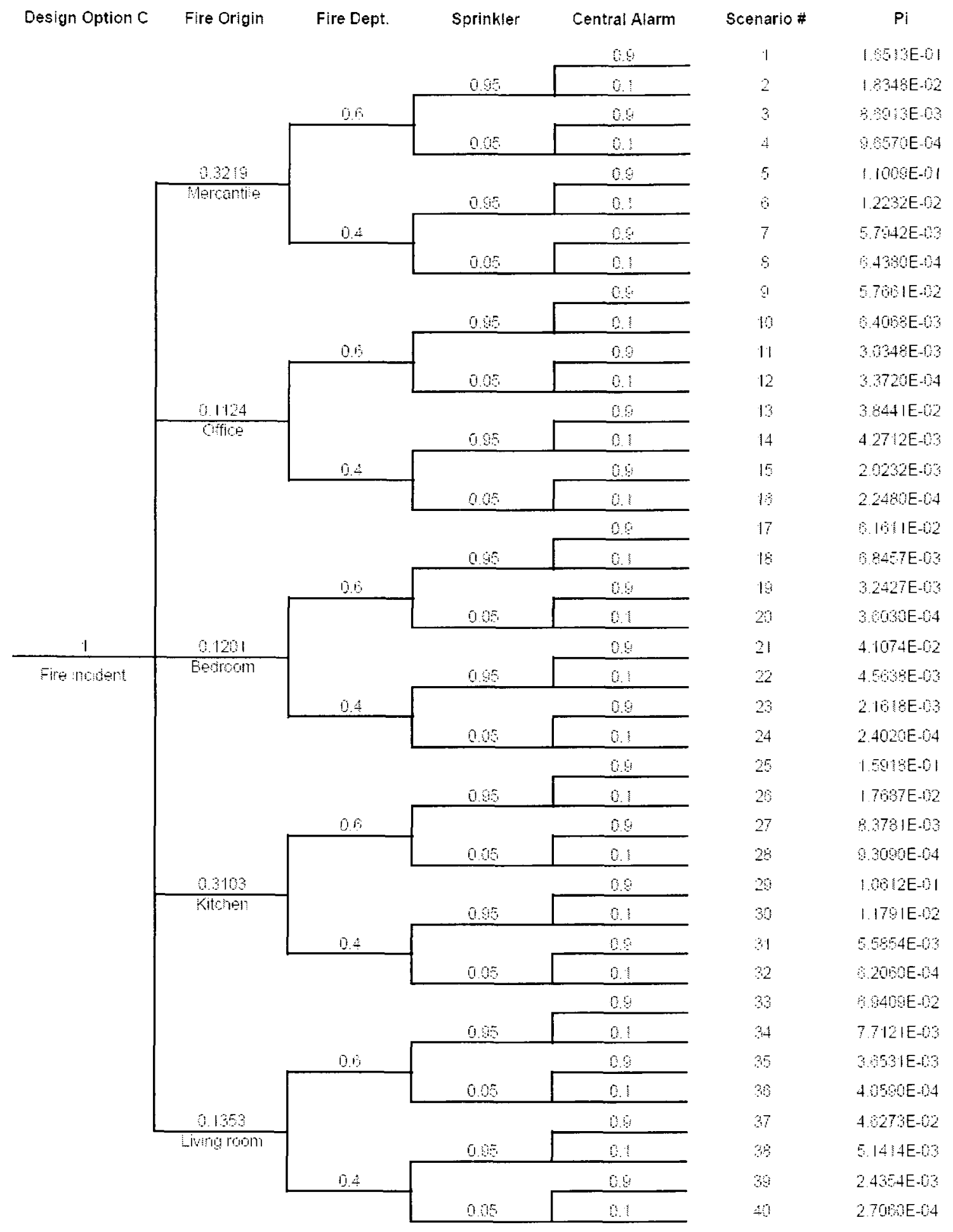

Figure 4.16: Scenario Probability of Design Option C 


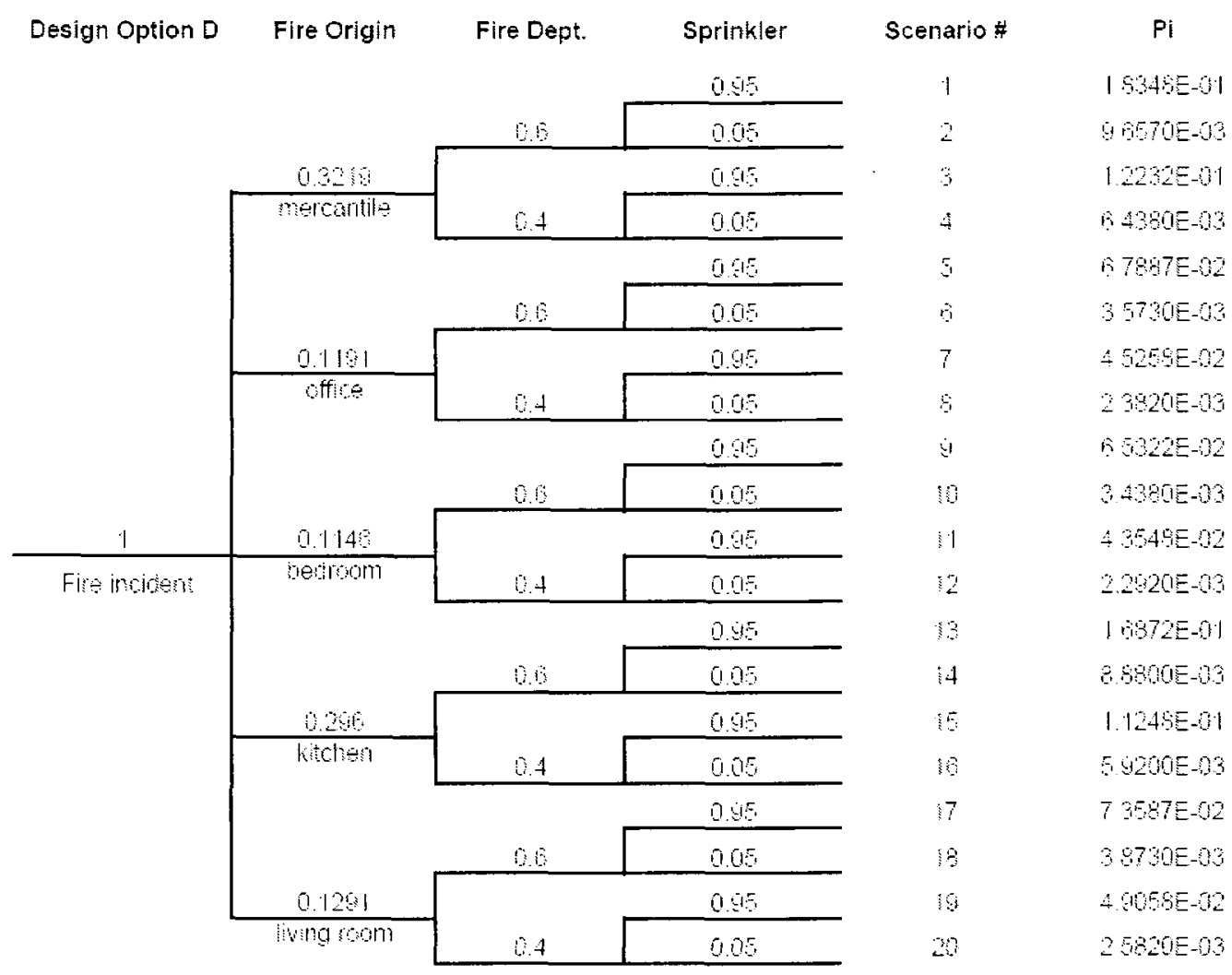

Figure 4.17: Scenario Probability of Design Option D 


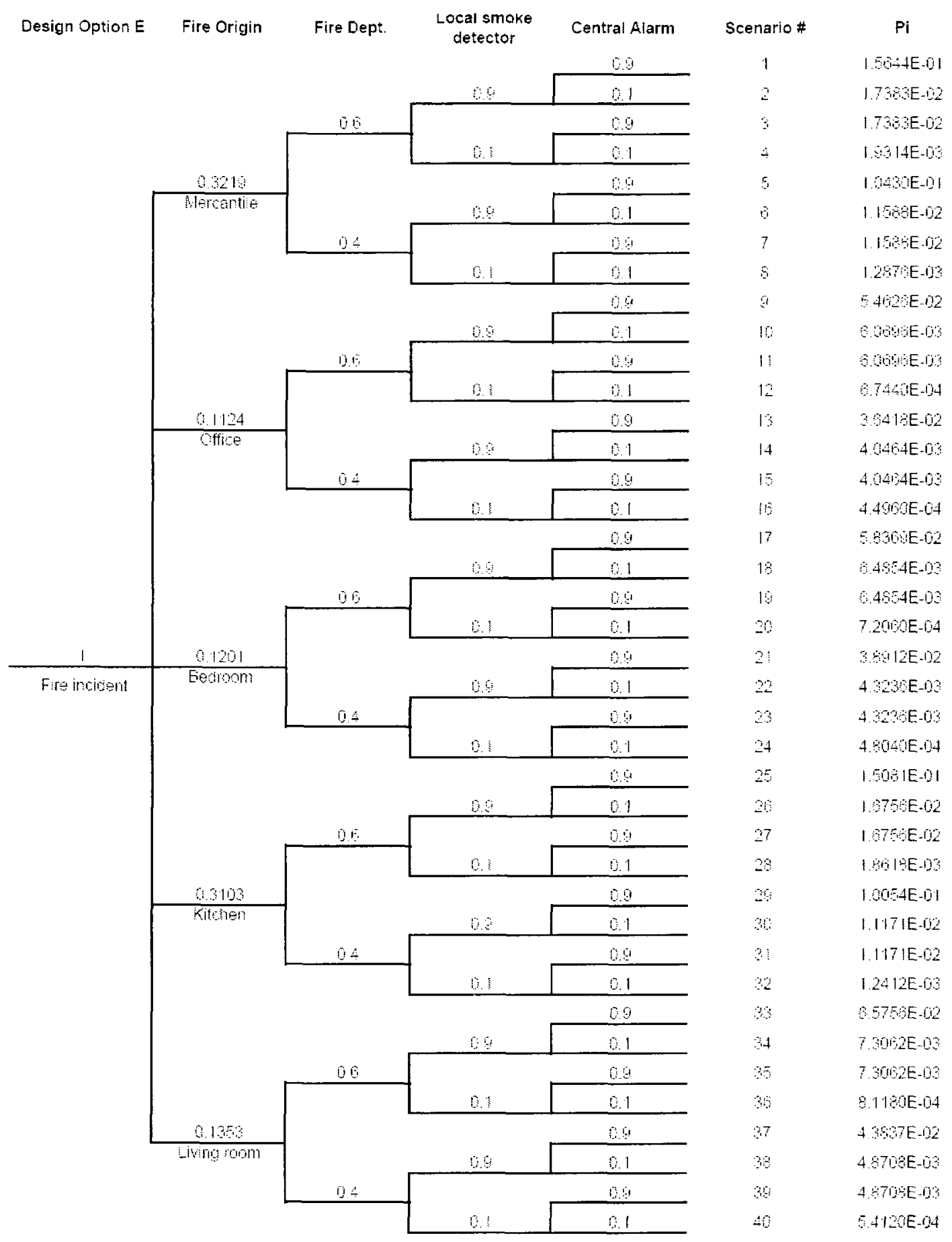

Figure 4.18: Scenario Probability of Design Option $E$ 


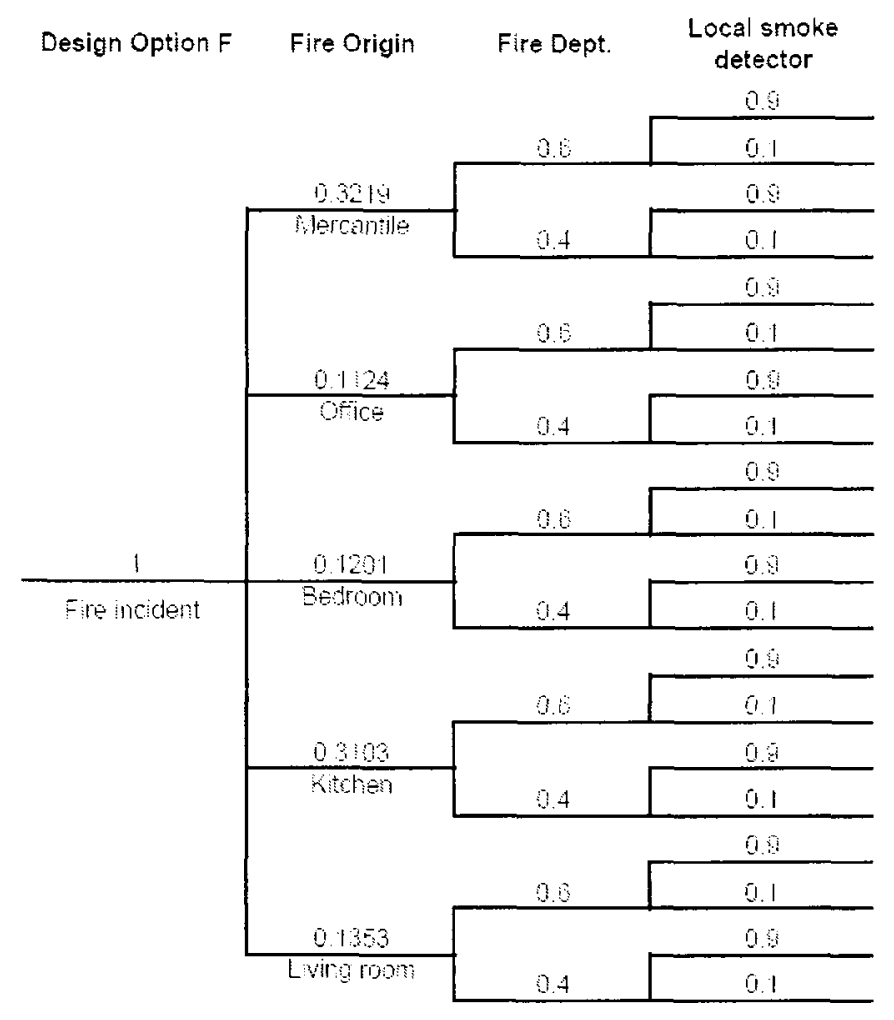

\begin{tabular}{|c|c|}
\hline Scenario \# & $\mathrm{PI}$ \\
\hline 1 & $1.739 \mathrm{BE}$ \\
\hline 2 & $1.8 \mathrm{~B} \mathrm{E}-\mathrm{O}$ \\
\hline 3 & | $158 \mathrm{E}-01$ \\
\hline 4 & $1.237 \mathrm{GE} .12$ \\
\hline 5 & GOGBE-Te \\
\hline 6 & $67440 E-93$ \\
\hline 7 & $404 \% 4 \mathrm{E}-12$ \\
\hline 8 & $4400 \mathrm{E}-1 \mathrm{a}$ \\
\hline 9 & $14054 E-12$ \\
\hline 10 & $72000 \mathrm{E}-\mathrm{S}$ \\
\hline 11 & $4323 \mathrm{E}-\mathrm{Q}$ \\
\hline 12 & A OCAOE-OS \\
\hline 13 & $16756-U$ \\
\hline 14 & $13 E 1 \mathrm{BE}-12$ \\
\hline 15 & $11771 \mathrm{E}$ \\
\hline 16 & $12+12 E-12$ \\
\hline 17 & $7302 \mathrm{E}-\mathrm{O} 2$ \\
\hline 16 & B 1180E-OS \\
\hline 19 & $4870 \mathrm{~B}-32$ \\
\hline 20 & $5,420 \mathrm{EA}$ \\
\hline
\end{tabular}

Figure 4.19: Scenario Probability of Design Option F 


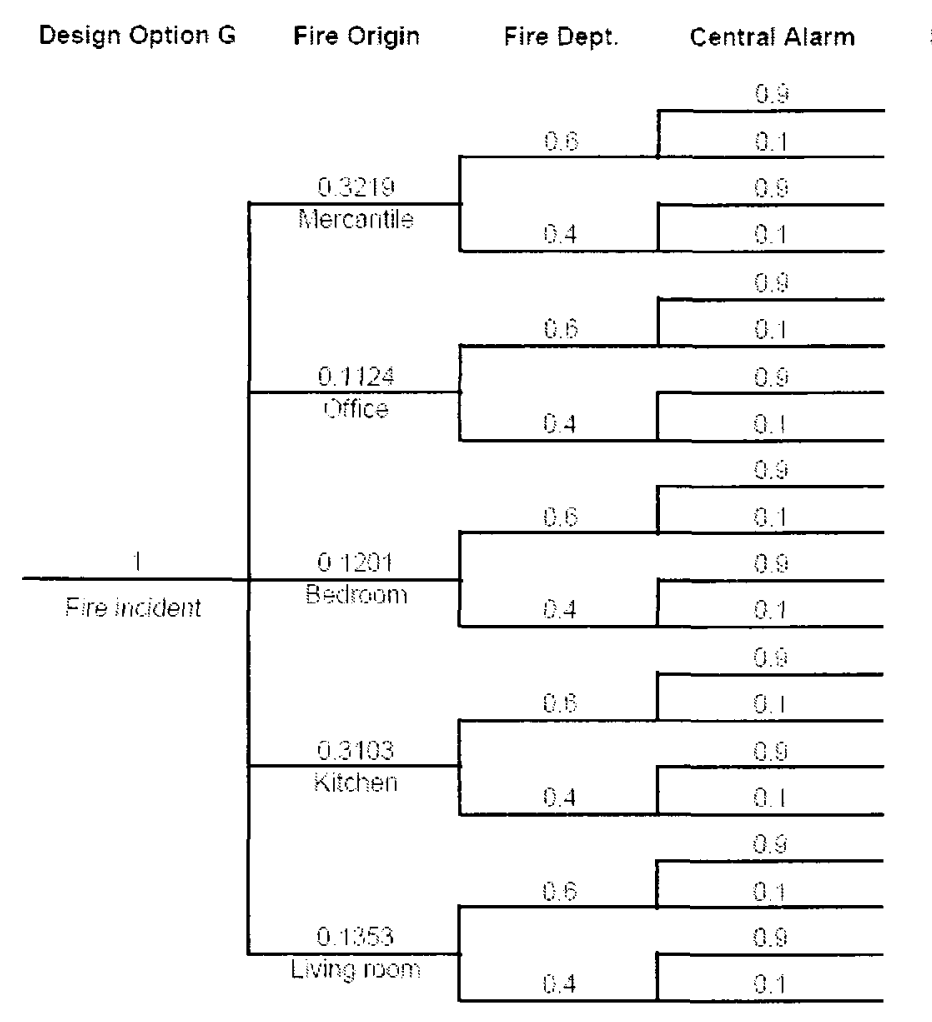

\begin{tabular}{|c|c|}
\hline Scenario \# & $\mathrm{PI}$ \\
\hline 1 & $1703 \mathrm{E}-01$ \\
\hline 2 & 193 A ECO \\
\hline 3 & $1.158 \mathrm{EE}-11$ \\
\hline 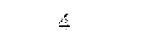 & $1.297 \mathrm{EE}$ \\
\hline 5 & $6.0666 \mathrm{E}-2$ \\
\hline 6 & $07440 \mathrm{E}-03$ \\
\hline 7 & AO4OAEO2 \\
\hline 8 & $440 \mathrm{OE}-03$ \\
\hline$\theta$ & $64854 \mathrm{E}-9$ \\
\hline 10 & $7.2060 \mathrm{E}-03$ \\
\hline 11 & $4320 \mathrm{E}-02$ \\
\hline 12 & $\triangle 8040 E-03$ \\
\hline 13 & | $6756 \mathrm{E}-1$ \\
\hline 14 & $1.8616 \mathrm{E}-02$ \\
\hline 15 & 1.17|E-01 \\
\hline 6 & $12412 \mathrm{E}-\mathrm{O} 2$ \\
\hline 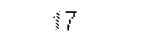 & $7310 \mathrm{E}-\mathrm{O}$ \\
\hline 10 & A IPिE-ด \\
\hline 9 & $48708 \mathrm{E}-92$ \\
\hline 20 & $5420 \mathrm{E}-13$ \\
\hline
\end{tabular}

Figure 4.20: Scenario Probability of Design Option G 


\begin{tabular}{|c|c|c|c|c|}
\hline \multirow[t]{6}{*}{ Design Option $\mathrm{H}$} & Fire Origin & Fire Dept. & Scenario \# & $\mathrm{PI}$ \\
\hline & & 08 & i & $1.8314 E-01$ \\
\hline & 53219 & 0.4 & 2 & $1.287 \mathrm{E} \cdot 01$ \\
\hline & Bercantile & 0.8 & 3 & OTAAGE 02 \\
\hline & 01124 & 0.4 & 4 & $4.4 \$ 1 \mathrm{E}-02$ \\
\hline & office & 06 & 5 & $7.205 \mathrm{E}-02$ \\
\hline 1 & 1201 & 0.4 & 8 & $48040 \mathrm{E}-02$ \\
\hline \multirow[t]{4}{*}{ Fre incident } & Eeroom & 0.6 & 7 & $18618 \mathrm{E}-01$ \\
\hline & 38103 & 0.4 & 8 & $1.2412 \mathrm{E}-01$ \\
\hline & Kitchar & 06 & 9 & \$11⿴囗t-02 \\
\hline & 130 & 04 & 10 & $5412 \mathrm{E}-02$ \\
\hline
\end{tabular}

Figure 4.21: Scenario Probability of Design Option H 


\subsection{Consequence Evaluation}

\subsubsection{Description of submodel predictions}

This section describes the predictions of the submodels dealing with fire development and smoke propagation in the building, occupant response and evacuation, as well as the performance of fire protection measures in the building.

Detailed results will be presented for fire scenario No.77 of Design Option A. In this scenario, the fire starts in the living room (Room $\# 25$ ) of a residential unit on the third floor. The fire department does not arrive at the fire scene until the end of the simulation at 30 minutes. The automatic sprinkler system is not activated. The local smoke detector and the central alarm systems are working properly and activated.

The design parameters of this scenario are summarized in the Table 4.23.

Table 4.23: Design Parameters of Scenario No. 77 of Design Option A

\begin{tabular}{|c|c|c|c|c|}
\hline Fire origin & $\begin{array}{c}\text { Fire } \\
\text { department }\end{array}$ & $\begin{array}{c}\text { Sprinkler } \\
\text { System }\end{array}$ & $\begin{array}{c}\text { Local Smoke } \\
\text { detector }\end{array}$ & Central alarm \\
\hline Room 25 & Non arrival & Not activated & Activated & Activated \\
\hline
\end{tabular}




\subsubsection{Fire development and smoke spread in the building}

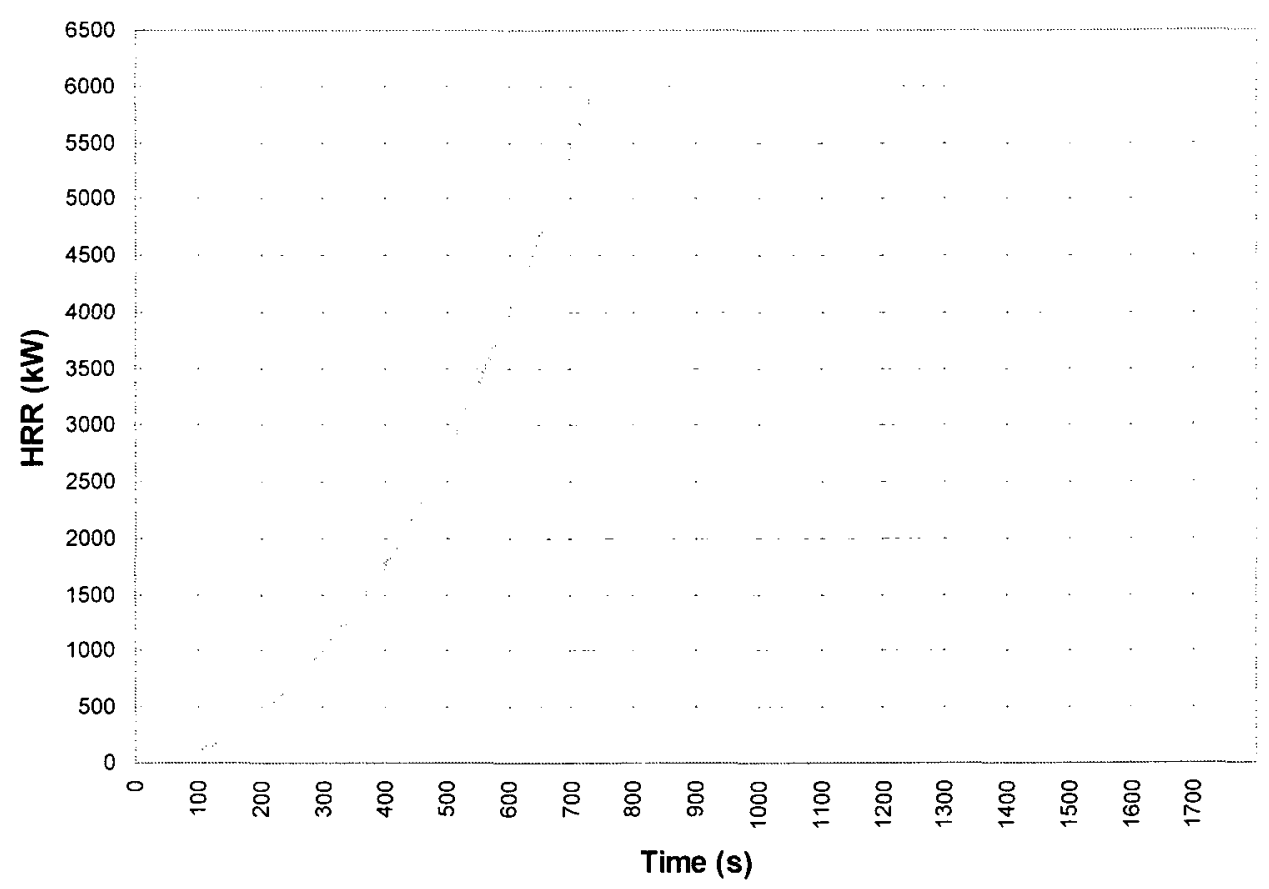

Figure 4.22: HRR Curves of Scenario 77 of Design Option A

Figure 4.22 shows the HRR vs. time in the compartment of fire origin of scenario 77 predicted by the CUrisk model. The design fire is assumed to be a $t^{2}$ fire. The fire starts in the living room (Room \#25) of the dwelling unit, and grows at a medium growth rate of $0.012 \mathrm{~kW} / \mathrm{s}^{2}$, and reaches the peak heat release rate of $6 \mathrm{MW}$ at around $750 \mathrm{~s}$. The fire then levels off at the heat release rate of $6 \mathrm{MW}$ until the end of the simulation. 


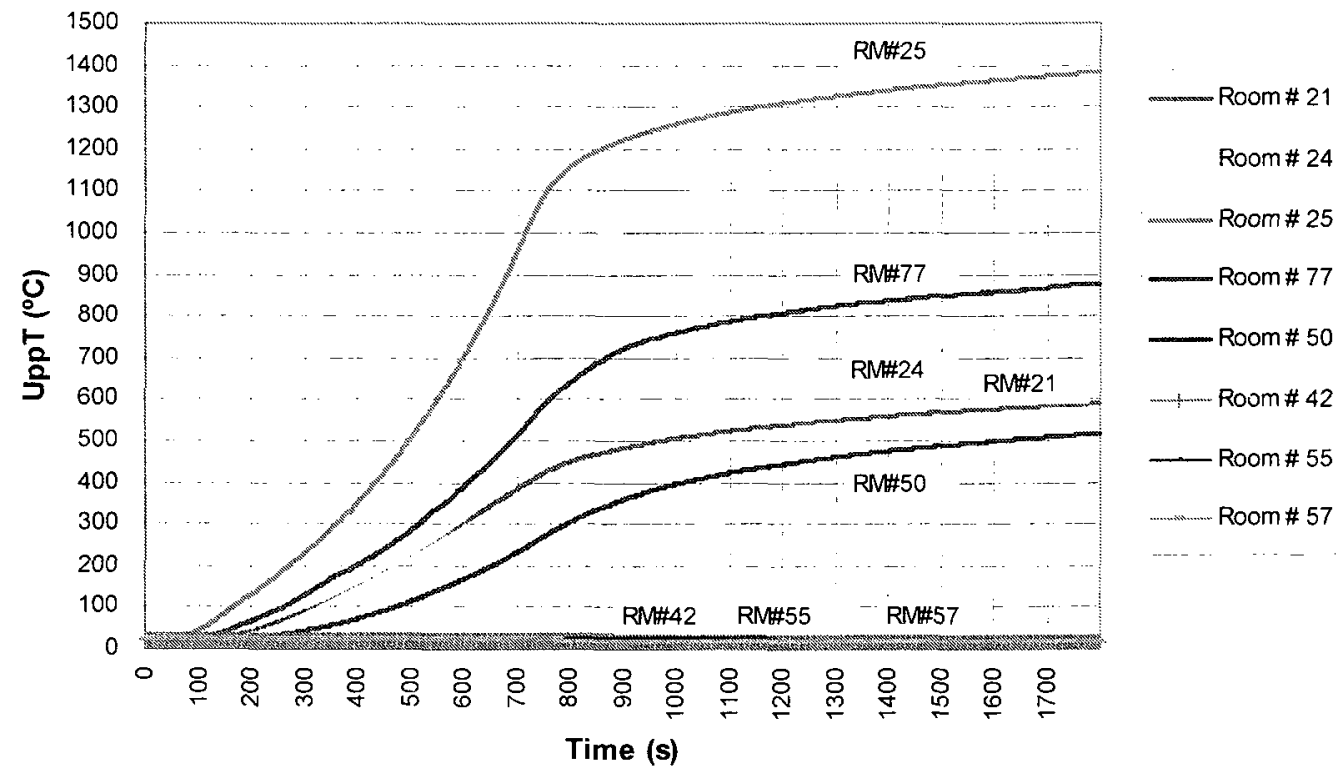

Figure 4.23: Upper Layer Temperature Curves of Selected Compartments of Scenario 77, Design Option A

Figure 4.23 shows the upper layer temperature as a function of time in the selected rooms in the building. Room $\# 25$ is the living room of the dwelling unit in the third floor. It is the compartment of fire origin. Room $\# 21$ and Room $\# 24$ are the adjacent rooms to the compartment of fire origin. Room \#77 is the internal stairwell and Room \#50 is in the upper floor of the dwelling unit. Room \#42 is the living room in the next door residential unit. Room \#55 is the open office on the second floor and room \#57 is the commercial area on the ground floor.

The temperature curves in Figure 4.23 show that the upper layer gas temperature in rooms increases in the fire compartment. It reaches the flashover criterion of $600{ }^{\circ} \mathrm{C}$ at 
around $550 \mathrm{~s}$. After flashover the temperature in the room increases continuously and reaches to $1381{ }^{\circ} \mathrm{C}$ by the end of the simulation.

The temperature profiles in the other rooms indicate that smoke spreads to the adjacent rooms (Room \#21, \#24, \#77, \#50). This is expected because all room doors within the dwelling units are left open. Only the entrance door to the units is assumed closed. The temperatures in the adjacent rooms are lower than that in the fire origin. In the Room $\# 50$, the upper layer temperature climbs to $517^{\circ} \mathrm{C}$ at $1800 \mathrm{~s}$.

In the compartments outside the fire unit (Room \#42, \#55, \#57), the temperatures remain almost at ambient temperature. This indicates that smoke does not spread to the adjacent residential units and to the rooms of the floors below.

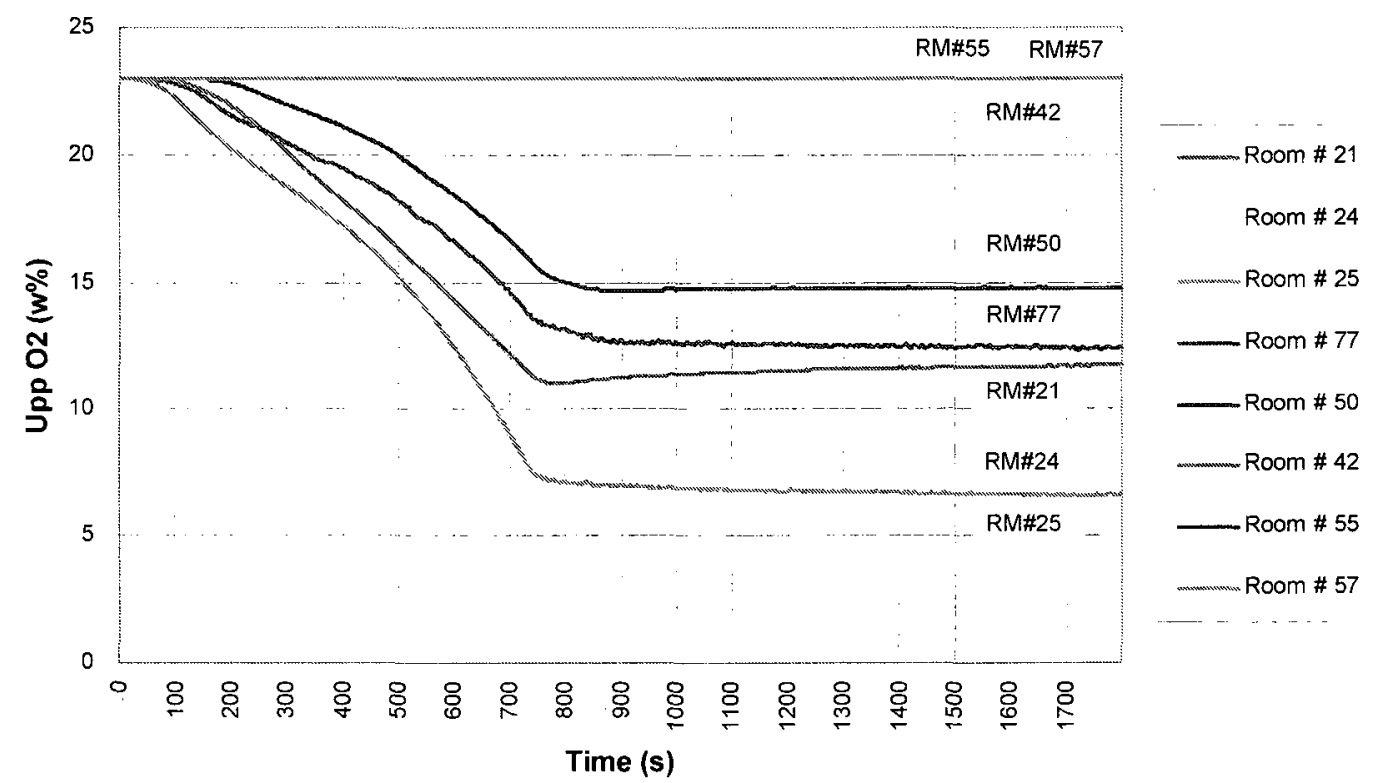

Figure 4.24: Upper Layer $\mathrm{O}_{2}$ Concentration of Selected Compartments of Scenario 77 of Design Option A 
Figure 4.24 shows the predicted $\mathrm{O}_{2}$ concentration in the upper layer as a function of time in the selected compartments. The concentration of $\mathrm{O}_{2}$ in the compartment of fire origin (Room \#25) drops rapidly after the fire starts. In about $750 \mathrm{~s}$, the $\mathrm{O}_{2}$ concentration in the upper layer drops from $23 \%$ to $7.4 \%$ and then it decreases slowly to $6.6 \%$ by the end of the simulation.

After about $57 \mathrm{~s}$, the smoke begins to leave the fire compartment and to spread into the adjacent compartments in the dwelling unit. Smoke reaches the kitchen quickly and due to its small size, the concentration of $\mathrm{O}_{2}$ drops as quickly as that of the compartment of fire origin. In the other adjacent compartments (Room \#21, \#50, \#77), the concentration of $\mathrm{O}_{2}$ also drops as a result of smoke propagation and reach values of $11.2 \%$ to $14.7 \%$ by the end of the simulation.

The $\mathrm{O}_{2}$ concentrations of the rooms in the other dwelling units and the lower floor office and mercantile spaces remain unchanged during the simulation indicating that smoke does not spread into these areas. 


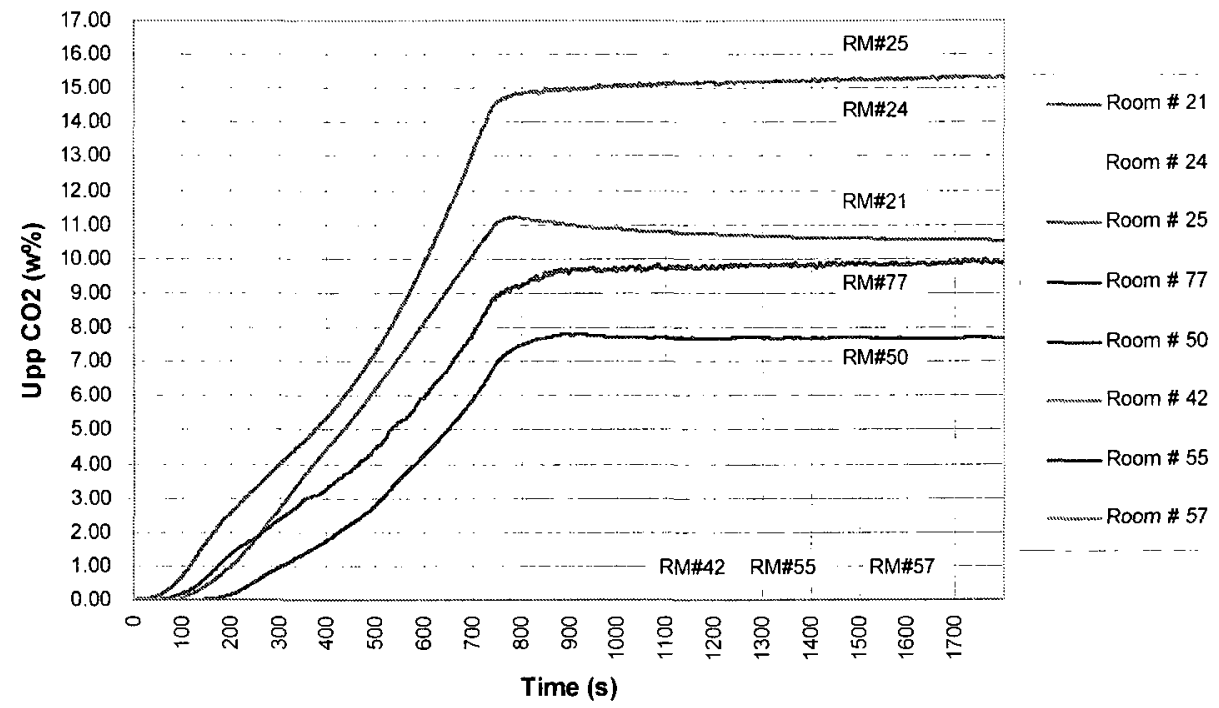

Figure 4.25: Upper Layer $\mathrm{CO}_{2}$ Concentration of Selected Compartments of Scenario 77 of Design Option A

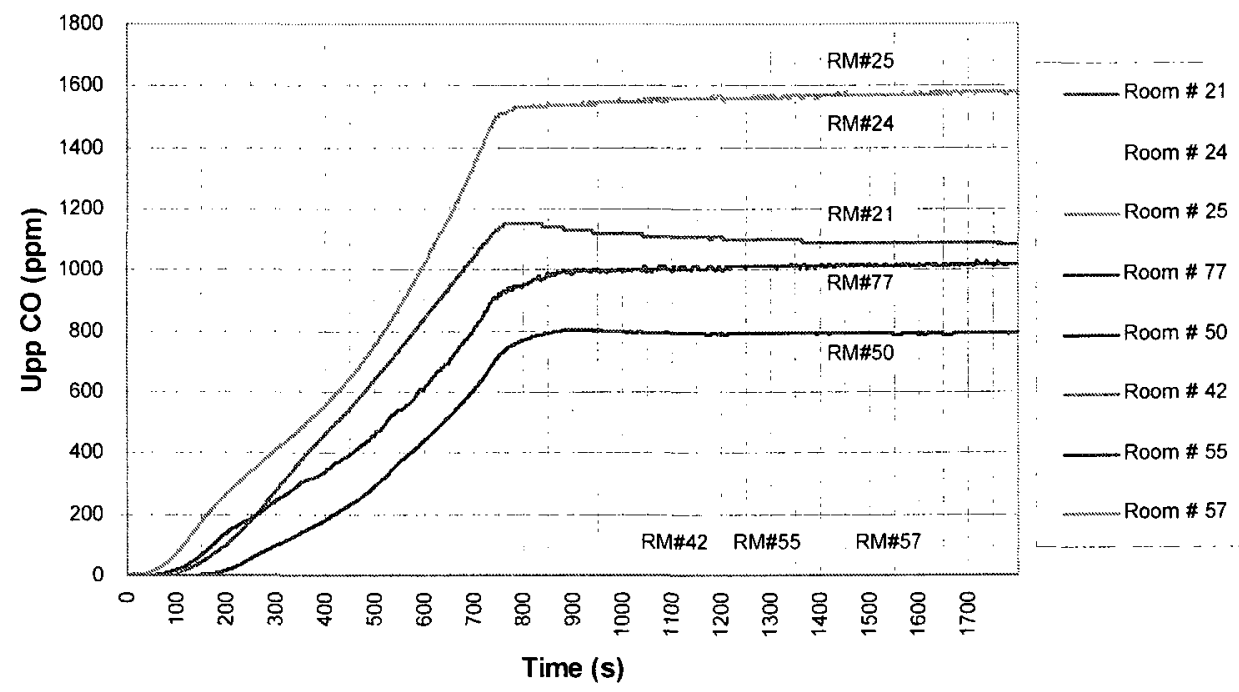

Figure 4.26: Upper Layer CO Concentration of Selected Compartments of Scenario 77,

\section{Design Option A}




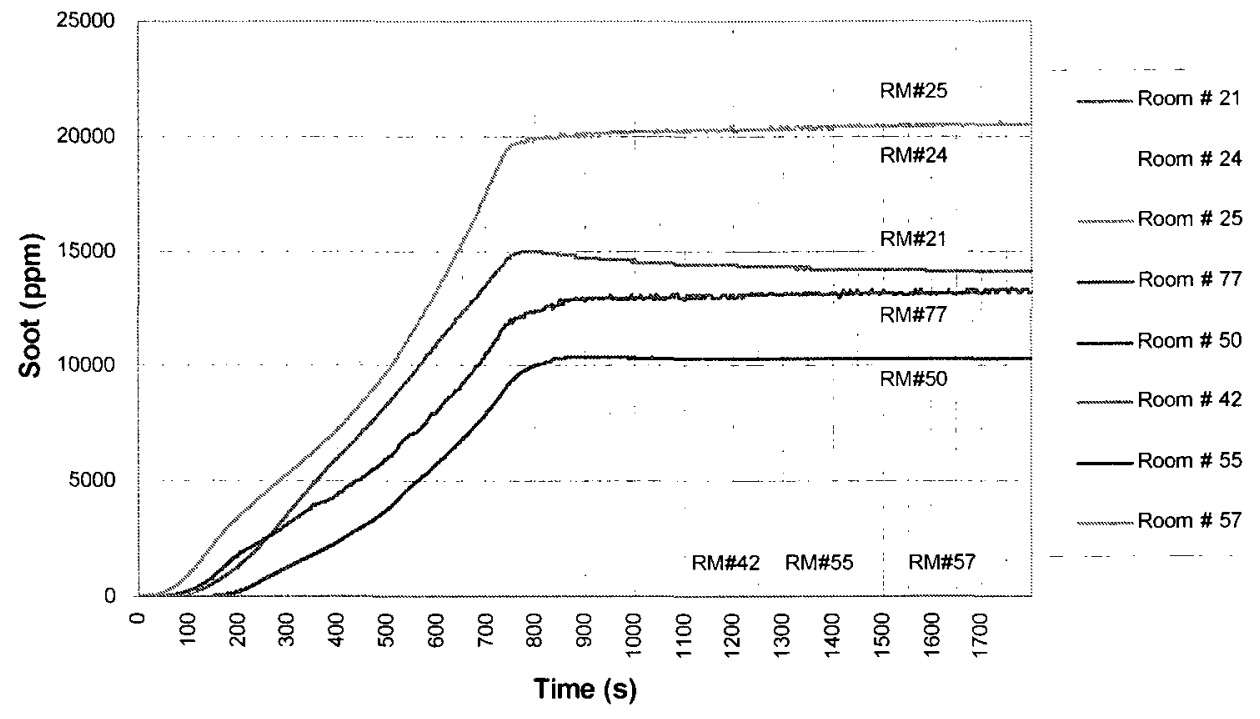

Figure 4.27: Soot Concentration Curves of Selected Compartments of Scenario 77, Design Option A

Figures 4.25-4.27 depict the accumulation of combustion products in the upper layer. The predicted concentrations of $\mathrm{CO}, \mathrm{CO}_{2}$ and soot in the compartment of fire origin, the selected adjacent compartments and other compartments are shown as the functions of time.

The concentrations of $\mathrm{CO}, \mathrm{CO}_{2}$ and soot show a similar pattern. In the first $746 \mathrm{~s}$ after fire ignition, they increase rapidly due to the rapid increase of the HRR in the compartment of fire. After $746 \mathrm{~s}$, the fire HRR becomes steady and this cause the concentrations of $\mathrm{CO}, \mathrm{CO}_{2}$ and soot to flatten as well. Figures 4.25-4.27 show that, in the compartment of fire origin, the combustion products start to increase right after fire initiation and reach their maximum level by the end of simulation. The $\mathrm{CO}, \mathrm{CO}_{2}$ and soot concentrations in the upper layer of adjacent compartments increase at a slower speed 
and remain at lower levels than in the fire compartment. Figures $4.25-4.27$ also show the concentrations of $\mathrm{CO}, \mathrm{CO}_{2}$ and soot in selected rooms of other compartment (Room $\# 42$, $\# 55$, and \#57) which stay at zero, because the smoke does not spread into other units.

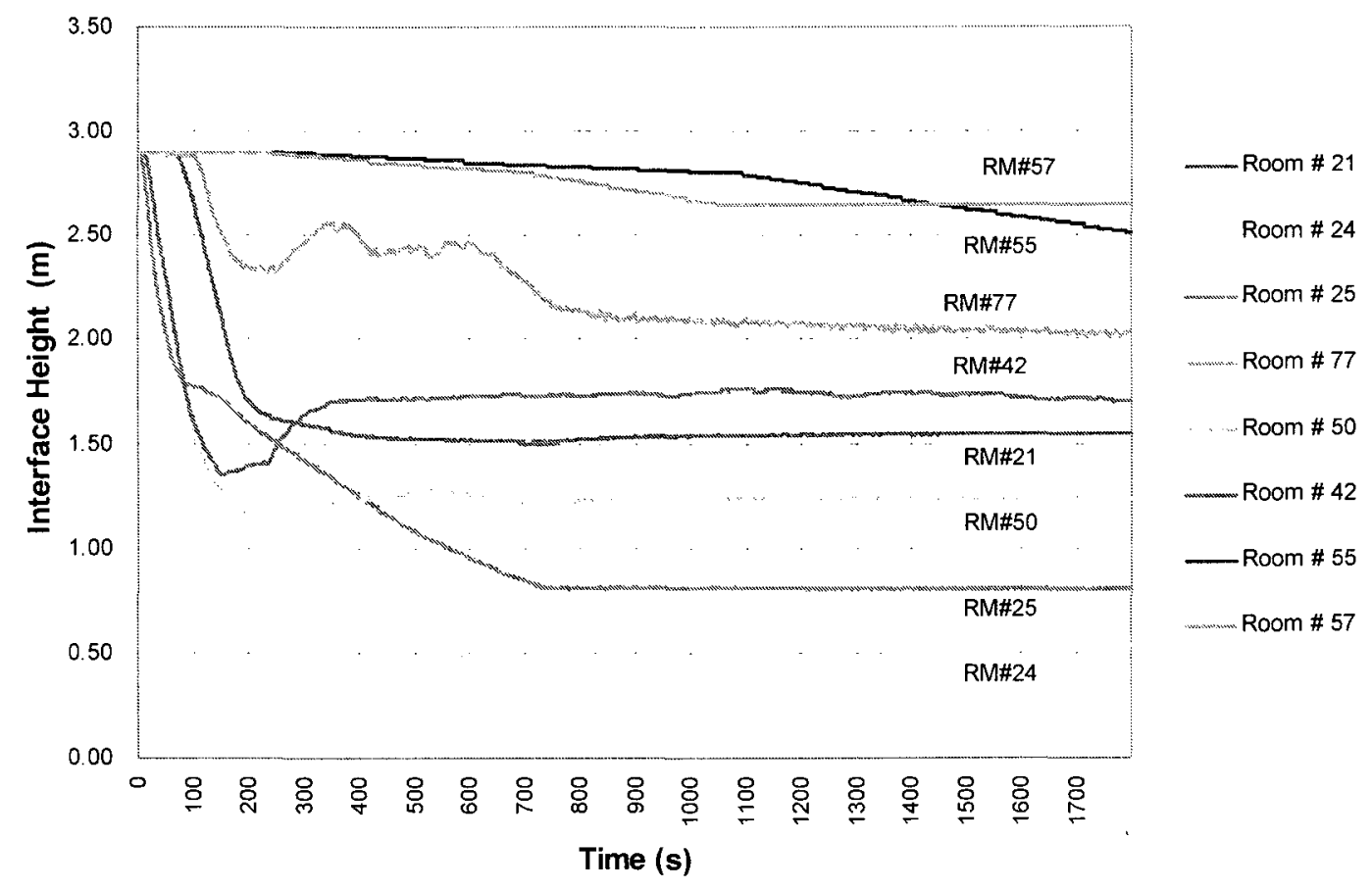

Figure 4.28: Interface Height of Selected Compartments of Scenario 77 of Design Option A

Figure 4.28 shows the interface height which separates the hot upper and the cold lower layers in the compartments.

In the compartment of fire origin (Room \#25), the interface height drops rapidly from ceiling height of $2.9 \mathrm{~m}$ to $0.8 \mathrm{~m}$ above the floor. It takes around $50 \mathrm{~s}$ for the interface 
height to drop from the ceiling height to $2.0 \mathrm{~m}$ above the floor. This means that occupants in the compartment are likely to be exposed to toxic smoke conditions after this time.

In the adjacent rooms of the compartment of fire origin, the interface height drops at a lower rate than that of the room of fire origin. However, it is found that the depth of the hot layer in the kitchen (Room\#24) decreases very fast. The smoke layer in the kitchen reaches the level of $2.0 \mathrm{~m}$ at around $114 \mathrm{~s}$. In about $600 \mathrm{~s}$, the interface height drops to less than $0.5 \mathrm{~m}$ above the floor, because the door between the compartment of fire origin and the kitchen is open and the kitchen has a small floor area.

\subsubsection{Performance of Automatic Sprinkler Systems}

During the calculation of fire and smoke development in a fire scenario, CUrisk determines the time of occurrence of four important events: 1) time of direct cue, 2) time of smoke detector activation, 3) time of sprinkler or heat detector activation, 4) time of flashover.

Table 4.24 shows the predicted times of occurrence of the four key events in the compartment of fire origin (Room \#25) for two scenarios. Scenario 73 has all the design scenario parameters of scenario 77 except that the sprinkler system is activated.

Table 4.24: Predicted Time of Occurrence of the Key Events of Scenarios 73 and 77, Design Option A

\begin{tabular}{|c|c|c|c|c|}
\hline Scenario \# & $\begin{array}{c}\text { Direct Cue } \\
\text { (s) }\end{array}$ & $\begin{array}{c}\text { Smoke Detector } \\
\text { Activation (s) }\end{array}$ & $\begin{array}{c}\text { Sprinkler } \\
\text { Activation (s) }\end{array}$ & Flashover (s) \\
\hline 77 & 94 & 139 & Not Activated & 551 \\
\hline 73 & 94 & 139 & 221 & Not Reached \\
\hline
\end{tabular}


Figure 4.29 shows the heat release rate of the two scenarios: scenario 73 with sprinkler activation and scenario 77 without sprinkler activation. As Figure 4.29 shows, the sprinkler activates $221 \mathrm{~s}$ in scenario 73 . At this time, the heat release rate reaches a maximum value of $0.54 \mathrm{MW}$ and starts to decrease, and goes to zero by $800 \mathrm{~s}$. In scenario 77 , the sprinkler system is not activated; the HRR in the room rises rapidly and reach the value of $6 \mathrm{MW}$ in $673 \mathrm{~s}$.

Figure 4.30 shows that the upper layer temperature in the compartment of fire origin for the two scenarios. The figure shows that the upper layer temperature starts to decrease at the time of sprinkler activation. The upper layer temperature in the compartment of fire origin only reaches $162^{\circ} \mathrm{C}$ at $270 \mathrm{~s}$ in scenario 73 . However, the upper layer smoke temperature of scenario 77 increases from ambient temperature to $600^{\circ} \mathrm{C}$ the temperature of flashover in $551 \mathrm{~s}$ and continue to increase until the end of the simulation reaches 1381 ${ }^{\circ} \mathrm{C}$.

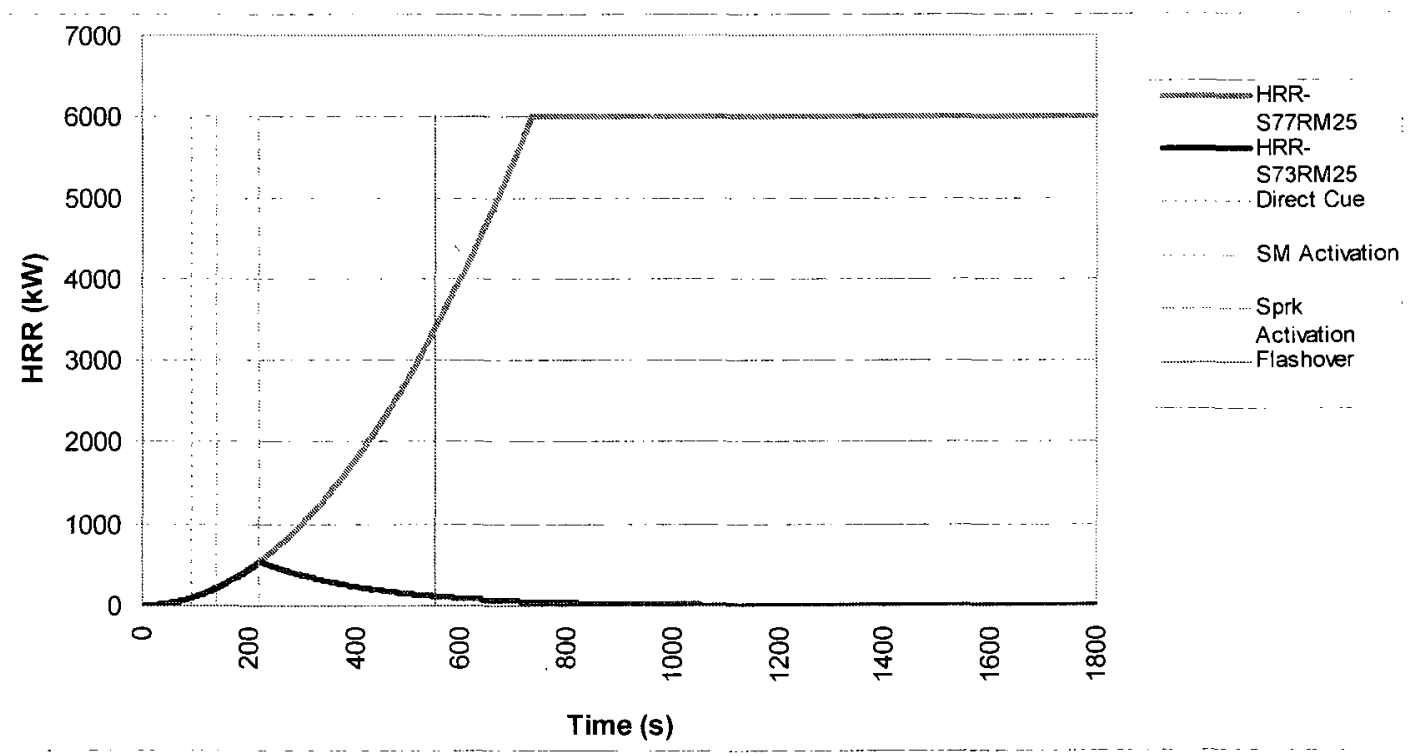

Figure 4.29: HRR Curves of Scenario 77 and Scenario 73 of Design Option A 


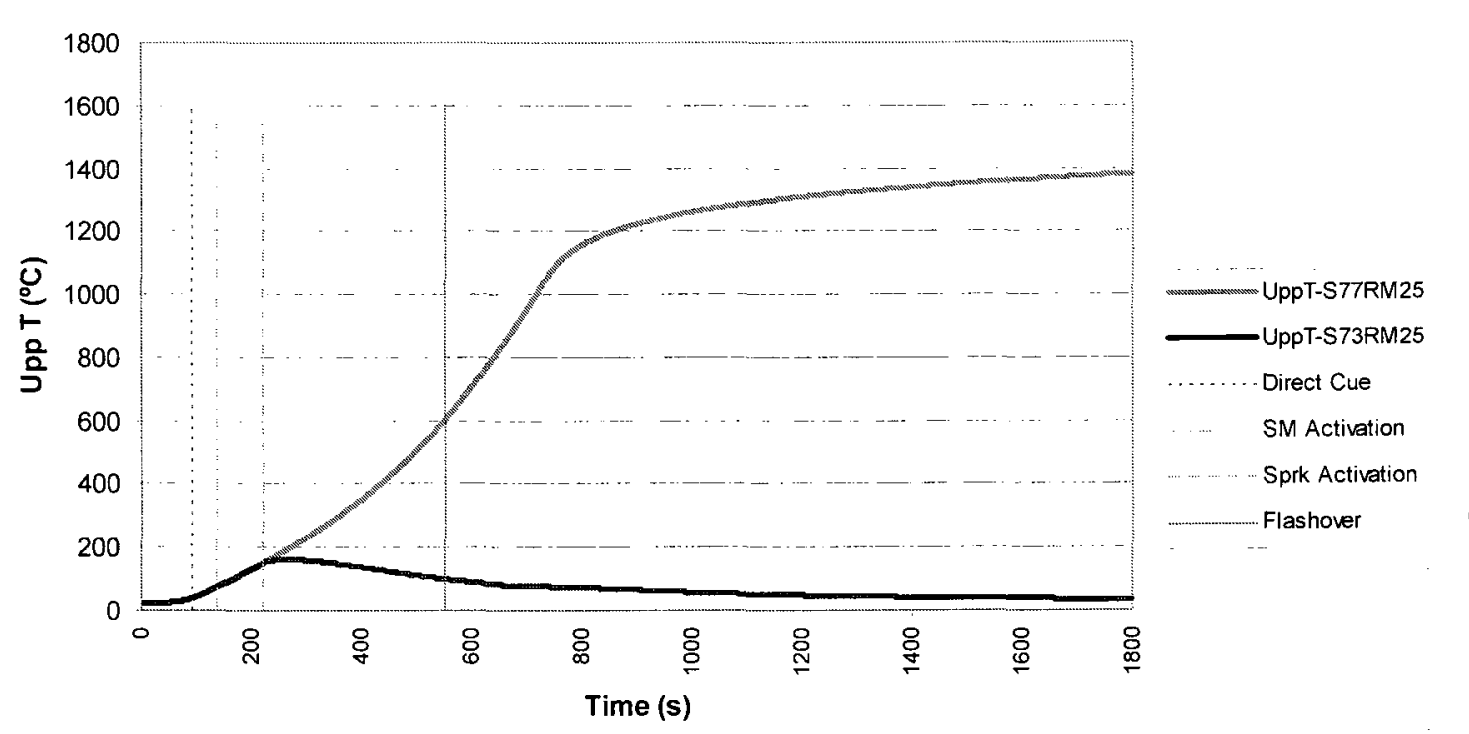

Figure 4.30: Upper Layer Temperature of the Compartment of Fire Origin of Scenario 77 and Scenario 73 of Design Option A

\subsubsection{Occupant response}

CUrisk categorizes occupants in the building into three groups: 1) occupants in the fire compartment $(\mathrm{OAC}) ; 2$ ) occupants in the adjacent compartments to the fire origin (OAC); 3) occupants in the other compartments (OOC).

Building occupants will perform different actions after realizing that there is a fire in the building. Occupants in the fire compartment (OAC) may do the following actions: call the fire department, pull the pull-station to trigger the central alarm, warn occupants in the adjacent and other compartments, and evacuate the building. The occupants in the adjacent compartments (OAC) may call fire department, warn occupants in the other compartments and evacuate. The occupants in the other compartments (OOC) may call 
the fire department and evacuate. The predicted cumulative probabilities of occupant response are calculated in the model based on the fire development and times of key events, occupant characteristics, and their relative locations in the building.

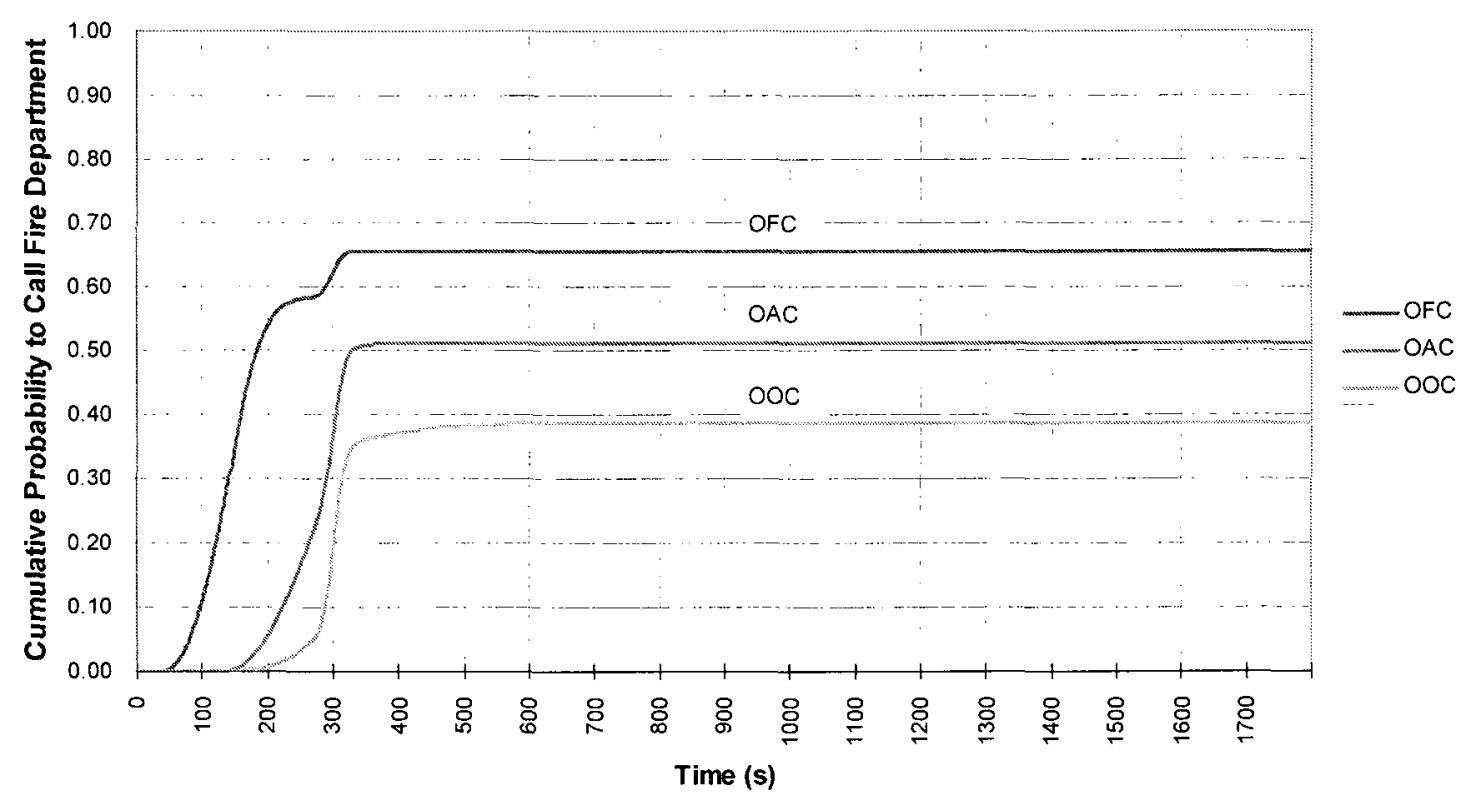

Figure 4.31: Cumulative Probabilities of Occupant Response - To Call Fire Department of Scenario 77, Design Option A

Figure 4.31 shows the predicted cumulative probabilities of occupants calling the fire department for Scenario 77, Design Option A. The cumulative probability that occupants in the compartment of fire origin call the fire department goes up $40 \mathrm{~s}$ after ignition and reaches 0.66 around the time of $320 \mathrm{~s}$. The probability of calling the fire department of occupants in the adjacent compartments starts to increase $80 \mathrm{~s}$ later than the probability of the occupants in the fire compartment and reaches a maximum value of 0.52 . The 
probability of calling the fire department by occupants in other compartments starts to increase $120 \mathrm{~s}$ after ignition and reaches a maximum value of 0.39 .

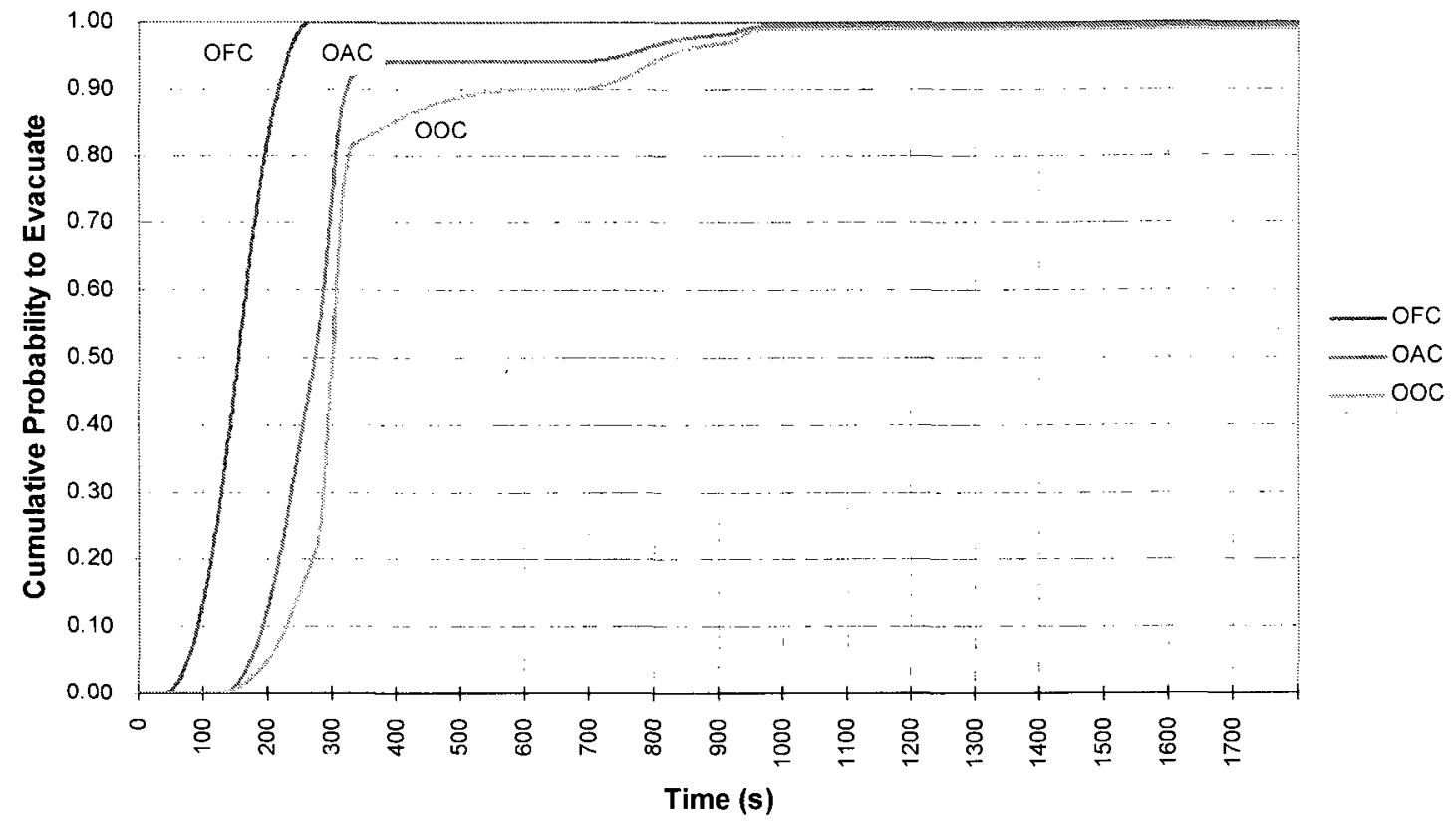

Figure 4.32: Cumulative Probabilities of Occupant Response - to Evacuate of Scenario 77,

\section{Design Option A}

Figure 4.32 shows the predicted cumulative probabilities of occupant response to evacuate the building of scenario 77, design option A. For the occupants in the compartment of fire origin, the cumulative probability to evacuate curve starts to increase at $40 \mathrm{~s}$ after fire ignition, and reaches 1.0 at $261 \mathrm{~s}$. The cumulative probabilities to evacuate for the occupants in the adjacent compartments and other compartments start at $120 \mathrm{~s}$ and increase as steeply as that for the occupant of the compartment of fire origin. The maximum cumulative probabilities to evacuate for occupants in both the adjacent compartments and other compartments reach 0.99 at $1000 \mathrm{~s}$ after fire ignition. 


\subsubsection{Evacuation process}

Evacuation starts at the time when an occupant decides to evacuate. CUrisk considers building geometry, occupant age and gender, smoke obscuration levels and population density in the egress routes, and predicts the location of each occupant during evacuation as a function of time [37].

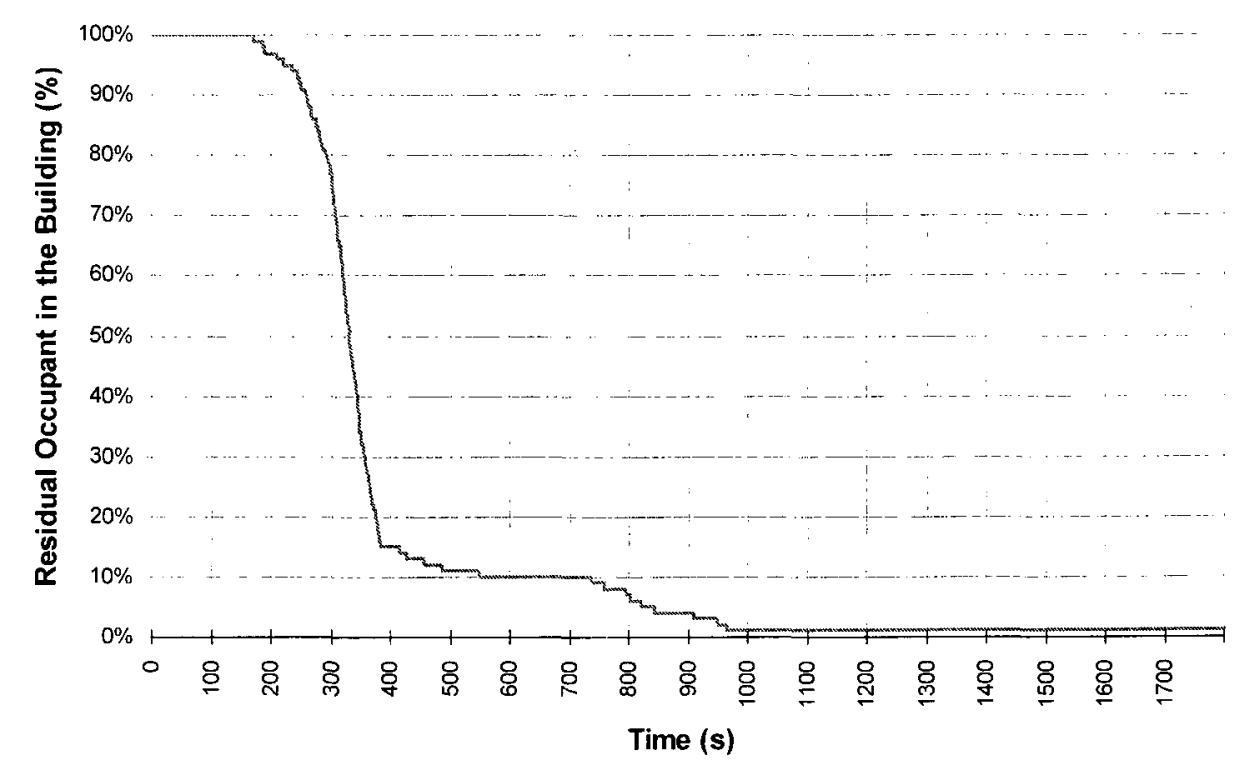

Figure 4.33: Evacuation Process - Residual Population in the Building of Scenario 77, Design Option A

Figure 4.33 shows the percentage of occupants still in the building during the evacuation process. The figure shows that the building evacuation starts at $150 \mathrm{~s}$ after the ignition. In the first $230 \mathrm{~s}$ of evacuation about $85 \%$ of the total occupants have successfully left the building. Then the rate of evacuation decreases and as a result the following $600 \mathrm{~s}$ an additional $14 \%$ of the occupants evacuate the building. The remaining 
$1 \%$ of the occupants (5 persons) stay in the building until the end of the simulation. This matches the occupant response curves of Figure 4.33 which shows that at the end of simulation time; $1 \%$ of the occupants did not decide to evacuate.

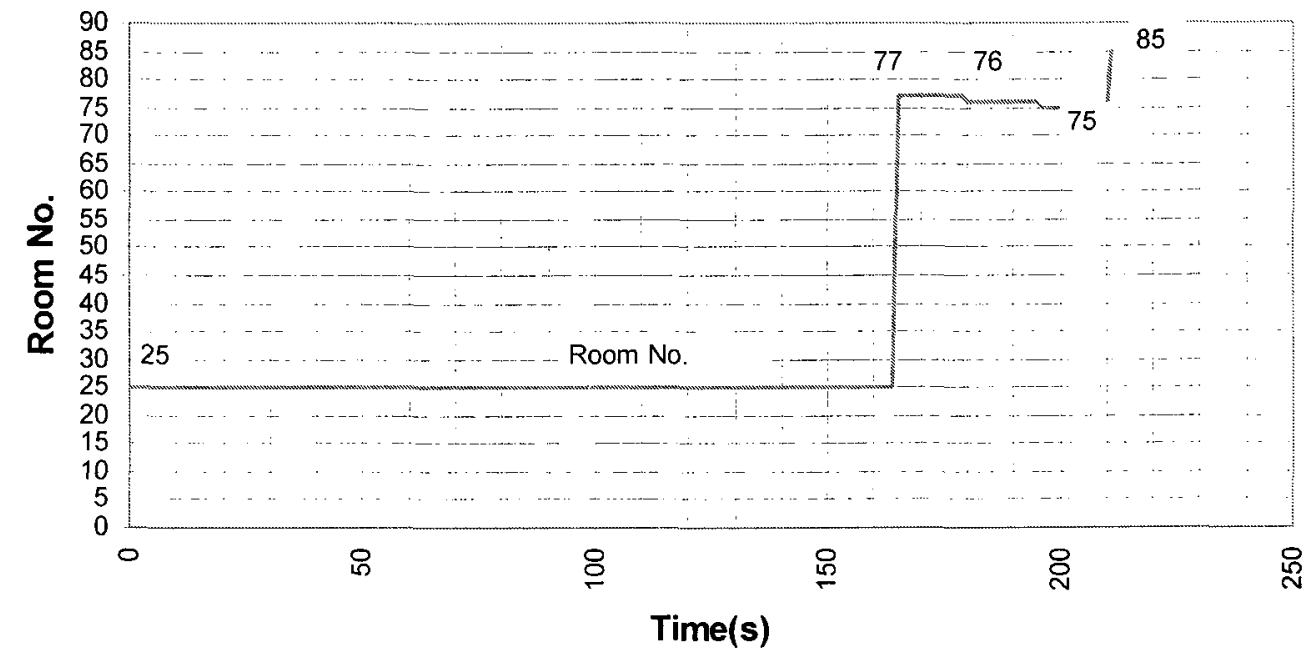

Figure 4.34: Evacuation Process - Individual Occupant

Figure 4.34 shows the predicted evacuation route of occupant \#19 during Scenario 77 of Design Option A. In this scenario, occupant \#19 is in the living room (room \#25) of the dwelling unit at the time of fire occurrence. This occupant stays in the room $\# 25$ until $164 \mathrm{~s}$ after ignition, and then he moves to the stairwell of the dwelling unit (Compartments \#77, \#76, \#75) at $165 \mathrm{~s}, 180 \mathrm{~s}$, and $196 \mathrm{~s}$ respectively. Occupant \#19 successfully evacuates the building to the outside (Compartment \#85) at $211 \mathrm{~s}$. 


\subsubsection{Probability of Death of a Occupant in the Building}

CUrisk calculates occupant casualties based on the fire and smoke conditions in the building, and occupant location. Figure 4.35 and Figure 4.36 show the probabilities of death of selected occupants of Scenario 77, Design Option A.

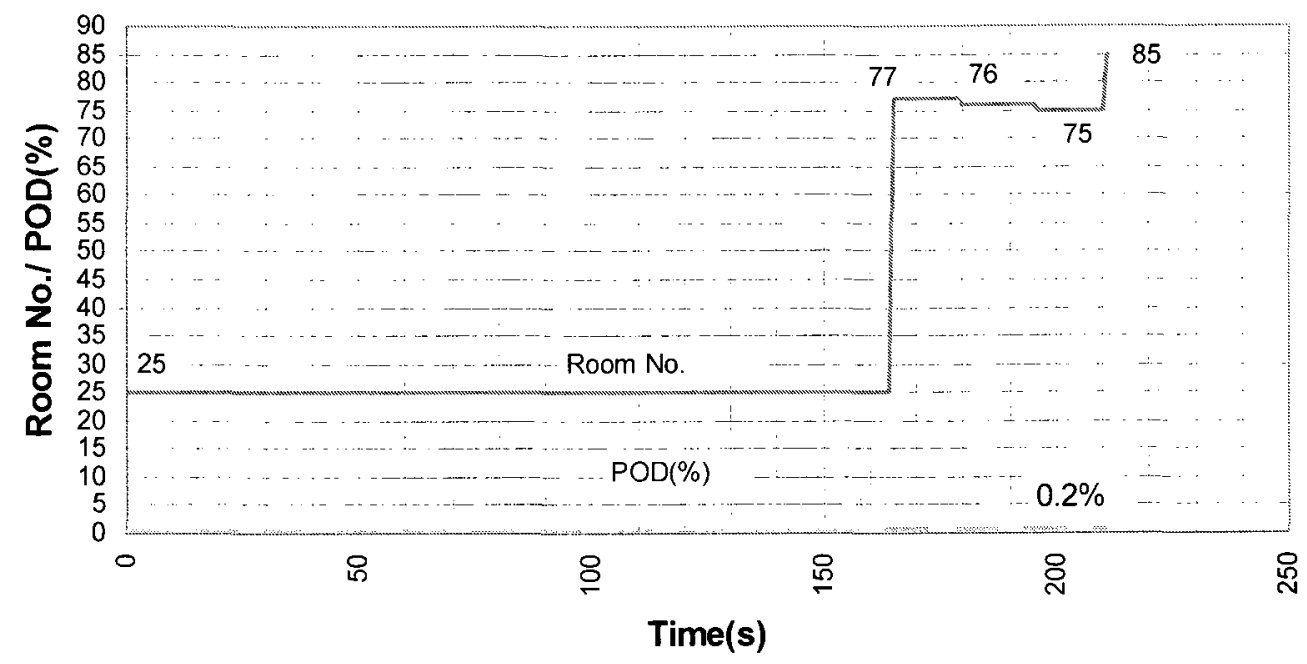

Figure 4.35: Probability of Death - Occupant \#19 of Scenario 77, Design Option A

Figure 4.35 shows the evacuation route of the occupant \#19 and the probability of death for this occupant as he moves through the building. This occupant evacuates the building in $211 \mathrm{~s}$ after ignition without any major injury. The maximum probability of death predicted for this occupant is $0.2 \%$. 


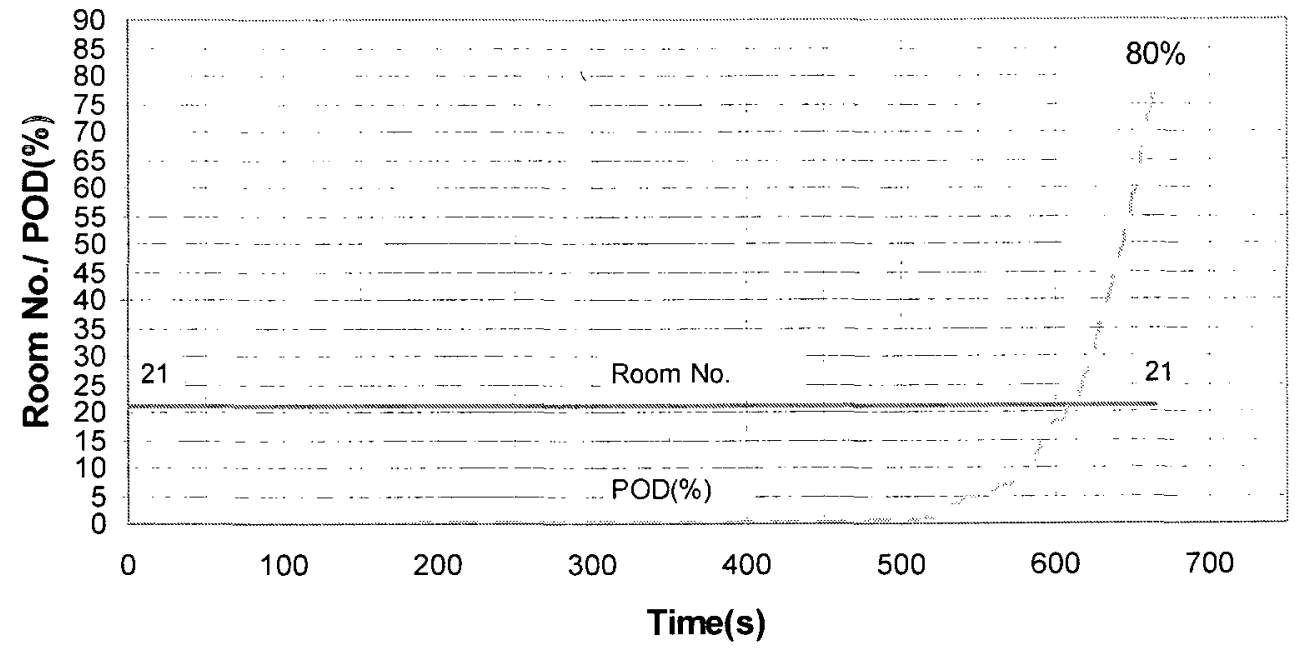

Figure 4.36: Probability of Death - Occupant \#17 of Scenario 77, Design Option A

Figure 4.36 shows the evacuation route of occupant \#17 and the probability of death as the result of the occupant being exposed to fire hazard conditions. The figure indicates that occupant $\# 17$ is trapped in room \#21. The victim suffers minor injury with a POD value of $0.1 \%$ from the time of $62 \mathrm{~s}$ in room $\# 21$. The probability of death for this occupant increases dramatically after 550 s and reaches the program predefined death threshold value of $80 \%$ at $665 \mathrm{~s}$.

\subsubsection{Damage to Building Property}

CUrisk predicts the direct fire losses by calculating the damage to the building, fire protection systems and building contents. 
Total Damages to the building

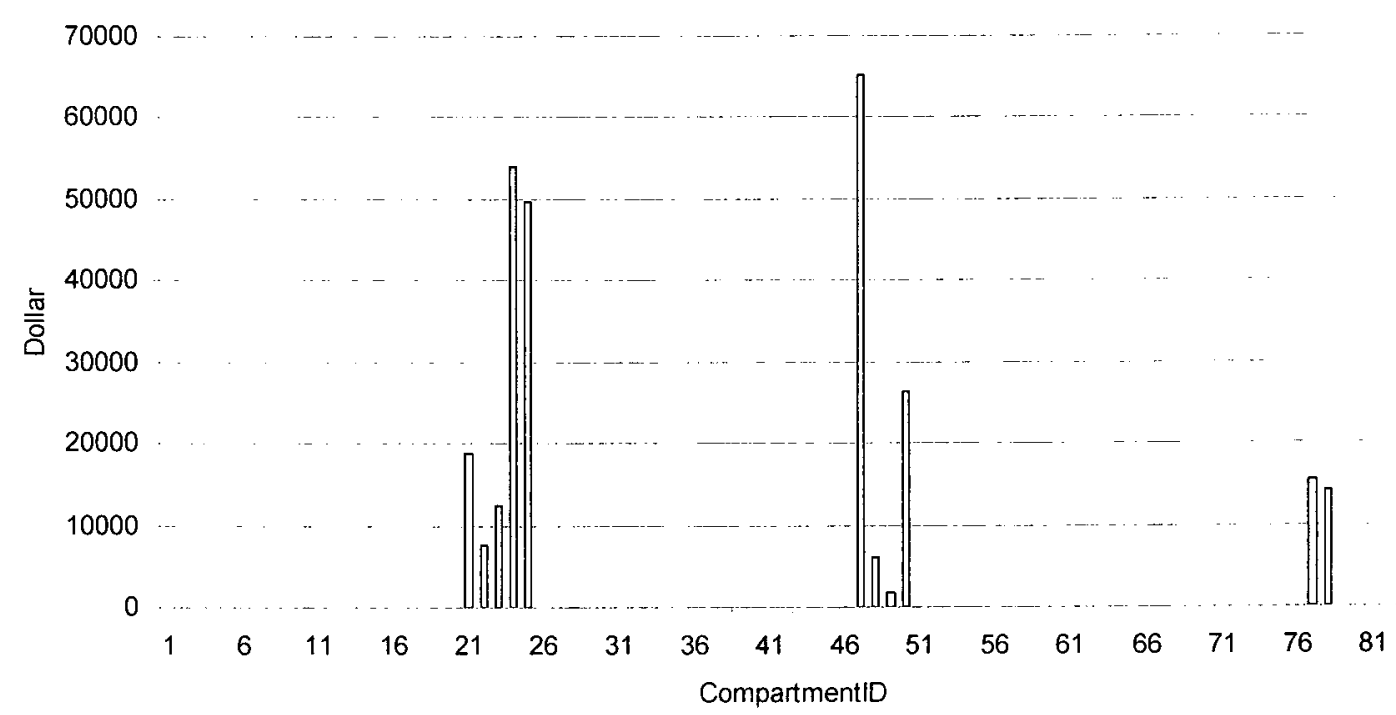

Figure 4.37: Total Damages to the Building of Scenario 77, Design Option A

Damages to Building and Fire protection Sytems

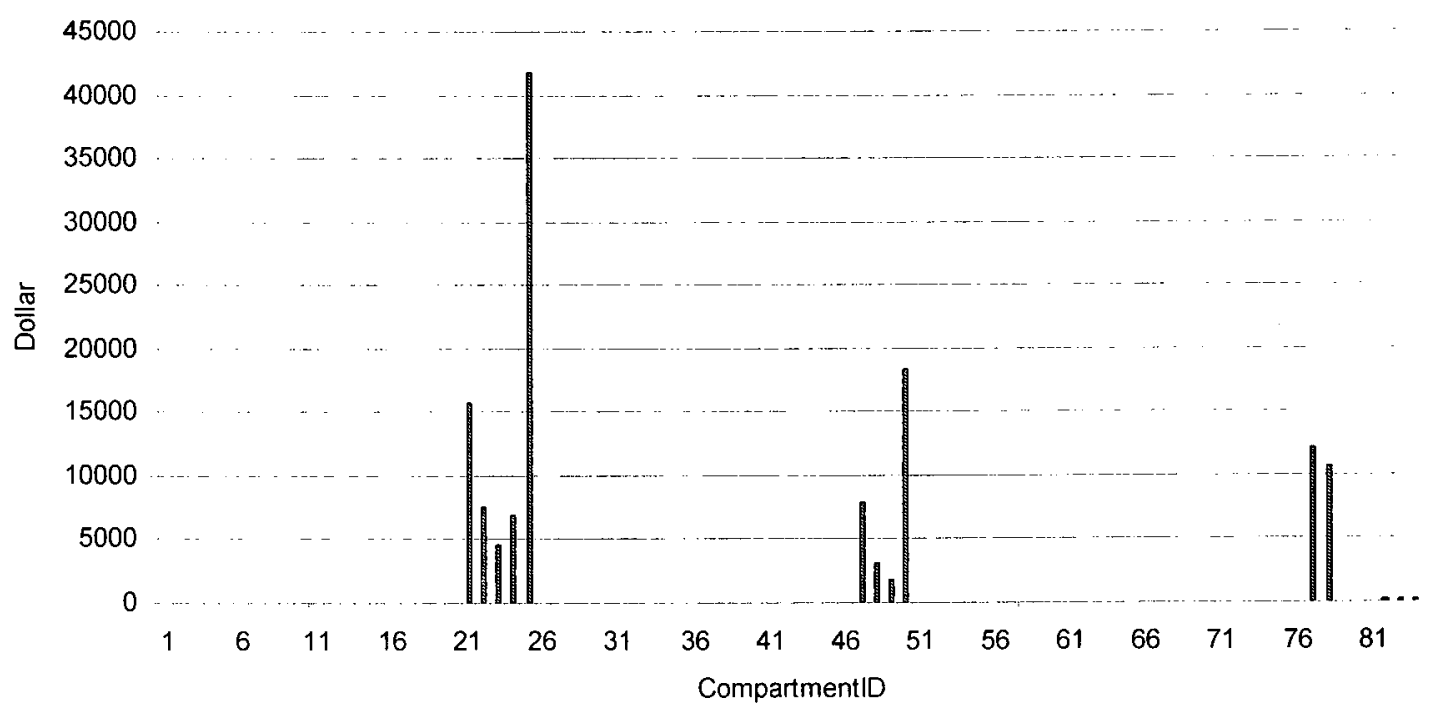

Figure 4.38: Damages to the Building and Fire Protection Systems of Scenario 77, Design Option A 


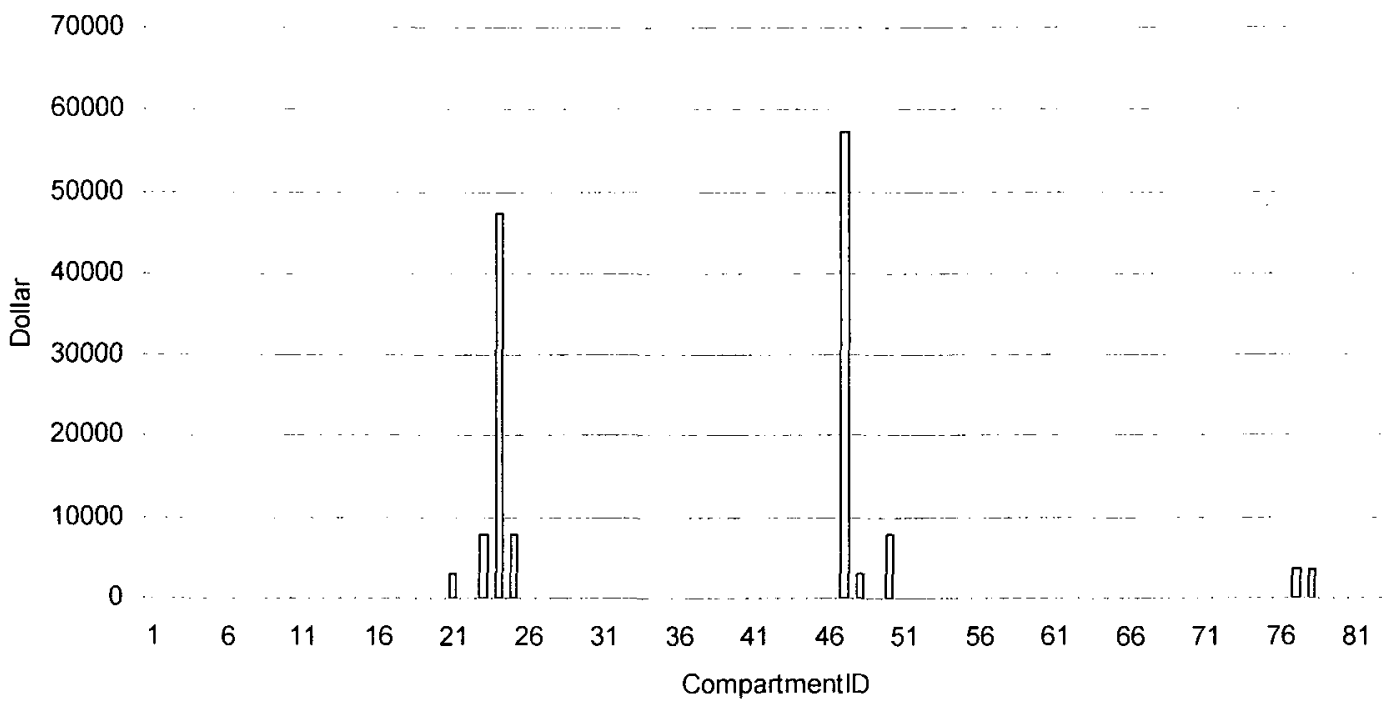

Figure 4.39: Damages to the Building Contents of Scenario 77, Design Option A

Figures 4.37-4.39 show the predicted total fire loss to the building, the damages to the building components and fire protection systems, and the damages to the building contents of each compartment of fire Scenario 77, Design Option A. It is found that in this scenario, the fire damages to the building property occur only in the dwelling unit of fire origin. In the compartment of the fire origin (Room \#25), the fire causes the highest damage to the building components and the fire protection devices in the room. The direct fire loss of Room \#25 is $\$ 46,549$ dollars. The compartment with the most building contents damage is Room \#47 (upstairs living room) with a content damage value of $\$ 57,300$ dollars. This is because smoke has spread to this compartment which has the highest building content value in the units. The dwelling unit stairwells (room\#77, \#78) also suffer damages of $\$ 13,005$ and $\$ 11,643$ dollars respectively. The cause of damages in stairwells is the high temperature of smoke. 


\subsubsection{Consequences of the case study}

Fire risk is the product of the probability of a scenario and its consequence. The objective of consequence evaluation is to quantify the negative impact of the fire in the risk analysis. CUrisk quantifies fire-induced impacts of a fire in terms of risk to life safety and risk of economic losses. It evaluates the consequences of fire for each scenario. The model evaluates the consequences to life safety and economic losses on the basis of the same scenario structures used in probability analysis shown in Figures 4.6-4.13. The consequences to the occupant life and economic fire losses of each design option calculated by the CUrisk model are outlined in the following Tables 4.25-4.32. Majority of damages for the sprinkler scenarios are due to damages to the contents in the commercial part of the building.

Table 4.25: Fire Consequence of Design option A

\begin{tabular}{|c|c|c|c|}
\hline Scenario \# & Num. of Death & Num. of Injury & Fire Loss(k\$/Fire) \\
\hline 1 & 0 & 0 & 445 \\
\hline 2 & 0 & 0 & 445 \\
\hline 3 & 0 & 0 & 445 \\
\hline 4 & 0 & 0 & 445 \\
\hline 5 & 0 & 0 & 687 \\
\hline 6 & 0 & 0 & 687 \\
\hline 7 & 0 & 0 & 687 \\
\hline 8 & 0 & 0 & 687 \\
\hline 9 & 0 & 0 & 445 \\
\hline 10 & 0 & 0 & 445 \\
\hline 11 & 0 & 0 & 445 \\
\hline 12 & 0 & 0 & 445 \\
\hline
\end{tabular}




\begin{tabular}{|c|c|c|c|}
\hline Scenario \# & Num. of Death & Num. of Injury & Fire Loss(k\$/Fire) \\
\hline 13 & 0 & 0 & 852 \\
\hline 14 & 0 & 0 & 852 \\
\hline 15 & 0 & 0 & 852 \\
\hline 16 & 0 & 0 & 852 \\
\hline 17 & 0 & 0 & 387 \\
\hline 18 & 0 & 0 & 387 \\
\hline 19 & 0 & 0 & 387 \\
\hline 20 & 0 & 0 & 387 \\
\hline 21 & 0 & 0 & 649 \\
\hline 22 & 0 & 0 & 649 \\
\hline 23 & 0 & 0 & 649 \\
\hline 24 & 0 & 0 & 649 \\
\hline 25 & 0 & 0 & 387 \\
\hline 26 & 0 & 0 & 387 \\
\hline 27 & 0 & 0 & 387 \\
\hline 28 & 0 & 0 & 387 \\
\hline 29 & 0 & 0 & 794 \\
\hline 30 & 0 & 0 & 794 \\
\hline 31 & 0 & 0 & 794 \\
\hline 32 & 0 & 0 & 794 \\
\hline 33 & 0 & 0 & 50 \\
\hline 34 & 0 & 0 & 50 \\
\hline 35 & 0 & 0 & 50 \\
\hline 36 & 0 & 0 & 50 \\
\hline 37 & 0 & 0 & 421 \\
\hline 38 & 0 & 0 & 421 \\
\hline 39 & 0 & 0 & 421 \\
\hline
\end{tabular}




\begin{tabular}{|c|c|c|c|}
\hline Scenario \# & Num. of Death & Num. of Injury & Fire Loss(k\$/Fire) \\
\hline 40 & 0 & 0 & 421 \\
\hline 41 & 0 & 0 & 50 \\
\hline 42 & 0 & 0 & 50 \\
\hline 43 & 0 & 0 & 50 \\
\hline 44 & 0 & 0 & 50 \\
\hline 45 & 0 & 0 & 792 \\
\hline 46 & 0 & 0 & 792 \\
\hline 47 & 0 & 0 & 792 \\
\hline 48 & 0 & 0 & 792 \\
\hline 49 & 0 & 0 & 114 \\
\hline 50 & 0 & 0 & 114 \\
\hline 51 & 0 & 0 & 114 \\
\hline 52 & 0 & 0 & 114 \\
\hline 53 & 0 & 2 & 598 \\
\hline 54 & 0 & 3 & 598 \\
\hline 55 & 0 & 2 & 598 \\
\hline 56 & 0 & 2 & 598 \\
\hline 57 & 0 & 0 & 114 \\
\hline 58 & 0 & 0 & 114 \\
\hline 59 & 0 & 0 & 114 \\
\hline 60 & 0 & 0 & 114 \\
\hline 61 & 0 & 2 & 911 \\
\hline 62 & 1 & 2 & 911 \\
\hline 63 & 0 & 1 & 911 \\
\hline 64 & 2 & 2 & 911 \\
\hline 65 & 0 & 0 & 116 \\
\hline 66 & 0 & 0 & 116 \\
\hline
\end{tabular}




\begin{tabular}{|c|c|c|c|}
\hline Scenario \# & Num. of Death & Num. of Injury & Fire Loss(k\$/Fire) \\
\hline 67 & 0 & 0 & 116 \\
\hline 68 & 0 & 0 & 116 \\
\hline 69 & 0 & 2 & 608 \\
\hline 70 & 0 & 2 & 608 \\
\hline 71 & 0 & 1 & 608 \\
\hline 72 & 0 & 2 & 608 \\
\hline 73 & 0 & 0 & 116 \\
\hline 74 & 0 & 0 & 116 \\
\hline 75 & 0 & 0 & 116 \\
\hline 76 & 0 & 0 & 116 \\
\hline 77 & 1 & 0 & 942 \\
\hline 78 & 2 & 0 & 942 \\
\hline 79 & 2 & 0 & 942 \\
\hline 80 & 2 & 0 & 942 \\
\hline
\end{tabular}


Table 4.26: Fire Consequence of Design option B

\begin{tabular}{|c|c|c|c|}
\hline Scenario \# & Num. of Death & Num. of Injury & Fire Loss(k\$/Fire) \\
\hline 1 & 0 & 0 & 436 \\
\hline 2 & 0 & 0 & 436 \\
\hline 3 & 0 & 0 & 679 \\
\hline 4 & 0 & 0 & 679 \\
\hline 5 & 0 & 0 & 436 \\
\hline 6 & 0 & 0 & 436 \\
\hline 7 & 0 & 0 & 845 \\
\hline 8 & 0 & 0 & 845 \\
\hline 9 & 0 & 0 & 378 \\
\hline 10 & 0 & 0 & 378 \\
\hline 11 & 0 & 0 & 642 \\
\hline 12 & 0 & 0 & 642 \\
\hline 13 & 0 & 0 & 378 \\
\hline 14 & 0 & 0 & 378 \\
\hline 15 & 0 & 0 & 787 \\
\hline 16 & 0 & 0 & 787 \\
\hline 17 & 0 & 0 & 48 \\
\hline 18 & 0 & 0 & 48 \\
\hline 19 & 0 & 0 & 420 \\
\hline 20 & 0 & 0 & 420 \\
\hline 21 & 0 & 0 & 50 \\
\hline 22 & 0 & 0 & 50 \\
\hline 23 & 0 & 0 & 786 \\
\hline 24 & 0 & 0 & 786 \\
\hline 25 & 0 & 0 & 113 \\
\hline 26 & 0 & 0 & 113 \\
\hline
\end{tabular}




\begin{tabular}{|c|c|c|c|}
\hline Scenario \# & Num. of Death & Num. of Injury & Fire Loss(k\$/Fire) \\
\hline 27 & 0 & 3 & 596 \\
\hline 28 & 0 & 3 & 596 \\
\hline 29 & 0 & 0 & 114 \\
\hline 30 & 0 & 0 & 114 \\
\hline 31 & 1 & 1 & 905 \\
\hline 32 & 1 & 2 & 905 \\
\hline 33 & 0 & 0 & 115 \\
\hline 34 & 0 & 0 & 606 \\
\hline 35 & 0 & 2 & 606 \\
\hline 36 & 0 & 3 & 116 \\
\hline 37 & 0 & 0 & 116 \\
\hline 38 & 0 & 0 & 935 \\
\hline 39 & 2 & 0 & 935 \\
\hline 40 & 2 & 0 & \\
\hline & & & 0 \\
\hline
\end{tabular}


Table 4.27: Fire Consequence of Design option C

\begin{tabular}{|c|c|c|c|}
\hline Scenario \# & Num. of Death & Num. of Injury & Fire Loss(kS/Fire) \\
\hline 1 & 0 & 0 & 941 \\
\hline 2 & 0 & 0 & 442 \\
\hline 3 & 0 & 0 & 685 \\
\hline 4 & 0 & 0 & 685 \\
\hline 5 & 0 & 0 & 442 \\
\hline 6 & 0 & 0 & 442 \\
\hline 7 & 0 & 0 & 851 \\
\hline 8 & 0 & 0 & 851 \\
\hline 9 & 0 & 0 & 384 \\
\hline 10 & 0 & 0 & 384 \\
\hline 11 & 0 & 0 & 648 \\
\hline 12 & 0 & 0 & 648 \\
\hline 13 & 0 & 0 & 384 \\
\hline 14 & 0 & 0 & 384 \\
\hline 15 & 0 & 0 & 793 \\
\hline 16 & 0 & 0 & 793 \\
\hline 17 & 0 & 0 & 48 \\
\hline 18 & 0 & 0 & 48 \\
\hline 19 & 0 & 0 & 420 \\
\hline 20 & 0 & 0 & 420 \\
\hline 21 & 0 & 0 & 50 \\
\hline 22 & 0 & 0 & 50 \\
\hline 23 & 0 & 0 & 792 \\
\hline 24 & 0 & 0 & 792 \\
\hline 25 & 0 & 0 & 114 \\
\hline 26 & 0 & 0 & 114 \\
\hline
\end{tabular}




\begin{tabular}{|c|c|c|c|}
\hline Scenario \# & Num. of Death & Num. of Injury & Fire Loss(kS/Fire) \\
\hline 27 & 0 & 1 & 597 \\
\hline 28 & 0 & 3 & 597 \\
\hline 29 & 0 & 0 & 114 \\
\hline 30 & 0 & 0 & 114 \\
\hline 31 & 0 & 2 & 911 \\
\hline 32 & 1 & 1 & 911 \\
\hline 33 & 0 & 0 & 116 \\
\hline 34 & 0 & 0 & 116 \\
\hline 35 & 0 & 2 & 608 \\
\hline 36 & 0 & 1 & 608 \\
\hline 37 & 0 & 0 & 116 \\
\hline 38 & 0 & 0 & 116 \\
\hline 39 & 2 & 0 & 941 \\
\hline 40 & 2 & 0 & 941 \\
\hline
\end{tabular}


Table 4.28: Fire Consequence of Design option D

\begin{tabular}{|c|c|c|c|}
\hline Scenario \# & Num. of Death & Num. of Injury & Fire Loss(k\$/Fire) \\
\hline 1 & 0 & 0 & 435 \\
\hline 2 & 0 & 0 & 676 \\
\hline 3 & 0 & 0 & 435 \\
\hline 4 & 0 & 0 & 842 \\
\hline 5 & 0 & 0 & 377 \\
\hline 6 & 0 & 0 & 639 \\
\hline 7 & 0 & 0 & 377 \\
\hline 8 & 0 & 0 & 784 \\
\hline 9 & 0 & 0 & 48.23 \\
\hline 10 & 0 & 0 & 420 \\
\hline 11 & 0 & 0 & 49 \\
\hline 12 & 0 & 0 & 786 \\
\hline 13 & 0 & 0 & 113 \\
\hline 14 & 0 & 3 & 596 \\
\hline 15 & 0 & 0 & 114 \\
\hline 16 & 2 & 2 & 904 \\
\hline 17 & 0 & 0 & 115 \\
\hline 18 & 0 & 2 & 606 \\
\hline 19 & 0 & 0 & 115 \\
\hline 20 & 2 & 0 & 934 \\
\hline
\end{tabular}


Table 4.29: Fire Consequence of Design option $E$

\begin{tabular}{|c|c|c|c|}
\hline Scenario \# & Num. of Death & Num. of Injury & Fire Loss(k\$/Fire) \\
\hline 1 & 0 & 0 & 924 \\
\hline 2 & 0 & 0 & 649 \\
\hline 3 & 0 & 0 & 649 \\
\hline 4 & 0 & 0 & 649 \\
\hline 5 & 0 & 0 & 814 \\
\hline 6 & 0 & 0 & 814 \\
\hline 7 & 0 & 0 & 814 \\
\hline 8 & 0 & 0 & 814 \\
\hline 9 & 0 & 0 & 612 \\
\hline 10 & 0 & 0 & 612 \\
\hline 11 & 0 & 0 & 612 \\
\hline 12 & 0 & 0 & 612 \\
\hline 13 & 0 & 0 & 756 \\
\hline 14 & 0 & 0 & 756 \\
\hline 15 & 0 & 0 & 756 \\
\hline 16 & 0 & 0 & 756 \\
\hline 17 & 0 & 0 & 414 \\
\hline 18 & 0 & 0 & 414 \\
\hline 19 & 0 & 0 & 414 \\
\hline 20 & 0 & 0 & 414 \\
\hline 21 & 0 & 0 & 776 \\
\hline 22 & 0 & 0 & 776 \\
\hline 23 & 0 & 0 & 776 \\
\hline 24 & 0 & 0 & 776 \\
\hline 25 & 0 & 2 & 584 \\
\hline 26 & 0 & 4 & 584 \\
\hline
\end{tabular}




\begin{tabular}{|c|c|c|c|}
\hline Scenario \# & Num. of Death & Num. of Injury & Fire Loss(k\$/Fire) \\
\hline 27 & 0 & 1 & 584 \\
\hline 28 & 0 & 3 & 584 \\
\hline 29 & 0 & 2 & 894 \\
\hline 30 & 0 & 2 & 894 \\
\hline 31 & 0 & 2 & 894 \\
\hline 32 & 1 & 1 & 894 \\
\hline 33 & 0 & 2 & 593 \\
\hline 34 & 0 & 2 & 593 \\
\hline 35 & 0 & 2 & 593 \\
\hline 36 & 0 & 2 & 593 \\
\hline 37 & 2 & 0 & 924 \\
\hline 38 & 2 & 0 & 924 \\
\hline 39 & 2 & 0 & 924 \\
\hline 40 & 2 & 0 & 924 \\
\hline
\end{tabular}


Table 4.30: Fire Consequence of Design option $F$

\begin{tabular}{|c|c|c|c|}
\hline Scenario \# & Num. of Death & Num. of Injury & Fire Loss(k\$/Fire) \\
\hline 1 & 0 & 0 & 934 \\
\hline 2 & 0 & 0 & 676 \\
\hline 3 & 0 & 0 & 842 \\
\hline 4 & 0 & 0 & 842 \\
\hline 5 & 0 & 0 & 639 \\
\hline 6 & 0 & 0 & 639 \\
\hline 7 & 0 & 0 & 784 \\
\hline 8 & 0 & 0 & 784 \\
\hline 9 & 0 & 0 & 420 \\
\hline 10 & 0 & 0 & 420 \\
\hline 11 & 0 & 0 & 786 \\
\hline 12 & 0 & 0 & 786 \\
\hline 13 & 0 & 3 & 596 \\
\hline 14 & 0 & 2 & 596 \\
\hline 15 & 2 & 2 & 904 \\
\hline 16 & 1 & 2 & 904 \\
\hline 17 & 0 & 2 & 606 \\
\hline 18 & 0 & 2 & 606 \\
\hline 19 & 2 & 0 & 934 \\
\hline 20 & 2 & 0 & 934 \\
\hline
\end{tabular}


Table 4.31: Fire Consequence of Design option G

\begin{tabular}{|c|c|c|c|}
\hline Scenario \# & Num. of Death & Num. of Injury & Fire Loss(k\$/Fire) \\
\hline 1 & 0 & 0 & 571 \\
\hline 2 & 0 & 0 & 646 \\
\hline 3 & 0 & 0 & 812 \\
\hline 4 & 0 & 0 & 812 \\
\hline 5 & 0 & 0 & 609 \\
\hline 6 & 0 & 0 & 609 \\
\hline 7 & 0 & 0 & 754 \\
\hline 8 & 0 & 0 & 754 \\
\hline 9 & 0 & 0 & 414 \\
\hline 10 & 0 & 0 & 414 \\
\hline 11 & 0 & 0 & 774 \\
\hline 12 & 0 & 0 & 774 \\
\hline 13 & 0 & 3 & 583 \\
\hline 14 & 0 & 2 & 583 \\
\hline 15 & 0 & 2 & 892 \\
\hline 16 & 1 & 2 & 892 \\
\hline 17 & 0 & 2 & 592 \\
\hline 18 & 0 & 2 & 592 \\
\hline 19 & 2 & 0 & 922 \\
\hline 20 & 2 & 0 & 922 \\
\hline
\end{tabular}


Table 4.32: Fire Consequence of Design option $H$

\begin{tabular}{|c|c|c|c|}
\hline Scenario \# & Num. of Death & Num. of Injury & Fire Loss(kS/Fire) \\
\hline 1 & 0 & 0 & 564 \\
\hline 2 & 0 & 0 & 803 \\
\hline 3 & 0 & 0 & 602 \\
\hline 4 & 0 & 0 & 746 \\
\hline 5 & 0 & 0 & 414 \\
\hline 6 & 0 & 0 & 771 \\
\hline 7 & 0 & 3 & 582 \\
\hline 8 & 2 & 2 & 888 \\
\hline 9 & 0 & 2 & 590 \\
\hline 10 & 2 & 0 & 918 \\
\hline
\end{tabular}




\subsection{Risk calculation}

CUrisk calculates the risk to building occupants for all expected fire scenarios using Equation 4.2

$$
R=\sum_{i=1}^{n}\left(P_{i} \times C_{i}\right)
$$

Where:

$$
\begin{aligned}
& n-\text { total number of senarios } \\
& \mathrm{i}-\text { scenario counter, } \mathrm{i}=1 \text { to } \mathrm{n} \\
& \mathrm{P}_{\mathrm{i}} \text {-Probability of fire scenario } \mathrm{i} \\
& \mathrm{C}_{\mathrm{i}} \text {-Consequences of fire scenario } \mathrm{i}
\end{aligned}
$$

The risk calculated by Equation 4.2 is the absolute risk given in terms of potential occupant life loss per year and potential economical loss per year for each design option in the building. CUrisk calculates two risk parameters: the expected risk to life (ERL) and the fire cost expectation (FCE) to reflect risks to life safety and property damages from all expected fires in the building.

ERL is defined as the expected death frequency per year divided by the building population.

$$
E R L=\frac{F \sum_{i=1}^{n}\left(P_{i} \times N_{i}\right)}{P O P}
$$

Equation 4.3

The expected risk of occupant injury (EROI) is defined as the expected injury frequency per year divided by the building population. 


$$
E R O I=\frac{F \sum_{i=1}^{n}\left(P_{i} \times M_{i}\right)}{P O P}
$$

Where:

$\mathrm{F}$ - Annual fire frequency of building, $\mathrm{F}=5.3 \times 10^{-2} /$ year, refer to Table 4.21 .

$\mathrm{i}$ - Number of scenarios, $\mathrm{i}=1$ to $\mathrm{n}$, refer to Figures $4.15-4.22$ scenario structure of design options.

$P_{i}$ - Probability of scenario $i$, refer to Figures $4.15-4.22$ for scenario probability of design options.

$N_{i}$ - Number of death of scenario i, refer to Tables 4-4.34 for fire consequences of design options.

$M_{i}$ - Number of injuries of scenario $i$, refer to Tables 4-4.34 for fire consequences of design options.

POP - Number of occupants in the building, $\mathrm{POP}=358$, refer to Table 4.2 Occupant Load of Building.

FCE is defined as the total fire cost of the building over the design life in years over total building investment calculated using Equation 4.5.

$$
F C E=\operatorname{COS} T_{\text {lixed }}+D L\left[C O S T_{\text {Maint ain }}+F \sum_{i=1}^{n}\left(P_{i} \times E_{i}\right)\right] \quad \text { Equation } 4.5
$$

Where: 
$\operatorname{COST}_{\text {Fixed }}$ - Fixed capital investment of active and passive fire protection systems, $\operatorname{COST}_{\text {Fixed }}$ - values of each design option can be obtained from the Building Cost submodel.

DL - Design life in years of the building, user input ( $\mathrm{DL}=50$ years in this study).

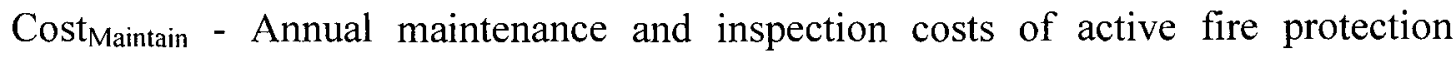
systems. Maintenance costs of each design option are obtained from the Building Cost submodel.

$P_{i}$ - Probability of scenario i, refer to Figures $4.15-4.22$ for scenario probability of design options

$E_{i}$ - Economic loss of scenario i, refer to Tables 4-4.34 for fire consequence of Design option $\mathrm{A} \sim \mathrm{H}$

F - Annual fire frequency of building, $F=5.3 \times 10^{-2} /$ year, refer to Table 4.21 for fire ignition probability for the case study building

$\left.F \sum_{i=1}^{n}\left(P_{i} \times E_{i}\right)\right]-$ represent the expected annual fire losses as a result of all possible fire scenarios in the building.

The results obtained by CUrisk for the eight fire safety design options are shown in Table 4.33 
Table 4.33: Fire Risks of Eight Design Options

\begin{tabular}{|c|c|c|c|c|c|c|}
\hline Option & $\begin{array}{c}\text { ERL } \\
(\mathbf{p} / \mathbf{y})\end{array}$ & $\begin{array}{c}\text { EROI } \\
(\mathbf{p} / \mathbf{y})\end{array}$ & $\begin{array}{c}\text { FCE } \\
(\mathbf{k \$} / \mathbf{5 0 y})\end{array}$ & $\begin{array}{c}\mathbf{C o s t}_{\text {Fix }} \\
(\mathbf{k S})\end{array}$ & $\begin{array}{c}\text { Cost }_{\text {Main }} \\
(\mathbf{k S / y})\end{array}$ & $\begin{array}{c}\text { FireLoss } \\
(\mathbf{k S / y})\end{array}$ \\
\hline$A$ & $1.057 \mathrm{E}-07$ & $1.058 \mathrm{E}-06$ & 2586.49 & 1579.00 & 6.00 & 14.18 \\
\hline B & $3.148 \mathrm{E}-07$ & $1.172 \mathrm{E}-06$ & 2424.56 & 1525.44 & 4.00 & 13.97 \\
\hline C & $1.634 \mathrm{E}-07$ & $8.310 \mathrm{E}-07$ & 2773.59 & 1566.44 & 5.70 & 18.48 \\
\hline D & $4.829 \mathrm{E}-07$ & $1.313 \mathrm{E}-06$ & 2395.12 & 1512.88 & 3.70 & 13.93 \\
\hline E & $2.966 \mathrm{E}-06$ & $2.168 \mathrm{E}-05$ & 3362.26 & 1240.83 & 3.40 & 38.89 \\
\hline F & $9.322 \mathrm{E}-06$ & $2.575 \mathrm{E}-05$ & 3367.71 & 1185.79 & 3.70 & 39.94 \\
\hline G & $3.269 \mathrm{E}-06$ & $2.575 \mathrm{E}-05$ & 3172.93 & 1226.80 & 3.10 & 35.84 \\
\hline H & $9.658 \mathrm{E}-06$ & $2.626 \mathrm{E}-05$ & 3005.72 & 1173.24 & 1.10 & 35.52 \\
\hline
\end{tabular}

Figures 4.40 and 4.41 shows the calculated expected risk to life (ERL) and fire cost expectation (FCE) values of the eight proposed design options normalized by dividing them by the corresponding values of the code-complying design option $\mathrm{C}$. The purpose of this case study is to identify a cost-effective design alternative with a low lifetime fire cost expectation for the building that provides a life safety level equivalent or better than the code-complying design option. 


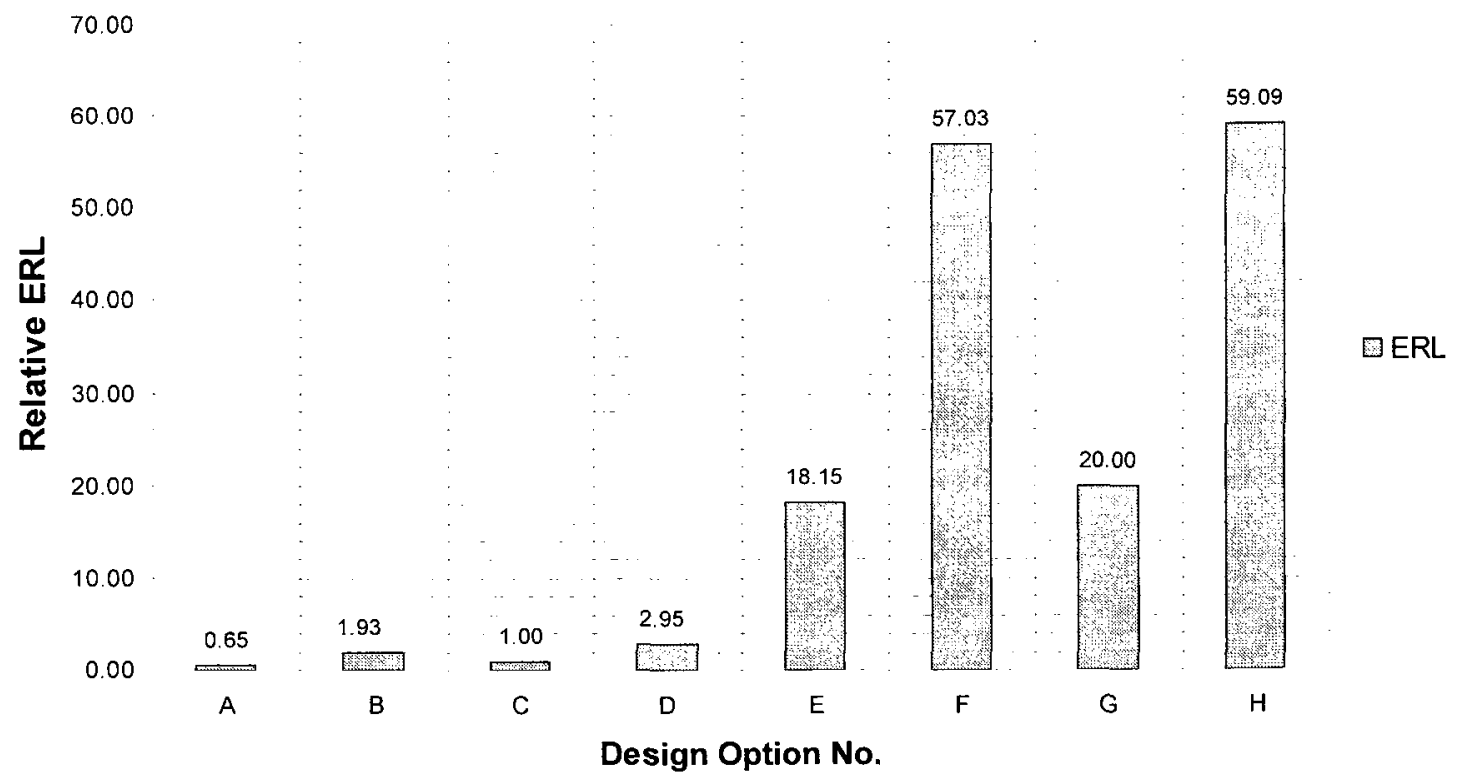

Figure 4.40: Relative ERL of Design Options

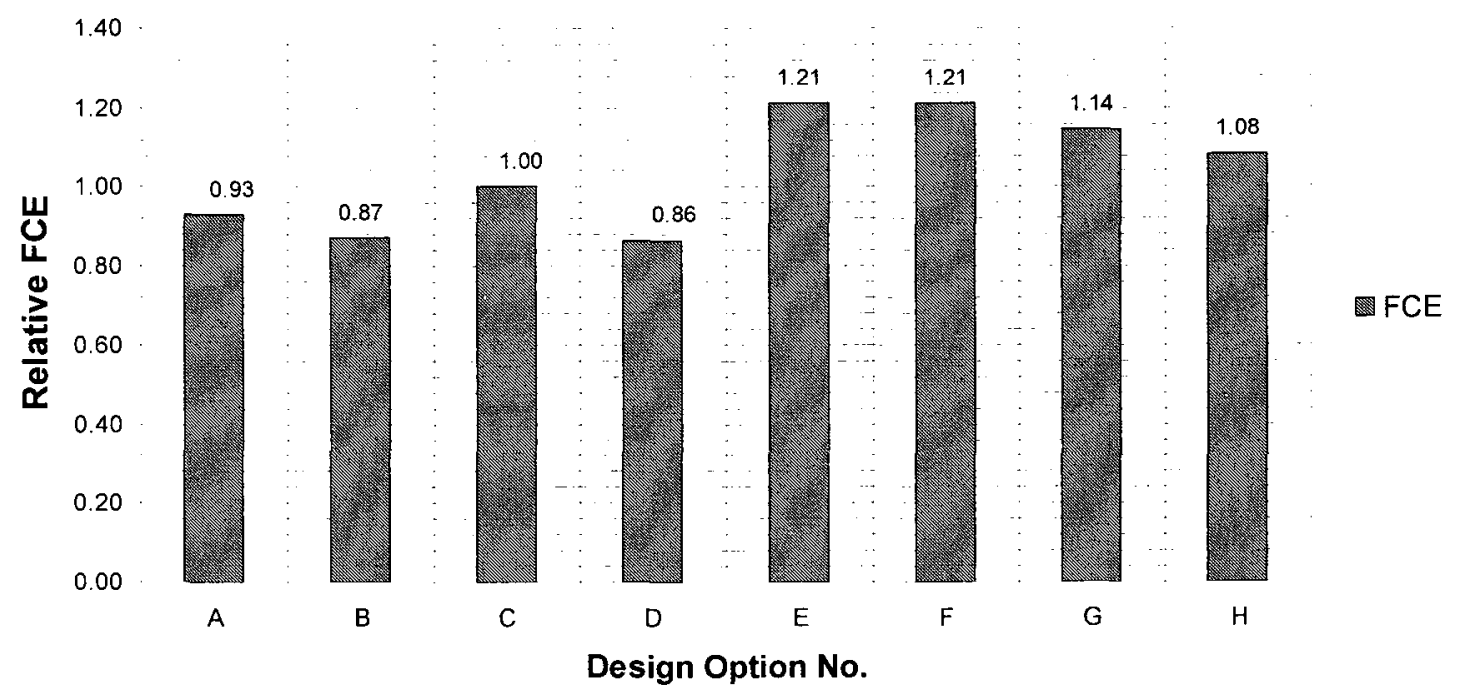

Figure 4.41: Relative FCE of Design Options 
The risk analysis calculations above indicate one cost effective design option for the case study building. The cost-effective design alternative is identified as design option A, by which the case study building is protected with an automatic sprinkler system, local smoke detectors and a central fire alarm system. This option has a normalized relative ERL of 0.65 and a relative FCE of 0.93 , which means that with this design option A, the total fire cost over the design life (50 years) is $7 \%$ lower than that of the code-complying reference design option $\mathrm{C}$, and the risk to life will be $35 \%$ less. Comparing with the reference design option, design option A greatly improves occupant life safety in this building with $187.1 \mathrm{k} \$$ less fire cost expectation in 50 years. 


\section{Chapter 5: RESULTS ANALYSIS AND DISCUSSION}

The validation of a comprehensive fire risk model such as CUrisk is difficult task for a number of reasons. First, the fire phenomenon and the occupant response and evacuation process in a building are complicated problems which involve numerous interactive factors including building characteristics, fire characteristics, occupant response and performances of fire protection measures. Secondly, it is also impossible to perform any controlled experiment on the system to verify the fire impact in term of risk to human life. Hence, the accuracy of the model seems impossible to be determined by theoretical analysis. The methods used for model validation in of this section include:

1) Qualitative examination of simulation results by engineering judgment

2) Comparing simulation results with statistical data found in literature 


\subsection{Risks Comparison by Occupancy Classification}

\subsubsection{Statistical Data of Risk to Life by Building Occupancies}

Table 5.1 summarises the statistical data of occupant death rates due to fires found in the literature. These data are used to compare with CUrisk simulation results.

Table 5.1: Statistical Data of Death Rate by Building Occupancies

\begin{tabular}{|c|c|c|c|c|c|c|c|}
\hline Occupancy & $\begin{array}{l}\text { Death/ } \\
\text { P.Year }\end{array}$ & $\begin{array}{l}\text { Death/ } \\
\text { P.Year }\end{array}$ & $\begin{array}{l}\text { Death/ } \\
\text { P.Year }\end{array}$ & $\begin{array}{l}\text { Death/ } \\
\text { P.Year }\end{array}$ & $\begin{array}{l}\text { Death/ } \\
\text { P.Year }\end{array}$ & $\begin{array}{l}\text { Death/ } \\
\text { P.Year }\end{array}$ & $\begin{array}{l}\text { Death/ } \\
\text { P.Year }\end{array}$ \\
\hline Mercantile & & & & $\mathrm{n} / \mathrm{a}$ & & & \\
\hline Office/Banking & & & & $0 \mathrm{E}+00$ & & & \\
\hline Residential & $2 \mathrm{E}-05$ & & & $\begin{array}{l}5.90 \mathrm{E}- \\
05\end{array}$ & & & $\begin{array}{c}2 \sim 3 E- \\
05\end{array}$ \\
\hline $\begin{array}{l}\text { Institutional/Publi } \\
\text { c Admin. }\end{array}$ & & & & $1 \mathrm{E}-06$ & & & \\
\hline Hotel & & & & $\begin{array}{c}1.28 \mathrm{E}- \\
05\end{array}$ & & & \\
\hline School & & & & $0 \mathrm{E}+00$ & & & \\
\hline Further Education & & & & $0 \mathrm{E}+00$ & & & \\
\hline Hospital & & & & $\mathrm{n} / \mathrm{a}$ & & & \\
\hline Industrial & & & & $\mathrm{n} / \mathrm{a}$ & & & \\
\hline Overall & & $\begin{array}{c}1.31 \mathrm{E}- \\
05\end{array}$ & $\begin{array}{c}1.09 \mathrm{E}- \\
05\end{array}$ & & $\begin{array}{c}1.31 \mathrm{E}- \\
05\end{array}$ & $1 \mathrm{E}-06$ & \\
\hline Year & 2007 & 2002 & 2002 & 1995 & 1999 & 1999 & 2000 \\
\hline Region & US & US & Canada & UK & US & Canada & Sweden \\
\hline Data Source & [48] & {$[1]$} & {$[1]$} & {$[51]$} & [39] & [39] & [49] \\
\hline
\end{tabular}




\subsubsection{Calculated Risk to Life of Case Study Building}

The results of the predicted risk to life safety for the fire safety design options considered by CUrisk are summarized in Table 5.2. These results are expressed in terms of the ERL and EROI and the units in the tables are the death or injuries rate per person per year respectively.

Table 5.2: Calculated risk to life safety of Case Study Building

\begin{tabular}{|c|c|c|c|c|c|}
\hline $\begin{array}{c}\text { Design } \\
\text { Option \# }\end{array}$ & Sprinkler & $\begin{array}{c}\text { Smoke } \\
\text { Alarm }\end{array}$ & $\begin{array}{c}\text { Central } \\
\text { Alarm }\end{array}$ & ERL & EROI \\
\hline A & Y & Y & Y & $1.057 \mathrm{E}-07$ & $1.058 \mathrm{E}-06$ \\
\hline B & Y & Y & - & $3.148 \mathrm{E}-07$ & $1.172 \mathrm{E}-06$ \\
\hline C & Y & - & Y & $1.634 \mathrm{E}-07$ & $8.310 \mathrm{E}-07$ \\
\hline D & Y & - & - & $4.829 \mathrm{E}-07$ & $1.313 \mathrm{E}-06$ \\
\hline E & - & Y & Y & $2.966 \mathrm{E}-06$ & $2.168 \mathrm{E}-05$ \\
\hline F & - & Y & & $9.322 \mathrm{E}-06$ & $2.575 \mathrm{E}-05$ \\
\hline G & - & - & Y & $3.269 \mathrm{E}-06$ & $2.575 \mathrm{E}-05$ \\
\hline H & - & - & - & $9.658 \mathrm{E}-06$ & $2.626 \mathrm{E}-05$ \\
\hline
\end{tabular}

In order to verify the accuracy of the simulation results, these results are further broken down by occupancy and shown in the Tables 5.3-5.5.

Table 5.3: Calculated Risk to Life Safety of Case Study Building - Mercantile

\begin{tabular}{|c|c|c|c|c|c|}
\hline $\begin{array}{c}\text { Design } \\
\text { Option \# }\end{array}$ & Sprinkler & $\begin{array}{c}\text { Smoke } \\
\text { Alarm }\end{array}$ & $\begin{array}{c}\text { Central } \\
\text { Alarm }\end{array}$ & ERL & EROI \\
\hline A & Y & Y & Y & $00 \mathrm{E}+00$ & $00 \mathrm{E}+00$ \\
\hline B & Y & Y & - & $00 \mathrm{E}+00$ & $00 \mathrm{E}+00$ \\
\hline C & Y & - & Y & $00 \mathrm{E}+00$ & $00 \mathrm{E}+00$ \\
\hline D & Y & - & - & $00 \mathrm{E}+00$ & $00 \mathrm{E}+00$ \\
\hline E & - & Y & Y & $00 \mathrm{E}+00$ & $00 \mathrm{E}+00$ \\
\hline F & - & Y & & $00 \mathrm{E}+00$ & $00 \mathrm{E}+00$ \\
\hline G & - & - & Y & $00 \mathrm{E}+00$ & $00 \mathrm{E}+00$ \\
\hline
\end{tabular}




\begin{tabular}{|c|l|l|l|l|l|}
\hline $\mathrm{H}$ & - & - & - & $00 \mathrm{E}+00$ & $00 \mathrm{E}+00$ \\
\hline
\end{tabular}

Table 5.4: Calculated Risk to Life Safety of Case Study Building - Office

\begin{tabular}{|c|c|c|c|c|c|}
\hline $\begin{array}{c}\text { Design } \\
\text { Option \# }\end{array}$ & Sprinkler & $\begin{array}{c}\text { Smoke } \\
\text { Alarm }\end{array}$ & $\begin{array}{c}\text { Central } \\
\text { Alarm }\end{array}$ & ERL & EROI \\
\hline A & Y & Y & Y & $00 \mathrm{E}+00$ & $00 \mathrm{E}+00$ \\
\hline B & Y & Y & - & $00 \mathrm{E}+00$ & $00 \mathrm{E}+00$ \\
\hline C & Y & - & Y & $00 \mathrm{E}+00$ & $00 \mathrm{E}+00$ \\
\hline D & Y & - & - & $00 \mathrm{E}+00$ & $00 \mathrm{E}+00$ \\
\hline E & - & Y & Y & $00 \mathrm{E}+00$ & $00 \mathrm{E}+00$ \\
\hline F & - & Y & & $00 \mathrm{E}+00$ & $00 \mathrm{E}+00$ \\
\hline G & - & - & Y & $00 \mathrm{E}+00$ & $00 \mathrm{E}+00$ \\
\hline H & - & - & - & $00 \mathrm{E}+00$ & $00 \mathrm{E}+00$ \\
\hline
\end{tabular}

Table 5.5: Calculated Risk to Life Safety of Case Study Building - Residential

\begin{tabular}{|c|c|c|c|c|c|}
\hline $\begin{array}{c}\text { Design } \\
\text { Option \# }\end{array}$ & Sprinkler & $\begin{array}{c}\text { Smoke } \\
\text { Alarm }\end{array}$ & $\begin{array}{c}\text { Central } \\
\text { Alarm }\end{array}$ & ERL & EROI \\
\hline A & Y & Y & Y & $7.886 \mathrm{E}-07$ & $7.893 \mathrm{E}-06$ \\
\hline B & Y & Y & - & $2.348 \mathrm{E}-06$ & $8.745 \mathrm{E}-06$ \\
\hline C & Y & - & Y & $1.219 \mathrm{E}-06$ & $6.198 \mathrm{E}-06$ \\
\hline D & Y & - & - & $3.602 \mathrm{E}-06$ & $9.791 \mathrm{E}-06$ \\
\hline E & - & Y & Y & $2.212 \mathrm{E}-05$ & $1.617 \mathrm{E}-04$ \\
\hline F & - & Y & & $6.952 \mathrm{E}-05$ & $1.921 \mathrm{E}-04$ \\
\hline G & - & - & Y & $2.438 \mathrm{E}-05$ & $1.921 \mathrm{E}-04$ \\
\hline H & - & - & - & $7.203 \mathrm{E}-05$ & $1.958 \mathrm{E}-04$ \\
\hline
\end{tabular}

To compare the statistical data listed in Table 5.1 with the simulation results of design option $\mathrm{F}$ is chosen because most the residential units in Canada do not have central alarm systems and sprinkler systems but they are equipped with smoke detectors. 
The predicted results in Tables 5.3-5.5 show that there is no occupant death in the mercantile and office occupancies. All fire deaths are found in the residential scenarios. These results agree well with the statistical data. Juneja [39] analyzed fire data in Ontario between 1995 2002 and concluded that residential fires account for 95\% occupants death in all occupancies, mercantile occupancy accounts for only $1 \%$ of the occupant fatality, and there is no fatal fire incident found in office (business and personal services) occupancy. Charters [51] examined the fire and other statistical data of U.K. between 1993 1996 and reaches a similar conclusion. In his paper, Charters presented a fire death rate index to evaluate the risk level presented by various occupancies expressed as number of deaths per year. He reports that the death rate in the residential (single dwelling) occupancy is $5.9 \times 10^{-5}$ persons per year. There is no occupant death fire incident found in the office (banking) occupancy in this period of time. Fire fatality data for mercantile occupancy is not available in Charters report.

The results of the simulation are expected due to the design of the case study building. In the mercantile section, there are a total of twelve exit doors opening directly to both the north and south streets. These doors provide adequate egress exits in case of a fire incident.

The office occupancy on the second floor has similar egress route conditions. There are two dedicated egress stairwells designed at each end of the open office space. These 2.4-meter wide stairs are capable of evacuating all the people in this area before the room conditions became untenable for the occupants. 
The residential units in the case study building are separated by 1-hr rated fire walls; hence fire spread is not an issue in this simulation. From Table 5.7, the prediction of risk to life safety in the residential occupancy, the calculated fire death rate of residential occupancy protected by local smoke detectors only (design option F) is $6.95 \times 10^{-5}$ person per year. This value is in good agreement with the statistical data of $2.95 \times 10^{-5}$ person per year found in U.S literature [48] and $5.90 \times 10^{-5}$ person per year in the U.K [51]. 


\subsection{Comparison of Risks of Different Fire Protection Measures}

\subsubsection{Risk data for different Fire Protection Measures}

The risk reduction data due to fire protection measures are sparse in the literature. NFPA reports $[43,44]$ provide comprehensive investigations on the performance of automatic sprinkler systems, as well as smoke alarms and other fire detection equipment. Juneja [39] reviewed the impact of fire protection systems in residential dwellings based on Ontario fatality data for 1995-2002. Butry et al. [48] analyzed NFIRS 5.0/NFPA adjusted data of 2002-2005 for U.S dwellings with different fire protection measures.

However, these data are collected primarily for the effectiveness of a single fire protection measure. The performance of a fire safety design option with multiple fire protection measures are rarely reported. In addition, these data are often reported for certain type of building occupancy. The methods of data collection and the units of data in the literature are not consistent, thus the collected statistics should be interpreted with caution.

Table 5.6 shows the relationship of reduction of death and fire protection measures installed in residential occupancies. In order to compare the performance of different fire protection measures, the statistical data found in the literature are normalized to the nonprotection option. The normalized statistical data of effectiveness of fire protection are shown in the Table 5.7. 
Table 5.6: Reduction of Death in Relation to Fire Protection Measures in Residential

Occupancies

\begin{tabular}{|c|c|c|c|c|c|}
\hline Data Source & {$[48]$} & {$[39]$} & {$[51]$} & {$[49]$} & {$[49]$} \\
\hline Units & Death/P.Year & Death/Fire & $\%$ & Death/P.Year & Death/P.Year \\
\hline SPRK+SM+CA & & & & & \\
\hline SPRK+SM & $0 \mathrm{E}+00$ & - & $69 \%$ & & $2.75 \mathrm{E}-05$ \\
\hline SPRK+CA & & & & & \\
\hline SPRK & & & $28 \sim 100 \%$ & & $3.89 \mathrm{E}-05$ \\
\hline SM+CA & & & & & $4.95 \mathrm{E}-05$ \\
\hline SM & $2.95 \mathrm{E}-05$ & $8.20 \mathrm{E}-02$ & & & \\
\hline CA & & & & & $7.02 \mathrm{E}-05$ \\
\hline None & $3.42 \mathrm{E}-05$ & $9 \mathrm{E}-02$ & $100 \%$ & $2 \sim 3 \mathrm{E}-05$ & \\
\hline
\end{tabular}

Table 5.7: Normalized Reduction of Fire Death in Relation to Fire Protection Measures in Residential Occupancies

\begin{tabular}{|c|c|c|c|c|c|}
\hline Data Source & {$[48]$} & {$[39]$} & {$[51]$} & {$[49]$} & {$[49]$} \\
\hline SPRK+SM+CA & - & - & - & - & - \\
\hline SPRK+SM & 0 & - & 0.69 & $0.18 \sim 0.23$ & - \\
\hline SPRK+CA & - & - & - & - & - \\
\hline SPRK & - & - & - & 0.31 & 0.55 \\
\hline SM+CA & - & - & - & - & - \\
\hline SM & 0.86 & 0.86 & $0.28 \sim 1.0$ & 0.52 & 0.71 \\
\hline CA & - & - & - & - & - \\
\hline None & 1 & 1 & 1 & 1 & 1 \\
\hline
\end{tabular}

Note: SPRK- Sprinkler 
SM - Local Smoke Alarm

CA - Central Alarm

\subsubsection{Calculated Risk to Life Safety by Fire Protection Measures}

The CUrisk calculated risk to life (ERL) due to fire when no active fire protection measure in residential occupancies is $7.203 \times 10^{-5}$ deaths/person.year. To compare the performance of different fire safety design options proposed for the case study building, the design option $\mathrm{H}$ in which there is no active fire protection is used as the base design option. The performance of all other design alternatives is compared with this design option. The normalized risks to life values of the eight design options of the case study are shown Table 5.8.

Table 5.8: Normalized Fire Risk to Life safety of the Design Options

\begin{tabular}{|c|c|c|c|c|c|}
\hline $\begin{array}{c}\text { Design } \\
\text { Option \# }\end{array}$ & Sprinkler & $\begin{array}{c}\text { Smoke } \\
\text { Alarm }\end{array}$ & $\begin{array}{c}\text { Central } \\
\text { Alarm }\end{array}$ & $\begin{array}{c}\text { ERL } \\
\text { (P/Year) }\end{array}$ & $\begin{array}{c}\text { EROI } \\
\text { (P/Year) }\end{array}$ \\
\hline A & Y & Y & Y & 0.011 & 0.040 \\
\hline B & Y & Y & - & 0.033 & 0.045 \\
\hline C & Y & - & Y & 0.017 & 0.032 \\
\hline D & Y & - & - & 0.050 & 0.050 \\
\hline E & - & Y & Y & 0.307 & 0.826 \\
\hline F & - & Y & & 0.965 & 0.981 \\
\hline G & - & - & Y & 0.338 & 0.981 \\
\hline H & - & - & - & 1 & 1 \\
\hline
\end{tabular}

Table 5.8 shows that local smoke detectors slightly reduce occupant fire death and injury rate. In design option $\mathrm{F}$, by which the case study building is protected with local smoke alarm only, the expected risk to life is only reduced by $3.5 \%$ to the value of $96.5 \%$. 
This number is lower than the past experience of risk reduction of local smoke alarms which is reduces the fire risk to occupants to about $1 / 3$. But with the consideration of the simulation conditions that fire starts at daytime and occupants are awake when the fire starts, the predicted results of design option $\mathrm{F}$ are considered reasonable.

Table 5.8 shows that the central alarm lowered the risk to life too. As the centralized fire alarm system not only detects fire and notifies the occupants in the fire compartment, the system also alerts the people away from the fire room and initiates evacuation throughout the building at an early time. Table 5.8 shows that for design option G, the death rate is reduced to $33.8 \%$. During the time of this study, there is no statistical data found in the literature to make a comparison.

Table 5.8 shows that the central alarm plus local smoke detectors design option has a slightly better performance than that of a central alarm alone in terms of fire death rate. The installation of a central fire alarm system and an additional smoke detector in the building, increase the reliability of fire detection and hence reduces the risk to life safety. The results show that for design option $\mathrm{E}$, the death rate is reduced to $30.7 \%$ from $33.8 \%$ the calculated value for the central alarm only option. As this central alarm plus local smoke detectors design option is an assumed design alternative which is rarely adopted in engineering practice, there is no such statistical data found in the literature to make a comparison.

The automatic sprinkler system has a significant effect on the risk to life results. As shown in Table 5.8, if the building is sprinkler protected, the predicted death rate is reduced to $5.0 \%$ of the value of the non-protection design option. This indicates that the 
sprinkler system offers much better performance against the fire than the other systems, because the sprinkler system is able to detect the fire in the early stages and to control the fire size effectively. Statistical data reported in the literature also indicate a considerable improvement of the building fire performance due to the installation of an automatic sprinkler system. The calculated results compared well with the normalized statistical fire death rate value of $0.0 \sim 55 \%$.

The local smoke detectors plus sprinkler design option B shows a better performance on death rate reduction due to fire. The normalized death rate of option B is reduced to $3.3 \%$ compared to the value of $5 \%$ from the sprinklers only option D. In addition to the performance of an automatic sprinkler system, the smoke alarm provides earlier fire detection and alarm warning to the occupants in the fire compartment, thus increasing the time available for safe evacuation. These results compare well with statistical data of normalized fire death rate of $0 \sim 23 \%$ shown in Table 5.7 .

The central smoke alarm plus sprinkler design option $\mathrm{C}$ shows a better performance on death rate reduction than design option $\mathrm{B}$. The normalized death rate of option $\mathrm{C}$ is reduced to $1.8 \%$ compared with the value of $3.3 \%$ from sprinkler and local smoke detectors option B. This is due to the reliability of detection and occupant response probability as discussed above for design options $\mathrm{F}$ and $\mathrm{G}$.

Design option A is an assumed design option which is not commonly adopted in fire protection engineering practice. The fire risk evaluation of this design alternative is presented here for comparison purposes only. Design option A provides the most comprehensive fire protection to the building as it includes installation of an automatic 
sprinkler system, a central fire detection and alarm system, and additional local smoke detectors. Table 5.8 shows that design option A has the highest fire death rate reduction of all eight design alternatives. The normalized death rate of design option $\mathrm{A}$ is reduced to $1.1 \%$.

\subsection{Summary}

In the previous sections, the predicted fire risk to occupant life (ERL) predicted by CUrisk for eight design options for a case study building has been compared with statistical fire risk data found in the literature. Comparisons were done of absolute risks for different occupancies, and relative risk reduction due to the presence of fire protection systems.

The results of the analysis indicate that the predictions made by CUrisk compare well with fire risk pattern reported in the literature. Residential dwellings have the highest fire death rate among all the three occupancies considered. There is no occupant fatality in the mercantile and office occupancies in this case study, a result that agrees with the statistical fire data. Considering the performance of fire protection measures, the life risk of the design options with fire protection measures is lower than that of the design option with no fire protection measures. In the case study building, the performance of a central fire alarm system is better than that of local smoke detectors, because the central fire alarm system not only has a higher operational reliability than ordinary local smoke alarm systems, but it is also able to alert the occupants away from the fire room and initiate evacuation throughout the building at an early time, thus reducing the possibility of occupants to encounter lethal conditions. Among the three fire protection measures 
chosen as a comparison in the study, the automatic sprinkler system has the greatest impact on fire risk.

The predictions of CUrisk compare well with statistical data in terms of fire risk to life safety. In the above analysis, the calculated ERL of eight design options were broken down by occupancies and they compared well with statistical fire risk data of the U.S and Canada. The relative performance of fire protection measures also compares well with statistical data. 


\section{Chapter 6: CONCLUSION AND RECOMMENDATIONS}

\subsection{Conclusions}

A new fire risk analysis computer model CUrisk developed at Carleton University has been presented. The framework and the theory of CUrisk have been described together with the theory of the various submodels.

The applicability of CUrisk has been evaluated by conducting a fire risk assessment case study of a real building: a multi-occupancy wood frame building situated in the urban area of Ottawa. A relative risk comparison approach was used to identify the costeffective design option from different proposed design alternatives.

The simulation results were examined using past engineering experience and comparisons with statistical data. The results of this study show that CUrisk predictions of risk levels are realistic and reasonable. The calculated absolute risk to life safety compares well with statistical data found in the literature.

As with the statistical data, the study results show that the residential occupancy has the highest death rate among all the occupancies in the case study building. There was no scenario in the office and mercantile occupancies in this study that caused deaths. The predictions of CUrisk also show that the use of active fire protection measures reduces fire risk in the building. In general, a central fire detection and alarm system provides 
better performance in reducing fire risk to occupant life safety than local smoke alarms. Automatic sprinkler systems have the greatest impact on reducing fire risk in the building.

\subsection{Future Work}

This study explored several aspects of using CUrisk to conduct fire risk assessment for performance-based fire protection design of buildings. The results indicate that CUrisk is a useful tool in fire safety engineering practice. It can be utilized to compare the risk levels for existing, renovated and new buildings, and it can be used to identify cost-effective fire protection design alternatives.

To improve CUrisk, the following recommendations are made and warrant further investigation:

1) Develop a fire spread submodel and integrate it into CUrisk

CUrisk needs a submodel to calculate the probability of fire spread in the building. Such a model could predict the number of casualties resulting from direct exposure to flames due to fire spread after flashover. At the time of this case study, the fire spread submodel of CURisk was still under development, and therefore the risk to life and property estimated in this case study excludes those caused by fire spread in the building. A file with a sparse matrix has been created manually to represent the fire spread probability from the fire compartment to any other compartment in the building. In order to provide better estimation of risks both to occupant life and property losses, it is necessary to develop and integrate into CUrisk a fire spread model. 
2) Improvement of the smoke model

CUsmoke calculates the spread of smoke and toxic gases in the building. The results of this submodel are used to calculate the number of deaths and injuries in a fire scenario. In the case study, it was found that in some worst case scenarios, the upper layer gas temperatures of the kitchen were $20 \sim 30 \%$ higher than published experimental data. These excessively high gas temperatures were all found during the post-flashover stage. At this time, the flows of air and combustion gases become very turbulent in the room, and it is unlikely that the upper layer and the lower layer are still separated. It is recommended to develop a module of CUsmoke using a single zone approach to model the post-flashover stage.

3) Improvement of occupant response model

It was found in the case study that occupants in other rooms of the residential unit other than the compartment of fire were not alerted by the local smoke alarm. This may result in an overestimation of the risk to occupant life safety. The occupant response submodel should be modified so that occupants in the same unit but not in the compartment of fire are considered as occupants of the compartment of fire in the calculation of the occupant response probabilities.

4) Uncertainty and Sensitivity Analysis

CUrisk assesses fire risk in a building using both deterministic and probabilistic approaches. This model incorporates a large number of design and fire parameter, which 
have uncertainties associated with them. To ensure the robustness and the quality of the model, an uncertainty and sensitivity analysis study is recommended in the future to estimate the variation in the output with respect the variation in the input of the model. 


\section{REFERENCES}

[1] John R. Hall, Jr., "Fire in U.S and Canada", National Fire Protection Association, www.nfpa.org/assets/files/PDF/osuscanada.pdf

[2] Hadjisophocleous, G.V. and Benichou, N, "Development of performance-based codes, performance criteria and fire safety engineering methods", NRCC-43976, [3] Hadjisophocleous,G.V. , and Fu, Z., "Report On The Fire Risk Assessment System Model", Internal Report, Carleton University, 2002

[4] "SFPE Handbook of Fire Protection Engineering", Third Edition, NFPA, 2002

[5] Dobbernack, R. "Fire Risk Assessment Methods", IBMB, 2003

[6] "SFPE Engineering guide to application of fire risk assessment in fire protection design", SFPE, 2005

[7] Frantzich, H. "Risk analysis and fire safety engineering", Fire Safety Journal, 31, pp $313-329,1998$

[8] Barry, T., "Risk-Informed, Performance-Based Industrial Fire Protection", Tennessee Valley Publication, 2002

[9] "NFPA 551: Evaluation of Fire Risk Assessments", NFPA, 2007 [10] "ASTM E1776-07 Standard Guide for Development of Fire-Risk-Assessment Standards “, ASTM, 2007 
[11] "ISO/TS 16732- Fire Safety Engineering - Guidance on fire risk assessment “, ISO, 2005

[12] John R. Hall, Jr., "Overview of standards for fire risk assessment", Fire Science and Technology, Vol.25 No.2, pp55-62, 2006

[13] Hadjisophocleous, G.V., and Fu, Z., "Literature review of fire Risk assessment methodologies", Internal Report, Carleton University,

[14] Kaiser, J., "Experience of Grentener Method", Fire Safety Journal, 2, 1980

[15] Nelson, H.E., Shibe, A.J., "A System for Fire Safety Evaluation of Health Care Facilities", NBSIR 78-1555, Centre for Fore Research, National Bureau of Standards, 1980

[16] "The Mond Index", 2 nd Edition, Imperial Chemical Industries PLC, Explosion Hazards Section, 1985

[17] Meacham, B.J. "The Evaluation of Performance-Based Codes and Fire Safety Design Methods", NIST-GCR-98-761, 1998

[18] "BS 7974: 2001 Application of fire safety engineering principles to the design of buildings. Code of practice", British Standards Institution, 2001

[19] Bukowski, R.W. "Risk and Performance Standards", NIST-GCR-98-761, 1998 [20] International Survey of Computer Models for Fire and Smoke-CRISP, http,//www.firemodelsurvey.com/pdf/CRISP_2001.pdf

[21] Bjorkman, J, "Risk Assessment Methods in system approach for fire safety", Seinajoki Polytechnic Publications, 2005 
[22] Hetzberg, T. "Design Fire for enclosures", SP Swedish National Testing and

Research Institute, 2003

[23] Frantzich, H. "Uncertainty and Risk Analysis in Fire Safety Engineering", Lund University, 1998.

[24] Thomas, I. R., "The Development of Cesare Risk", Fire Protection Engineering Magazine, Summer 2003.

[25] "FIRE-RISK Core Model and Residential Buildings Modelling Phase ", Fire Code Reform Centre Ltd, Australia, 2001.

[26] Marchant, R., Kurban, N., Wise, S., "Development and Application of the Fire Brigade Intervention Model", $1^{\text {ST }}$ International Conference on Fire Service Deployment Analysis, 1999.

[27] Zhao, Beck, V., "The Definition of Scenarios for the CESARE-Risk Model", Proceedings of the fifth International Symposium on Fire Safety Science, Melbourne, Australia, 1997.

[28] Dutcher, C.R., Yung, D., Hadjisophocleous, G V., "FIRECAM System model Documentation “, National Research Council of Canada, IRC-IR-732, 1996.

[29] Benichou, N., Yung, D., "FIRECAM, an equivalency and performance-compliance tool for cost-effective fire safety design“, National Research Council of Canada, NRCC44695, 2001

[30] Benichou, N., Kashef, A., Torvi, D., Hadjisophocleous, G., Reid, I., "FIERAsystem, A Fire Risk Assessment Model for Light Industrial Building Fire Safety Evaluation" National Research Council of Canada, IRC-RR-120, 2002 
[31] Hadjisophocleous,G.V. , and Fu, Z., "Development And A Case Study Of A New Comprehensive Risk Assessment Model CUrisk For Building Fire", Internal Report, Carleton University,

[32] Raboud, D.W., Benichou, N., Kashef, A., Proulx, G., Hadjisophocleous, G.V., "FIERAsystem Occupant Response (OCRM) and Occupant Evacuation (OEVM) Models Theory Report", National Research Council of Canada, IRC-RR-100, 2002 [33] Fu, Z., Hadjisophocleous, G.V., "A Two-Zone Fire Growth and Smoke Movement Model for Multi-Compartment Buildings", National Research Council of Canada, NRCC-41111, 2000.

[34] Wang, Y., "A Study of Smoke Movement in Multi-Storey Buildings Using Experiments and Computer Modelling", Carleton University, M.A.SC. Thesis, 2009 [35] Wang, N., "Prediction of Heat Transfer and Probability of Insulation Failure in Wood-Framed Walls", Carleton University, M.A.SC. Thesis, 2009

[36] Esposito, D.C., "Economic Impact of Fires in Buildings", MASC. Thesis, 2004

[37] Gruchy, D., "Modelling Occupant Evacuation During Fire Emergencies in Buildings", Carleton University, M.A.SC. Thesis, 2004

[38] Purser, D.A., "Human Tenability", Proceedings of the United Engineering Foundation Conference on the Technical Basis fore Performance-based Fire Regulations - A Discussion of capabilities, Needs and Benefits of Fire Safety Engineering, San Diego, 2001

[39] Juneja, C.S., "Analysis of Ontario Fires and Reliability of Active Fire Protection Systems", MASC. Thesis, 2004 
[40] Bwalya, A.C.; Bénichou, N.; Sultan, M.A., "Literature Review on Design Fires", National Research Council of Canada, IRC-RR-137, 2003

[41] Zalok, E.; Bwalya, A.; Hadjisopocleous, G. ,"Medium-scale fire experiments of commercial premises", National Research Council of Canada, NRCC-45397, 2005

[42] Bukowski, R.W., "Estimates of the Operational Reliability of Fire Protection Systems", Journal of Fire Sciences, 24(3): 237-259, 2006,

[43] Hall, J.R., "U.S. Experience with Sprinklers and Other Automatic Fire Extinguishing Equipment", NFPA, 2007

[44] Ahrens, M., "U.S. Experience with Smoke Alarms and Other Fire Detection/Alarm Equipment", Executive Summary, NFPA, 2007

[45] Gaskin, J. and Yung, D., "Canadian and USA Fire Statistics for use in the Risk-Cost Assessment Model", IRC Report 1993

[46] Tillander, K., "Utilisation of Statistics to Assess Fire Risk in Buildings", VTT Publications 537, 2004

[47] Holborn, P.G., "Fire in Workplace Premises, Risk Data" Fire Safety Journal 37, 2002

[48] Butry, D.T., Brown, M.H., Fuller, S.K., "Benefit Cost Analysis of Residential Fire Sprinkler Systems", NISTIR-7451, 2007

[49] Nystedt F., "Deaths in Residential Fires": An Analysis of Appropriate Fire Safety Measures", Report 1026, Lund University, 2003

[50] "Trends and Patterns of U.S. Fire Losses in 2007", NFPA Reports, 2007 
[51]Charter, D., "A Study of Fire Risk Performance Parameters", Fire Science and

Technology, Vol. 25 No. 2, 2006

[52] "Fire-Rated wood-frame floor and wall assemblies", America Wood Council, 2009, http://www.awc.org/Codes/dcaindex.html 


\section{APPENDIX}

WS4-1.1 Wood Wall Assembly and WIJ-1.1 Ceiling Assembly Structure (Adopted from [52]) 


\section{WS4-1.1 One-Hour Fire-Resistive Wood-Frame Wall Assembly}

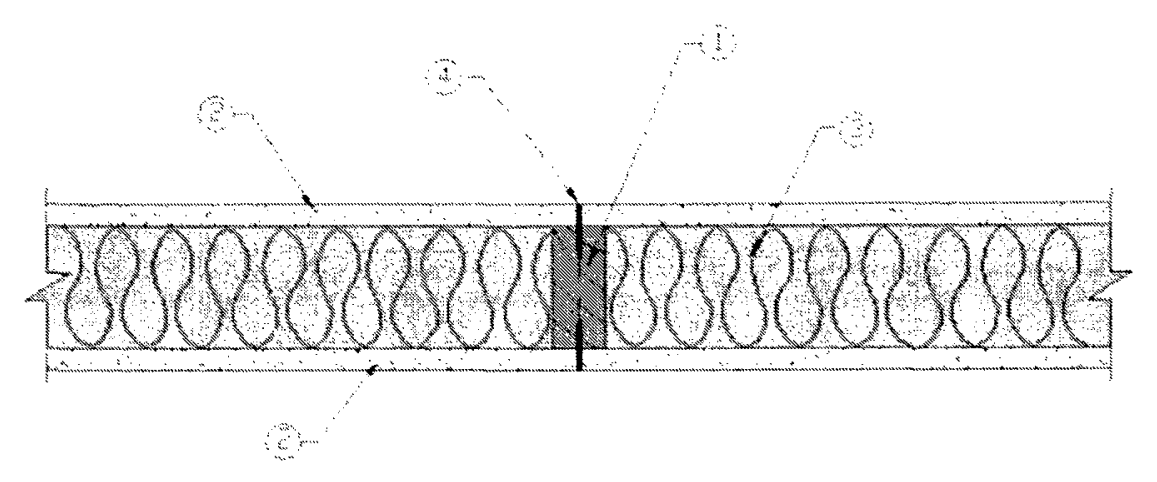

1.Framing - Nominal $2 \times 4$ wood studs spaced 16 in. o.c. double top plates, single bottom plate.

2. Sheathing - 5/8 in. Type $\mathrm{X}$ gypsum wallboard, $4 \mathrm{ft}$. wide, applied horizontally. Horizontal joints are unblocked. Horizontal application of wallboard represents the direction of least fire resistance as opposed to vertical application.

3.Insulation - 3-1/2 in. thick mineral wool insulation ( $2.5 \mathrm{pcf}$, nominal)

4.Fasteners - 2-1/4 in. \#6 Type S dry wall screws, spaced 12 in. o.c.

Joints and Fastener Heads - Wallboard joints covered with paper tape and joint compound, fastener heads covered with joint compound. 


\section{WIJ-1.1 One-Hour Fire-Resistive Ceiling Assembly}

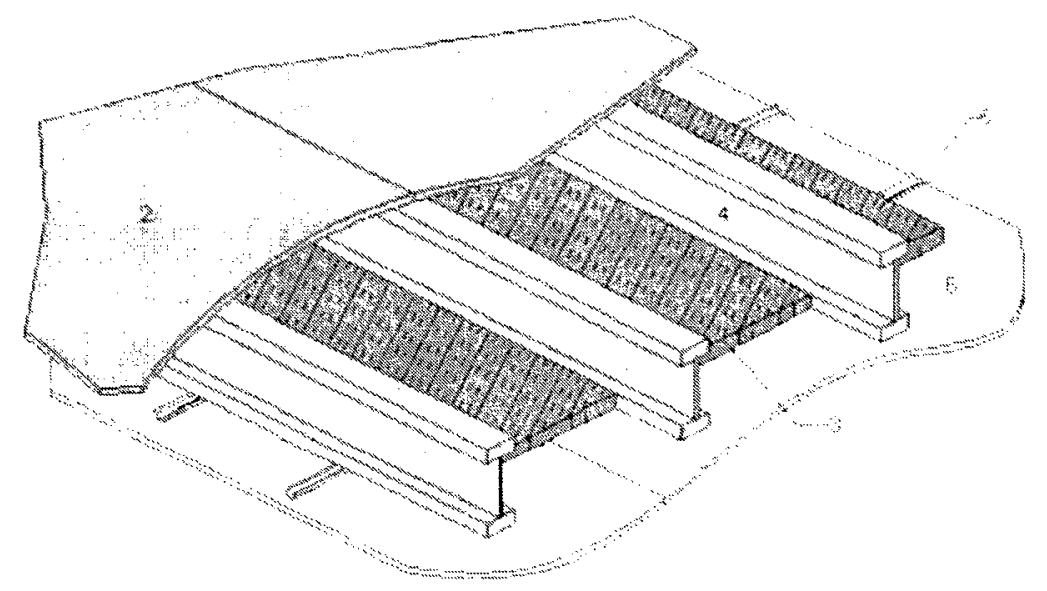

1.Floor Topping (optional, not shown): Gypsum concrete, lightweight or normal concrete topping.

2.Floor Sheathing: Minimum 23/32 inch thick tongue-and-groove wood sheathing 3.Insulation: Minimum 1-1/2 inch thick mineral wool insulation batts -2.5 pcf (nominal), supported by furring channels.

4.Structural Members: Wood I-joists spaced a maximum of 24 inches on center.

5.Furring Channels: Minimum 0.026 inch thick galvanized steel hat-shaped furring channels, attached perpendicular to I-joists using 1-5/S inch long drywall screws. Furring channels spaced 16 inches on center and doubled at each wallboard end joint extending to the next joist.

6.Gypsum Wallboard: Minimum 5/8 inch thick Type C gypsum wallboard installed with long dimension perpendicular to furring channels and fastened to each channel with minimum 1-1/E inch long Type $\mathrm{S}$ drywall screws.

7.Finish System (not shown): Face layer joints covered with tape and coated with joint compound. Screw7 heads covered with joint compound. 